\title{
Quantifying effects of vehicle weight and terrain on emissions, fuel economy, and engine behavior
}

\author{
Corey M. Strimer \\ West Virginia University
}

Follow this and additional works at: https://researchrepository.wvu.edu/etd

\section{Recommended Citation}

Strimer, Corey M., "Quantifying effects of vehicle weight and terrain on emissions, fuel economy, and engine behavior" (2006). Graduate Theses, Dissertations, and Problem Reports. 1787.

https://researchrepository.wvu.edu/etd/1787

This Thesis is protected by copyright and/or related rights. It has been brought to you by the The Research Repository @ WVU with permission from the rights-holder(s). You are free to use this Thesis in any way that is permitted by the copyright and related rights legislation that applies to your use. For other uses you must obtain permission from the rights-holder(s) directly, unless additional rights are indicated by a Creative Commons license in the record and/ or on the work itself. This Thesis has been accepted for inclusion in WVU Graduate Theses, Dissertations, and Problem Reports collection by an authorized administrator of The Research Repository @ WVU. For more information, please contact researchrepository@mail.wvu.edu. 
Quantifying Effects of Vehicle Weight and Terrain on Emissions, Fuel Economy, and Engine Behavior

\title{
Corey M. Strimer
}

Thesis submitted to the College of Engineering and Mineral Resources at West Virginia University in partial fulfillment of the requirements

for the degree of

\author{
Master of Science \\ in \\ Mechanical Engineering
}

\author{
Approved by \\ Nigel Clark, Ph.D., Chair \\ Mridul Gautam, Ph.D. \\ Gregory Thompson, Ph.D. \\ Mechanical and Aerospace Engineering \\ Morgantown, West Virginia \\ 2006
}

Keywords: Diesel Emissions, In-Use Emissions Testing, Mobile Measurement

Techniques, Road Load, Road Grade, Weight Effects

Copyright 2006 Corey Strimer 


\title{
Quantifying Effects of Vehicle Weight and Terrain on Emissions, Fuel Economy, and Engine Behavior
}

\author{
Corey M. Strimer
}

\begin{abstract}
On-board emissions measurement for heavy-duty vehicles has garnered greater significance because 2007 marks the beginning of gaseous emissions monitoring for in-use vehicles in the United States [1]. Emissions compliance must be shown in a "not to exceed" (NTE) zone that emphasizes engine operation at higher power. An over-the-road 1996 Peterbilt tractor was instrumented with the West Virginia University Mobile Emissions Measurement System (MEMS) to determine how often the truck entered the NTE, and the emissions from the vehicle, as it was driven over varying terrain at multiple test weights. Distance-specific $\mathrm{NO}_{\mathrm{X}}$ emissions increase by approximately $\mathrm{X} / 2 \%$ for an $\mathrm{X} \%$ increase in test weight. Fuel economy declined by approximately 0.5 miles/gallon for every $15,000 \mathrm{lb}$. in added test weight. Almost a quarter of entrances into the NTE region were caused by changing gears. This result should be considered when comparing data from manual transmission vehicles to those with automatic transmissions.
\end{abstract}




\section{Acknowledgements}

Throughout my education, there are many people who have supported me and helped me along the way.

Although my Master of Science degree at WVU had a slight break in the middle, I thank Dr. Nigel Clark for giving me the opportunity to pursue this degree. Without his support, advice, direction, and guidance I would have never been able to have the chance to complete this degree. Also, I would like to thank Dr. Clark for encouraging me to return following the completion of my Master of Engineering Management degree. I truly appreciate Dr. Greg Thompson's help during my education, especially during the period when I was having huge issues reducing my data. I thank Dr. Gautam for being on my committee and helping me to earn my Master of Science degree.

During my graduate education, I had the pleasure of working with great people at the Westover laboratory. I thank Dan Carder, Wes Riddle, and Ben Shade for helping me learn about the MEMS equipment and making the hours at the shop enjoyable.

In order to obtain my data, I had a lot of help from CDL drivers for the on-road testing portion of my research. I would like to thank Ted Christian, John Dadisman, Sr., John Dadisman, and Adam Leach for driving the test vehicle on the test routes whenever it was necessary. There were many runs then the computer would lock up or something would go wrong, but the driver's always made sure they were available to complete any test run that was needed.

Also, I would like to thank my girlfriend, Betsey Kennedy, for putting up with me through this program. At times, when it did not seem like anything was going well, you would always encourage me and keep me going. I truly appreciate you listening to my complaining and my worries that I would fail all of my classes.

Throughout my life, I have had the love and support of the most wonderful family in the world. Thank you to my Mom and Dad for teaching me the value of hard work and letting me know that they would support me in anything I decided to do with my life. The rest of my family, my aunts, uncles, cousins, sisters, and others are too numerous to list here, but they have all played a huge role in my life achievements. Thank you all for always being there for me and encouraging me along the way! 


\section{Table of Contents}

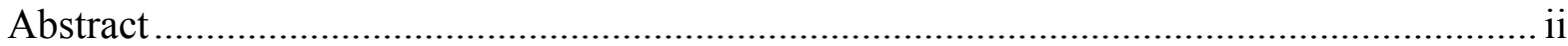

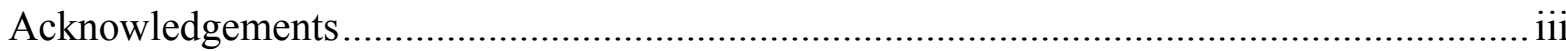

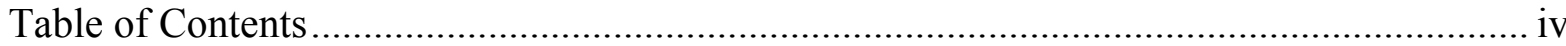

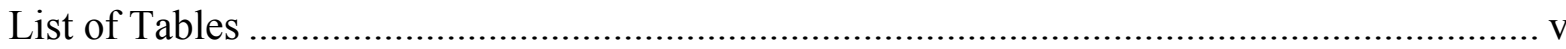

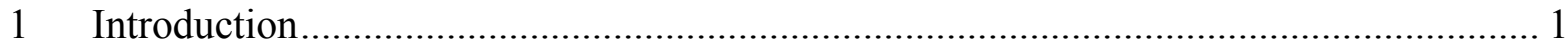

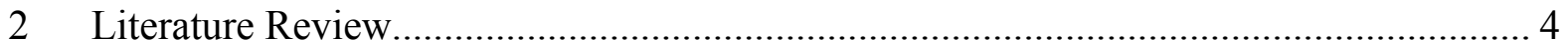

$2.1 \quad$ History of Emissions Measurement ................................................................ 4

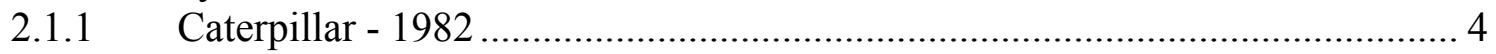

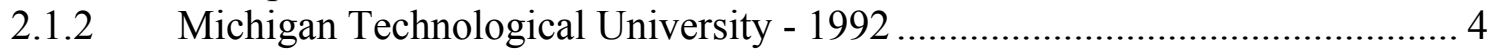

2.1.3 Honda R\&D Americas and Nicolet - 2000 ……......................................... 5

2.1.4 Horiba, Ltd. Real-time On-board Measurement System .................................. 5

2.1.5 Clean Air Technologies International, Inc. (CATI) ........................................ 6

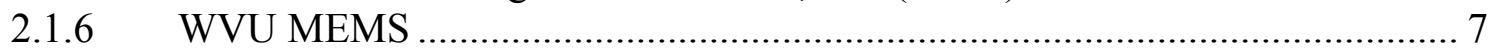

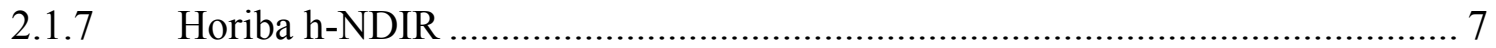

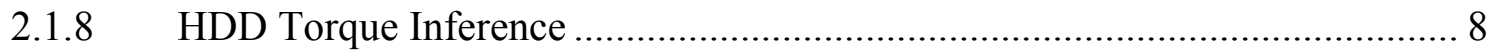

2.1.9 RAVEM (Ride-Along Vehicle Emission Measurement System ....................... 8

2.1.10 University of Alberta ................................................................................ 9

2.1.11 EPA On-Road Diesel Emissions Characterization Facility (ODEC) …......... 10

2.1.12 University of California - Riverside ........................................................ 11

2.2 Vehicle Weight Effect Studies................................................................... 12

2.2.1 University of California - Riverside.......................................................... 12

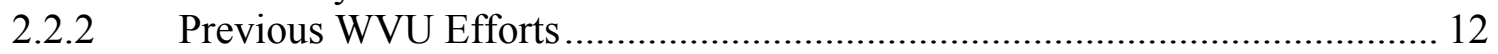

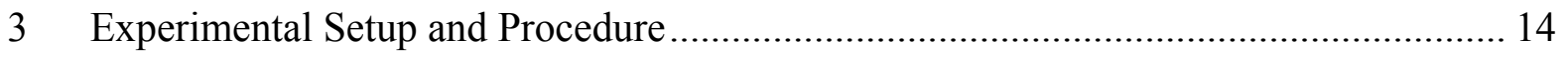

$3.1 \quad$ Experimental Equipment ………………………...................................... 14

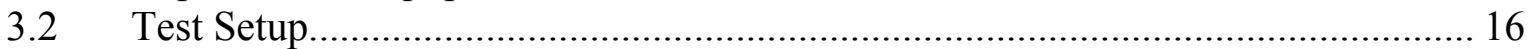

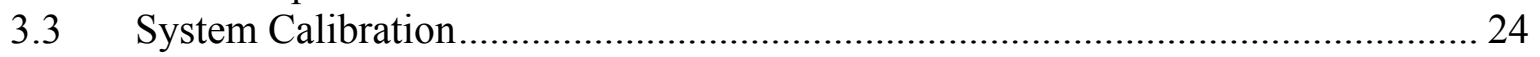

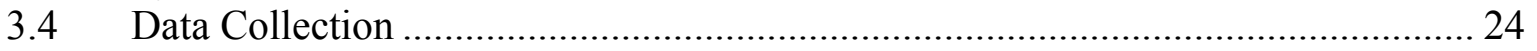

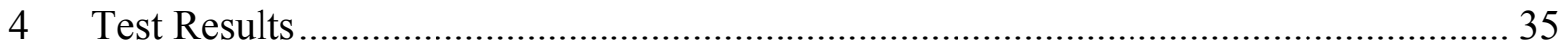

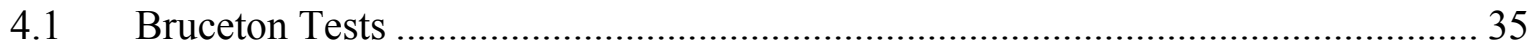

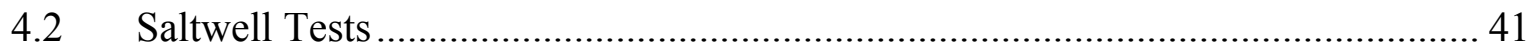

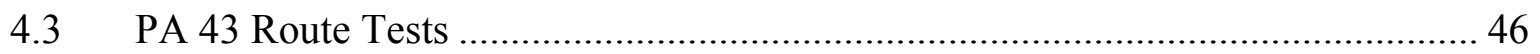

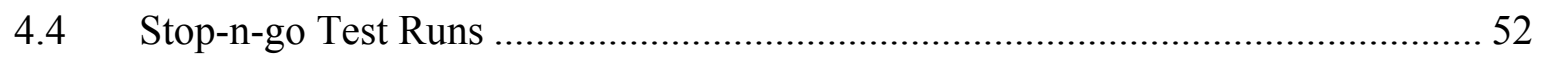

4.5 Entrance and Exit of the NTE Region ...............................................................5

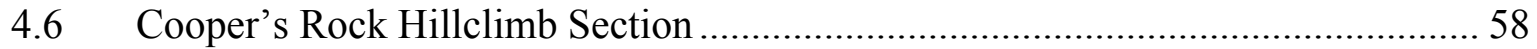

4.7 Vehicle Power versus Engine Power ............................................................................. 61

4.7.1 Road Load Equation - Flat Road, Constant Speed........................................... 61

4.7.2 Road Load Equation - Acceleration Load...................................................... 62

4.7.3 Road Load Equation - Road Grade Consideration.......................................... 62

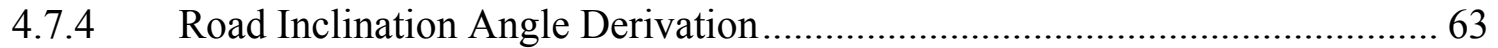

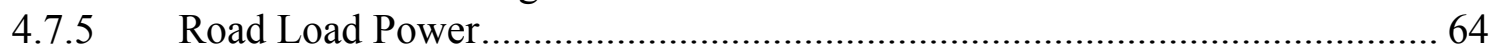

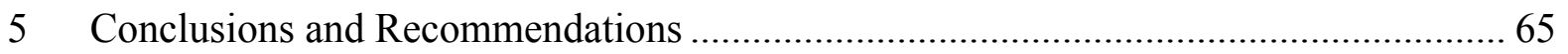

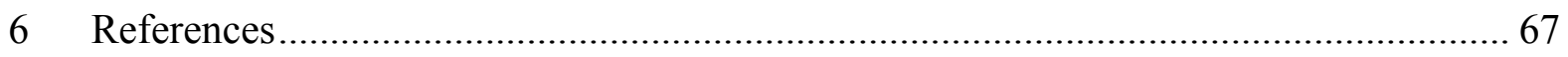




\section{List of Tables}

Table 1 - EPA Emission Standards for Heavy-Duty Diesel Trucks ..................................... 2

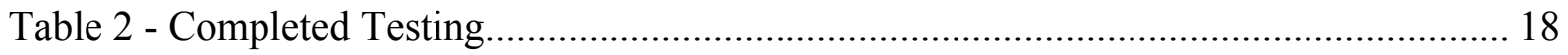

Table 3 - Statistical Data for Bruceton Test Runs ............................................................. 20

Table 4 - Statistical Data for Saltwell Test Runs........................................................... 21

Table 5 - Statistical Data for PA 43 Test Runs ............................................................... 23

Table 6 - Statistical Data for Stop-n-go Test Runs .......................................................... 24

Table 7 - NTE Zone Data Bruceton Runs.................................................................. 35

Table 8 - Bruceton Theoretical and Actual NTE $\mathrm{NO}_{\mathrm{X}}$ Data Comparison ........................... 38

Table 9 - NTE Zone Data for Saltwell Runs.............................................................. 41

Table 10 - Saltwell Theoretical and Actual NTE $\mathrm{NO}_{\mathrm{X}}$ Comparison ................................... 44

Table 11 - NTE Zone Data for PA 43 Runs................................................................... 46

Table 12- NTE Zone Data for Stop-n-go Runs........................................................... 52

Table 13 - Modes for Entering and Exiting NTE Region ............................................. 55

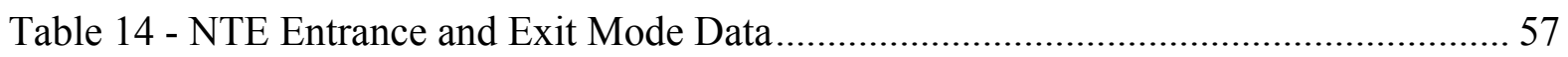

Table 15 - NTE Region Data for Cooper's Rock Section .............................................. 59 


\section{List of Figures}

Figure 1 - NTE Region Definition .............................................................................. 2

Figure 2 - Annubar Flow Meter Diagram ...................................................................... 14

Figure 3 - Emissions Box Components ....................................................................... 15

Figure 4 - Engine Lug Curve for 1996 Peterbilt Test Vehicle.......................................... 16

Figure 5 - 1996 Peterbilt with MEMS System Installed.................................................. 17

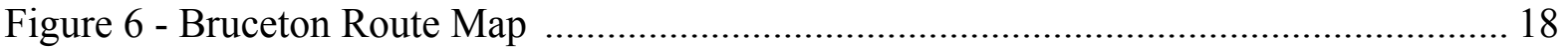

Figure 7 - Bruceton Route Altitude Profile........................................................................ 19

Figure 8 - Saltwell Route Map.................................................................................... 20

Figure 9 - Saltwell- Uphill Altitude Profile ................................................................. 21

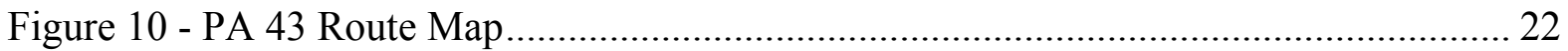

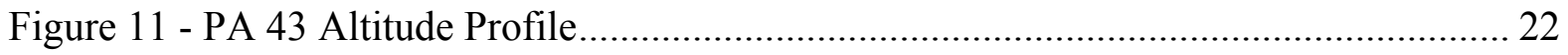

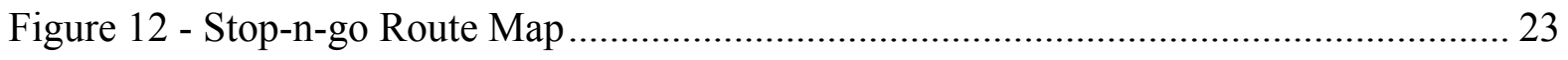

Figure 13 - Differential Pressure versus Time for Saltwell Route at 34,640 lb.................. 25

Figure 14 - Exhaust Temperature versus Time for Saltwell Route at 34,640 lb. ................ 25

Figure 15 - Annubar Absolute Pressure for Saltwell Route at 34,640 lb. ......................... 26

Figure 16 - Exhaust Flowrate at Standard Conditions versus Time for Saltwell Route at

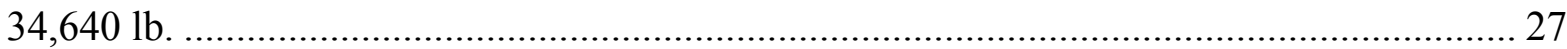

Figure 17 - ECU Fueling Rate versus Time for Saltwell Route at 34,640 lb.................... 27

Figure $18-\mathrm{NO}_{\mathrm{X}}$ Corrected Flowrate versus Time for Saltwell Route at 34,640 lb............ 28

Figure 19 - Broadcast Fueling versus Shifted and Corrected MEXA NO X Flowrate............ 29

Figure 20 - Carbon Dioxide Flowrate versus Time for Saltwell Route at 34,640 lb............ 30

Figure 21 - Broadcast Fueling versus Shifted $\mathrm{CO}_{2}$ Flowrate ......................................... 30

Figure 22 - Engine Speed versus Time for Saltwell Route at 34,640 lb........................... 31

Figure 23 - Percent Load versus Time for Saltwell Route at 34,640 lb.............................. 32

Figure 24 - Engine Power versus Time for Saltwell Route at 34,640 lb. .......................... 32

Figure 25 - Engine Torque versus Time for Saltwell Route at 34,640 lb........................... 33

Figure 26 - ECU Vehicle Speed versus Time for Saltwell Route at 34,640 lb................... 34

Figure 27 - Bruceton Average NTE bsNOX versus Test Weight .................................... 36

Figure 28 - Bruceton Average NTE bsCO $\mathrm{C}_{2}$ versus Test Weight..................................... 37

Figure 29 - Bruceton Distance-Specific NTE NO $\mathrm{N}_{\mathrm{X}}$ versus Test Weight ............................ 38 
Figure 30 - Bruceton Distance-Specific NTE $\mathrm{CO}_{2}$ versus Test Weight 39

Figure 31 - Bruceton NTE Fuel Economy versus Test Weight ...................................... 40

Figure 32 - Overall Bruceton Fuel Economy versus Test Weight.................................... 41

Figure 33 - Saltwell Average NTE bsNO X versus Test Weight ....................................... 42

Figure 34 - Saltwell Average NTE bsCO $\mathrm{C}_{2}$ versus Test Weight ....................................... 42

Figure 35 - Saltwell Distance-Specific NTE $\mathrm{NO}_{\mathrm{X}}$ versus Test Weight............................... 43

Figure 36 - Saltwell Distance-Specific NTE $\mathrm{CO}_{2}$ versus Test Weight............................... 44

Figure 37 - Saltwell NTE Fuel Economy versus Test Weight........................................... 45

Figure 38 - Overall Saltwell Fuel Economy versus Test Weight ...................................... 46

Figure 39 - PA 43 Average NTE bsNO ${ }_{X}$ versus Test Weight......................................... 47

Figure 40 - PA 43 Average NTE bsCO $\mathrm{CO}_{2}$ versus Test Weight ......................................... 48

Figure 41 - PA 43 Distance-Specific NTE NOX versus Test Weight ................................ 49

Figure 42- Average Power Demand per Mile (bhp-hr/mile) for All Routes ....................... 50

Figure 43 - PA 43 Distance-Specific NTE $\mathrm{CO}_{2}$ versus Test Weight ................................. 50

Figure 44 - PA 43 NTE Fuel Economy versus Test Weight........................................... 51

Figure 45 - Overall PA 43 Fuel Economy versus Test Weight ...................................... 52

Figure 46 - NTE Entrance and Exit for 34,640 lb. Westover to Bruceton Test Run .............. 55

Figure 47 - NTE Entrance and Exit for 20,740 lb. Westover to Bruceton Test Run ............. 56

Figure 48 - NTE Entrance and Exit for 79,700 lb. Westover to Saltwell Test Run .............. 56

Figure 49 - Speed versus Time for Cooper's Rock Section ............................................... 58

Figure 50 - Instantaneous $\mathrm{NO}_{\mathrm{X}}$ Flowrate versus Time .............................................. 59

Figure 51 - Distance-Specific $\mathrm{NO}_{\mathrm{X}}$ versus Time for Cooper's Rock Section....................... 60

Figure 52 - Brake-Specific NTE NO for Cooper's Rock Section ..................................... 61

Figure 53 - Calculated Road Load Power and Engine Output Comparison ......................... 64 


\section{Nomenclature}

$\begin{array}{ll}\text { CARB } & \text { California Air Resources Board } \\ \text { cfm } & \text { Cubic Feet Per Minute } \\ \text { CVS } & \text { Constant Volume Sampling } \\ \text { CO } & \text { Carbon Monoxide } \\ \mathrm{CO}_{2} & \text { Carbon Dioxide } \\ \text { EERL } & \text { Engine and Emissions Research Laboratory } \\ \text { EGS } & \text { Electrochemical Gas Sensor } \\ \text { FTIR } & \text { Fourier Transform Infrared } \\ \text { g/bhp-hr } & \text { Grams per Brake-Horsepower Hour } \\ \text { HC } & \text { Hydrocarbons } \\ \text { lpm } & \text { Liters Per Minute } \\ \text { MEMS } & \text { Mobile Emissions Measurement System } \\ \text { MPH } & \text { Miles per hour } \\ \text { NDIR } & \text { Non-dispersive Infrared } \\ \text { NDUV } & \text { Non-dispersive Ultraviolet } \\ \text { NH4 } & \text { Ammonia } \\ \text { NO } & \text { Nitric Oxide } \\ \text { NO } 2 & \text { Nitrogen Dioxide } \\ \text { NO } & \text { Oxides of Nitrogen } \\ \mathrm{O}_{2} & \text { Oxygen } \\ \mathrm{O}_{3} & \text { Ozone } \\ \text { OREMS } & \text { On-Road Emissions Measurement System } \\ \text { PM } & \text { Particulate Matter } \\ \text { ppm } & \text { Parts Per Million } \\ \text { PREVIEW } & \text { Portable Real-Time Emission Vehicular Integrated Engineering Workstation } \\ \text { ROVER } & \text { Real-time On-road Vehicle Emissions Recorder } \\ \text { scfm } & \text { Standard Cubic Feed Per Minute } \\ \text { SOX } & \text { Oxides of Sulfur } \\ \text { THC } & \text { Total Unburned Hydrocarbons } \\ \text { US EPA } & \text { United States Environmental Protection Agency } \\ \text { UDDS } & \text { Urban Dynamometer Driving Schedule } \\ \text { WVU } & \text { West Virginia University } \\ & \end{array}$




\section{Introduction}

As early as the 1960 's, the US government began to realize that air pollution was a major problem and certain regulations must be in place to control and combat this problem. With the initiation of the Clean Air Act (CAA) in 1963, restrictions were placed upon power plants and factories to curb their emissions of chemicals such as lead, ozone, sulfur dioxide $\left(\mathrm{SO}_{2}\right)$, oxides of nitrogen $\left(\mathrm{NO}_{\mathrm{X}}\right)$, and particulate matter $(\mathrm{PM})$. Additionally, a 1970 amendment to the CAA imposed these regulations to motor vehicles, thus creating emissions standards that govern the amount of pollution that is allowed to be created by a given vehicle [2].

As a method of enforcing these regulations upon motor vehicles, diesel engine manufacturers were required to begin to test the emissions of their engines in specialized test procedures such as the Federal Test Procedure (FTP). These dynamometer tests required the engine to perform a specified cycle so that engines from different manufacturers could be tested and compared against on another. However, engine manufacturers began to make engines that did not show emissions while in-use that were as low as FTP emissions levels. In 1998, a consent decree was signed by Caterpillar, Inc., Detroit Diesel Corporation, Navistar International Transportation Company, Volvo Truck Corporation, Cummins Engine Company, and Mack Trucks, Inc. that required the manufacturers to meet 2004 emissions requirements in advance of the original deadline, pay civil penalties, and develop in-use testing programs that would test the vehicles while they were undergoing on-road driving scenarios [2]. For this testing, a not-to-exceed (NTE) region was established to indicate the area in which the engine performed most of its work. Figure 1 shows this region in relation to the engine's torque and power. 


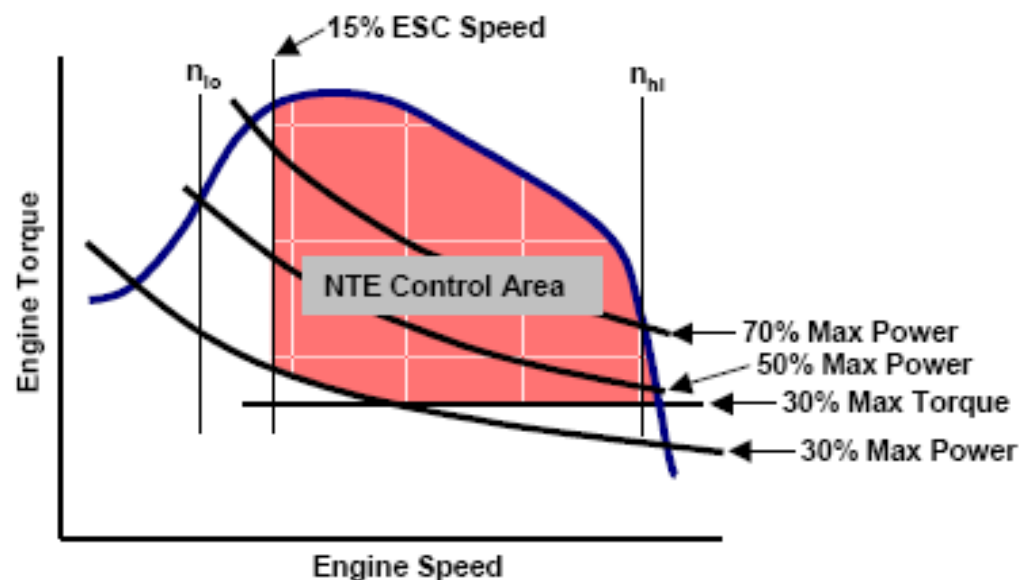

Figure 1 - NTE Region Definition Reproduced from [4]

Diesel engine manufacturers were required to begin some in-use testing during the 2005 calendar year. Complete in-use testing compliance will be mandatory for diesel vehicles in 2007 [1]. At this point, a gaseous emissions monitoring system is required that can measure oxides of nitrogen $\left(\mathrm{NO}_{\mathrm{X}}\right)$, carbon monoxide $(\mathrm{CO})$, carbon dioxide $\left(\mathrm{CO}_{2}\right)$, and non-methane hydrocarbons (NMHC). For the purposes of the research presented in this paper, $\mathrm{CO}_{2}$ and $\mathrm{NO}_{\mathrm{X}}$ have been the main constituents of interest. However, there are other emissions constituents that have been regulated by the EPA as well. These compounds can be found in Table 1 along with the allowable emissions quantities on a brake-specific basis.

Table 1 - EPA Emission Standards for Heavy-Duty Diesel Trucks [5]

\begin{tabular}{|c|c|c|c|c|}
\hline & THC & NOx & CO & PM \\
\hline \multicolumn{5}{|c|}{$1987-2003$ Model Year Engines } \\
\hline Year & g/bhp·hr & g/bhp·hr & g/bhp·hr & g/bhp·hr \\
\hline 1988 & 1.3 & 10.7 & 15.5 & 0.6 \\
\hline 1990 & 1.3 & 6.0 & 15.5 & 0.6 \\
\hline 1991 & 1.3 & 5.0 & 15.5 & 0.3 \\
\hline 1994 & 1.3 & 5.0 & 15.5 & 0.1 \\
\hline 1998 & 1.3 & 4.0 & 15.5 & 0.1 \\
\hline \multicolumn{5}{|c|}{2004 and later Model Year Engines } \\
\hline Option & NMHC & NOX & CO & PM \\
\hline 1 & 2.4 (combined) & 15.5 & 0.1 \\
\hline 2 & 2.5 & 0.5 & 15.5 & 0.1 \\
\hline \multicolumn{5}{|c|}{2007 and later Model Year Engines } \\
\hline \multicolumn{7}{|c|}{ NMHC } & NO $_{X}$ & PM & CO \\
\hline 2007 & 0.01 & 0.20 & 0.14 & 15.5 \\
\hline
\end{tabular}


In-use data may be used both to demonstrate emissions compliance and to formulate emissions inventories. Current emissions inventories calculate emissions using distancebased quantity for each exhaust constituent as well as some factors for the vehicle's activity. Then, these numbers are applied over a statistics-based population of vehicles to arrive at the estimated amount of emissions being produced for entire fleets of vehicles. However, this single value ignores the fact that many vehicles are operated at different weights and individual terrains. These two factors can greatly alter the emissions profile of a vehicle and should be considered in emissions inventories if data beyond a gross emissions average is sought. 


\section{Literature Review}

In efforts to learn more about engine behavior and its relation to exhaust emissions, much work has taken place to develop systems to analyze vehicle emissions directly from the vehicle's exhaust. In addition, some studies have been conducted to analyze the effect of a vehicle's weight and its emissions profile.

\subsection{History of Emissions Measurement}

\subsubsection{Caterpillar - 1982}

In 1982, Caterpillar presented a paper at the Earthmoving Industry Conference which detailed a field measurement technique for quantifying $\mathrm{NO}_{\mathrm{X}}$ emissions at the "Point-Of-Use" [6]. This paper was written to describe the technique that could be used if emission controls were required for certain areas of California, which was being proposed at the time. Englund wrote that the exhaust gasses could be sampled using a bag sampling technique and then analyzed in a laboratory using given emissions characterization equipment. The system utilized a probe, prefilter, line, pump, air-cooled condensing coil, and two bags. Water was removed from the system before the bag sample was collected to ensure proper emissions data. Laboratory tests showed that this system resulted in measurements within $10 \%$ of those taken in full-scale laboratory conditions, thus illustrating the feasibility of this field measurement technique.

\subsubsection{Michigan Technological University - 1992}

Chan, Carlson, and Johnson [7] developed a system to measure emissions directly from an automotive tailpipe in 1992. Their emissions measurement apparatus (EMA) include an exhaust dilution system as well as instrumentation to quantify emissions from a parked vehicle. It was capable of obtaining the concentrations of diesel particulate matter (DPM), $\mathrm{CO}, \mathrm{CO}_{2}, \mathrm{NO}$, and $\mathrm{NO}_{2}$. One shortcoming of this system was the fact that the system could only measure the emissions for a single engine load and speed. This system was shown to be able to reproduce laboratory testing results when compared directly. Also, the equipment could be used to detect changes in a vehicle's characteristic emissions cause by problems with the engine or its management software. 


\subsubsection{Honda R\&D Americas and Nicolet - 2000}

At the SAE 2000 World Congress, a paper presented by Honda R\&D Americas and Nicolet Instrument Corporation detailed the development of an on-board emissions analyzer system [8]. The system was capable of recording very low emission levels below $1 \mathrm{ppm}$ in an on-road setting. This specification came about because the primary system objective was to measure low component concentrations which were present once the engine had been warmed to proper operating temperature. Analyzers and systems already were in place for measure the cold-start conditions when emissions are magnitudes higher.

For their system, Honda and Nicolet used FTIR to determine the exhaust gas constituents present in the analyzed emissions. Their work focused on monitoring NMHC, $\mathrm{NO}_{\mathrm{X}}$, and $\mathrm{CO}$. The sample in this system also had to be dried to avoid errors in the data reporting, so Nafion ${ }^{\circledR}$ dryers were used to remove water from the exhaust sample. This solution was found in the study to have the lowest effect on the hydrocarbon recovery in the emissions analyzer. In addition, the system was validated against proven bench analyzers and found to be in agreement.

\subsubsection{Horiba, Ltd. Real-time On-board Measurement System}

During the year 2000, Horiba published a paper with the Society of Automotive Engineers that detailed a real-time on-board measurement system that measured mass emissions of $\mathrm{NO}_{\mathrm{X}}$, fuel consumption, road load, and engine output [9]. Because changes in climates, seasons, and road conditions affect diesel vehicles in various ways, on-road measurements are required to obtain useful information regarding a vehicle's emissions profile. Since these same diesel vehicles can be difficult to accommodate in laboratory dynamometer settings, on-road measurement becomes even more necessary. This system came about because of the development of a zirconium $\left(\mathrm{ZrO}_{2}\right)$ sensor that could be used to detect $\mathrm{NO}_{\mathrm{X}}$ and measure the air-fuel ratio for an engine's instantaneous operating condition. Two of these sensors were mounted in the exhaust pipe of the vehicle being tested. Also, a Karman vortex volumetric sensor determined the air flow into the engine for calculation purposes. Additionally, sensors were used to capture environmental and vehicle operating conditions that were later used in data analysis. 
Finally, the data were recorded in an on-board data acquisition unit. The data from each test could be taken to an external data processor to obtain useful information. In the analysis, a negative correlation was discovered between distance-based $\mathrm{NO}_{\mathrm{X}}$ emissions and fuel economy. Also, the system was found to have strong correlation to laboratory based equipment: $4 \%$ difference for $\mathrm{NO}_{\mathrm{X}}$ mass emissions and $3 \%$ difference for fuel consumption.

\subsubsection{Clean Air Technologies International, Inc. (CATI)}

Vojtisek-Lom and Allsop [10] developed a system that measured emissions of $\mathrm{NO}_{\mathrm{X}}, \mathrm{CO}_{2}$, and $\mathrm{PM}$ in an on-board setting. Their system was designed to be used on a vehicle in its real-world condition, with no effect on its operation. For example, the researchers developed the system so that buses could be tested in actual conditions with no impact to the number of passengers that could be carried. Because of this, their system drew its power from the 12-volt system of the vehicles being tested, which can create additional loading on the engine. Exhaust flow is measured from engine operating data and mass balance equations due to the invasive nature of many flow measuring devices. The scientists determined that using mass flow monitoring would add too much equipment to the vehicle and make it nearly impossible to conduct the tests in the desire real-world setting.

The tests concluded that the data obtained from the testing is not as accurate as laboratory data, but the equipment does allow vehicles to be outfitted quickly and easily. Because of this ease of testing, the authors of the paper stated that the benefit of their system must be considered to be not taking the vehicle out of service to perform the emissions testing. Also, simulated loadings would not be necessary for the Clean Air Technologies system.

Vojtisek-Lom, et. al [11] conducted a study over 2.5 days at the Tulare, CA rest area during which $40 \mathrm{HDD}$ vehicles were tested. The vehicles in the study were selected at random from the traffic traveling during the week of April 22, 2002 on Highway 99 southbound in Tulare, CA. Selected at random, the chosen trucks were put through an array of tests including the SAE J1667 smoke opacity test, a stationary idling test of varying test conditions, and an on-road test consisting on a 3 mile stretch of highway with 
a cruising speed of $55 \mathrm{MPH}$. The equipment used in the testing consisted of three OEM2100 "Montana" systems developed by CATI. These systems used an NDIR sensor to measure $\mathrm{HC}, \mathrm{CO}$, and $\mathrm{CO}_{2}$, electrochemical cells to analyze $\mathrm{NO}_{\mathrm{X}}$ and $\mathrm{O}_{2}$, and laser light scattering for PM. The study found that high $\mathrm{NO}_{\mathrm{X}}$ at idle corresponded strongly to high $\mathrm{NO}_{\mathrm{X}}$ output during acceleration of the vehicle. This suggests that idle testing could be used to predict which vehicles will produce high $\mathrm{NO}_{\mathrm{X}}$ during on-road acceleration. However, some vehicles exhibited high $\mathrm{NO}_{\mathrm{X}}$ characteristics during the "cruise" portion of the testing, so these results could not have been obtained through testing of the vehicle's idle emissions characteristics. Several high $\mathrm{NO}_{\mathrm{X}}$ observations were reported that fell just outside of the NTE region as well. The researchers also noted that PM was high during deceleration, which was "likely" due to the use of engine braking to slow the vehicle.

\subsubsection{WVU MEMS}

In 2001, researchers from WVU published an SAE paper that detailed the development of the Mobile Emissions Measurement System (MEMS) [12]. This system was capable of monitoring $\mathrm{CO}_{2}$ and $\mathrm{NO}_{\mathrm{X}}$ within $5 \%$ of laboratory emissions measurement equipment. Additionally, the system was capable of recording emissions during 30-second events in order to meet the requirements of the 1998 Consent Decrees. The MEMS was utilized for the research within this thesis. Further explanation of the operation of the system can be found in Section 3 of this document.

\subsubsection{Horiba h-NDIR}

During 2002, Horiba detailed the development of an NDIR sensing system that could be used on emissions that did not have the water removed from the sample [13]. With this paper, Nakamura, et. al. illustrated that results could be shown from on-board emissions measurements to the laboratory equipment without having to dry the exhaust sample. This design challenges in developing this sensor for on-board use included being vibration proof, consuming little power, having small dimensions, and being easy to operate. The system was tested on both a gasoline and diesel engine with similar test setups. For the diesel engine testing, Horiba utilized an Annubar ${ }^{\circledR}$ flow meter, AFR 
sensor, and $\mathrm{NO}_{\mathrm{X}}$ sensor in order to obtain the data. The h-NDIR setup utilizes an $\mathrm{H}_{2} \mathrm{O}$ detector to correct the measured $\mathrm{CO}$ and $\mathrm{CO}_{2}$ concentrations for the amount of $\mathrm{H}_{2} \mathrm{O}$ which is in the sample. The study found that the on-board sensors measured fuel consumption within $7 \%$ of laboratory equipment, and $\mathrm{CO}$ and $\mathrm{CO}_{2}$ within $5 \%$ and $6 \%$, respectively.

\subsubsection{HDD Torque Inference}

Thompson, et. al. [14] published a paper that described a method of inferring torque and power from HDD engines during on-road testing. Data were created that presented emissions in time-specific or distance-specific terms. It is desirable to report the emissions on a work-specific basis in order to compare the data to that obtained during certification data on engine dynamometers. To do this, the work output of the engine must be obtained during data collection. Communications protocols exist for obtaining the necessary engine operating information including engine speed and percent load for the instantaneous operating condition. This percent load information can be used, along with the engine's manufacturer-given lug curve and zero-load curb idle data to determine the engine's output. For small engine loads, the errors using this method become very large because of the denominator of the fraction used in the calculation becomes very small. Inside the NTE zone, the method delivers less than a $10 \%$ error in the instantaneously inferred torque, and the error decreases as the chosen window of data is increased to be averaged over a longer period of time.

\subsubsection{RAVEM (Ride-Along Vehicle Emission Measurement System)}

Engine, Fuel, and Emission Engineering, Incorporated developed a system called the Ride-Along Vehicle Emission Measurement System (RAVEM) to monitor gaseous and particulate emissions while the vehicle is in service [15]. Specifically, the system measured $\mathrm{NO}_{\mathrm{X}}, \mathrm{CO}_{2}$, and PM for the vehicle being tested. Their system was designed to also be used to monitor emissions from non-road emissions sources such as bulldozers, locomotives, and marine vessels that could not be tested using chassis or engine dynamometers. 
Overall, the RAVEM system used a constant volume sampling approach to remove a fraction of the vehicle exhaust gas from the exhaust pipe for analysis. After this, the sample was diluted in a 1.3 meter dilution tunnel which allowed for the derivation of the exhaust flowrate. The system determined the concentrations of exhaust gas constituents with California Analytical Instruments (CAI) model ZRH-2 NDIR CO and $\mathrm{CO}_{2}$ analyzer, a CAI 400S-HCLD heated chemilumenescent $\mathrm{NO}_{\mathrm{X}}$ sensor. With these sensors, the system was able to give instantaneous emissions information, and obtained bag samples of the diluted exhaust gas for comparative analysis.

The testing with the RAVEM system included three groups of vehicles. The first was a fleet of diesel powered garbage vehicle that were tested while operating on their traditional garbage pickup route. These vehicles exhibited exhaust characteristics that were far above the federal emissions standards for the given engine. For example, a 1997 model truck was shown to emit $9.5 \mathrm{~g} / \mathrm{bhp}-\mathrm{hr} \mathrm{NO}_{\mathrm{X}}$ and $0.20 \mathrm{~g} / \mathrm{bhp}-\mathrm{hr} \mathrm{PM}$ when the regulation only allowed for $5.0 \mathrm{~g} / \mathrm{bhp}-\mathrm{hr} \mathrm{NO}_{\mathrm{X}}$ and $0.10 \mathrm{~g} / \mathrm{bhp}-\mathrm{hr} \mathrm{PM}$. Additionally, a fleet of California Department of Transportation highway maintenance vehicles were tested as well as a fleet of refuse trucks in Mexico City. Overall, the RAVEM system

performed well in these tests while replicating exhaust gas constituent measurement when compared with laboratory equipment.

\subsubsection{University of Alberta}

In 2002, Hawirko and Checkel [16] published a detailed report of their on-board system to measure driving behavior, engine parameters and exhaust emissions of a gasoline powered vehicle. The system utilized a laptop computer to acquire data from multiple sources. One data source was a Vetronix PXA-1100 five gas analyzer that collected data using NDIR methods for $\mathrm{HC}, \mathrm{CO}$ and $\mathrm{CO}_{2}$ and electro-chemical sensors for $\mathrm{NO}_{\mathrm{X}}$ and $\mathrm{O}_{2}$. This analyzer operated using the 12-volt power supply of the vehicle. Additionally, the system employed a Siemens HFM 62B mass air flow sensor to determine the flowrate of air entering the engine's intake. The amount of fuel consumed by the vehicle was determined using a ECM AFRecorder 2400E sensor to obtain an airfuel ratio. Also, the system measured vehicle performance parameters of vehicle speed and coolant temperature. To determine the conditions in which the vehicle was 
operating, ambient temperature sensors were also used to determine the temperature changes while the vehicle was being tested. All of the data were stored in a laptop computer running National Instruments Labview 6 i.

In another publication, this system was utilized to collect extensive data that were used to determine emissions factors for various atmospheric conditions [17]. Over the course of one year, data were recorded for temperatures ranging from $-14^{\circ} \mathrm{F}$ to $68^{\circ} \mathrm{F}$. The research concluded that two emissions factors were adequate for predicting a vehicle's behavior over various atmospheric conditions. These two factors were used to estimate the emissions during the "cold-start" portion during which the catalytic converter was not hot enough to remove pollutants from the exhaust gas and a later condition in which the converter was working properly. The study documented the relationship between ambient temperature and emissions levels. As the temperature decreases from $68^{\circ} \mathrm{F}$ to $-14^{\circ} \mathrm{F}$, the emissions can increase by 100,60 and 10 times their original levels for $\mathrm{HC}, \mathrm{CO}$, and $\mathrm{NO}_{\mathrm{X}}$, respectively.

\subsubsection{EPA On-Road Diesel Emissions Characterization Facility (ODEC)}

The United States Environmental Protection Agency constructed an emissions testing facility that could be used by HDD tractors in an on-road environment [18]. This system consisted of a 45-foot Great Dane trailer that included all of the necessary equipment to quantify the regulated emissions from a diesel vehicle. ODEC was designed to allow the vehicle to be tested in any highway driving condition and any vehicle weight from an empty trailer (approximately 37,000 lb.) to the maximum legal driving weight $(80,000 \mathrm{lb}$.).

The system measures $\mathrm{CO}, \mathrm{NO}_{\mathrm{X}}$ and total hydrocarbons (THCs) using direct exhaust sampling. A dilution tunnel setup was considered to match chassis dynamometer test facilities, but the size and additional equipment required to determine the dilution ratio removed this option. Samples were kept heated to $191 \pm 6^{\circ} \mathrm{C}$ to avoid condensation of hydrocarbons out of the exhaust sample. The instruments for exhaust gas characterization were calibrated daily, and system bias was recorded for all tests. The exhaust flowrate was computed using an averaging pitot tube setup in which the pressure drop is measured across an obstruction of known geometry in the exhaust flow. Engine 
power was calculated through sensors at the flywheel to determine engine speed and at the transmission output for determining drive shaft speed. Additionally, a Wheatstone bridge strain gauge setup was attached directly to the drive shaft to record the actual shaft torque during vehicle operation.

All of the emissions measurement equipment was stored in the trailer and a computer interface allowed the test engineer to update and check the status of the data acquisition system and emissions monitoring components. To remove any additional load from the engine, a separate generator provided all the necessary power for the emissions monitoring equipment. In addition, an air conditioner powered by this generator allowed the load effects of the vehicle's climate control system on the emissions to be negated.

In comparison tests, the data from the ODEC was found to be very comparable to data obtained from the WVU Chassis Dynamometer. These data were examined for three separate testing cycles and found to be comparable for this complete range of test patterns.

\subsubsection{University of California - Riverside}

Cocker, et. al. [19] explored the concept of an in-use diesel emissions monitoring system in 2004. Their design consisted of a 53-ft refrigerated trailer that held all of the necessary emissions monitoring equipment for on-road, in-use emissions testing. All power for the emissions testing equipment was supplied by a Caterpillar diesel generated mounted at the rear of the trailer. This prevented any additional electrical power requirements from being placed upon the engine of the vehicle being tested. Exhaust gases were measured using a CVS system which allowed for dilution tunnel flowrates from 1000 to $4000 \mathrm{cfm}$. Moisture and condensation were kept out of the sampled exhaust with heated probes, sample lines, and filters. Emissions data were obtained at $10 \mathrm{~Hz}$ and included $\mathrm{NO}_{\mathrm{X}}, \mathrm{CO}, \mathrm{CO}_{2}, \mathrm{THC}$, and methane. The $\mathrm{NO}_{\mathrm{X}}$ was monitored using a chemiluminescence detection system. The $\mathrm{CO}$ and $\mathrm{CO}_{2}$ data were taken with NDIR technology. Laboratory methods of monitoring THC and methane were added to the trailer for the tests, and the flame ionization detector (FID) was used to obtain the concentrations of these exhaust constituents. Engine data were taken directly from the 
test vehicle's ECU, and the parameters monitored included engine speed, engine percent load, fuel rate, intake manifold pressure, engine coolant temperature, and boost pressure.

For verification of this system, tests were conducted in an on-road environment using various dynamometer driving cycles and an actual 53.2 mile highway testing route. From these tests, $\mathrm{NO}_{\mathrm{X}}$ values were shown to be around $50 \%$ higher than the certification values for the vehicles tested. Also, the slow moving traffic flow and "off-FTP cycle" emissions were determined to greatly increase the distance-based emissions rates for the $\mathrm{NO}_{\mathrm{X}}$ portion of the vehicle's emissions.

\subsection{Vehicle Weight Effect Studies}

Two major studies have been conducted to examine the effect of vehicle weight on emissions of diesel powered vehicles. These projects have occurred mostly with the use of a chassis dynamometer to simulate vehicle loading.

\subsubsection{University of California - Riverside}

In a journal article published with Environmental Science and Technology, Durbin, et. al. [20] described their work to characterize the effect of vehicle weight on exhaust emissions from light heavy-duty trucks powered by both gasoline and diesel fuel. For this study, testing took place on a Burke E. Porter 48-in. single roll electric dynamometer that has a 12,000 lb. capacity. In all, five diesel fueled vehicles were tested along with two gasoline vehicles. All vehicles were tested over various driving cycles including the Federal Test Procedure [FTP], Cold start and Hot running ST01, and CD level of service (LOS). Each vehicles was tested at empty, half load, and full load to determine the effects of vehicle weight on emissions. The study showed a "trend of increasing $\mathrm{PM}$ and $\mathrm{CO}_{2}$ " and "modest increases" in $\mathrm{NO}_{\mathrm{X}}$ production.

\subsubsection{Previous WVU Efforts}

Gajendran and Clark [21] explored the effect of vehicle weight on emissions for Class 7 and 8 vehicles in their 2003 journal paper. In this research, seven vehicles were tested with model years ranging from 1989 to 1998 and an array of engines from Detroit Diesel, Cummins, and Mack. The vehicles tested consisted of transit buses and tractor trucks that were each tested on cycles representing their typical use. The testing was 12 
completed on the West Virginia University Transportable Heavy Duty Emissions Testing Laboratories (TransLab). Once the data were collected, they were used to create an emissions model for predicting emissions at varying vehicle weights.

With the data combined, $\mathrm{NO}_{\mathrm{X}}$ emissions exhibited a pattern of doubling for an approximate $54 \%$ increase in vehicle weight. Overall, $\mathrm{NO}_{\mathrm{X}}$ had a nearly linear correlation with vehicle weight. Due to the inverse relationship of vehicle weight and fuel economy, the emissions of $\mathrm{NO}_{\mathrm{X}}$ in fuel specific units (g/gal) did not vary with test weight due to the increased amount of fuel required. The study discovered that HC emissions did not vary with test weight, and $\mathrm{CO}$ emissions were highly variable under transient conditions. Additionally, CO and PM showed no effect of test weight when operated in a steady state situation 


\section{Experimental Setup and Procedure}

\subsection{Experimental Equipment}

Aspects of a full-scale emissions testing facility including exhaust sampling and analysis, engine computer interface, and data acquisition must be made mobile through miniaturization, yet still maintain accuracy and reliability. For the purposes of this research, the WVU Mobile Emissions Measurement System (MEMS) was utilized. This system can obtain all the necessary data in order to quantify emissions of $\mathrm{NO}_{\mathrm{X}}$ and $\mathrm{CO}_{2}$ on the basis of mass or distance [12]. The system also measures hydrocarbons, but this data was not examined in this research. Portions of Section 3 have appeared previously in an SAE paper published in 2005 and presented at the 2005 SAE Powertrain Conference [22].

To obtain these data, the exhaust flowrate was first calculated. This was done using a differential pressure transducer across an obstruction flowmeter. Due to the known geometry of the obstruction, this differential pressure data along with the temperature of the exhaust flow and the absolute pressure in the flow can be used to obtain the full exhaust flowrate. A diagram of the annubar flowmeter apparatus can be seen in Figure 2.

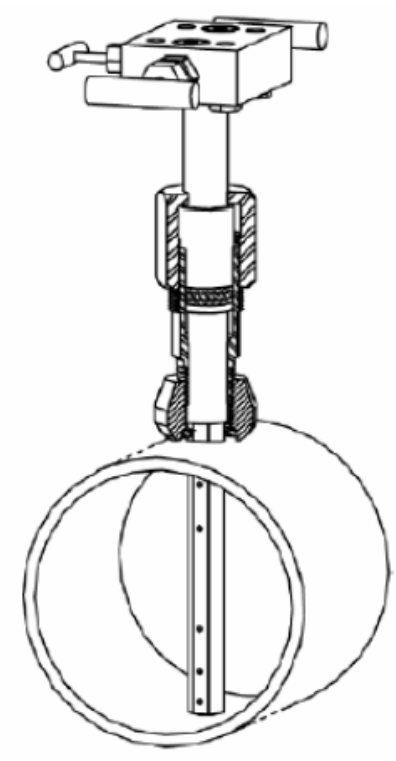

Figure 2 - Annubar Flow Meter Diagram: Reproduced from [23] 
According to CFR 1065, a sample probe is inserted directly into the exhaust tube [5]. Pumps inside what is known as the "Emissions Box" draw the sample through a heated line which was maintained at $400^{\circ} \mathrm{F}$ in order to prevent the condensation of water in which $\mathrm{NO}_{2}$ is soluble. This emissions box is shown in the picture in Figure 3.

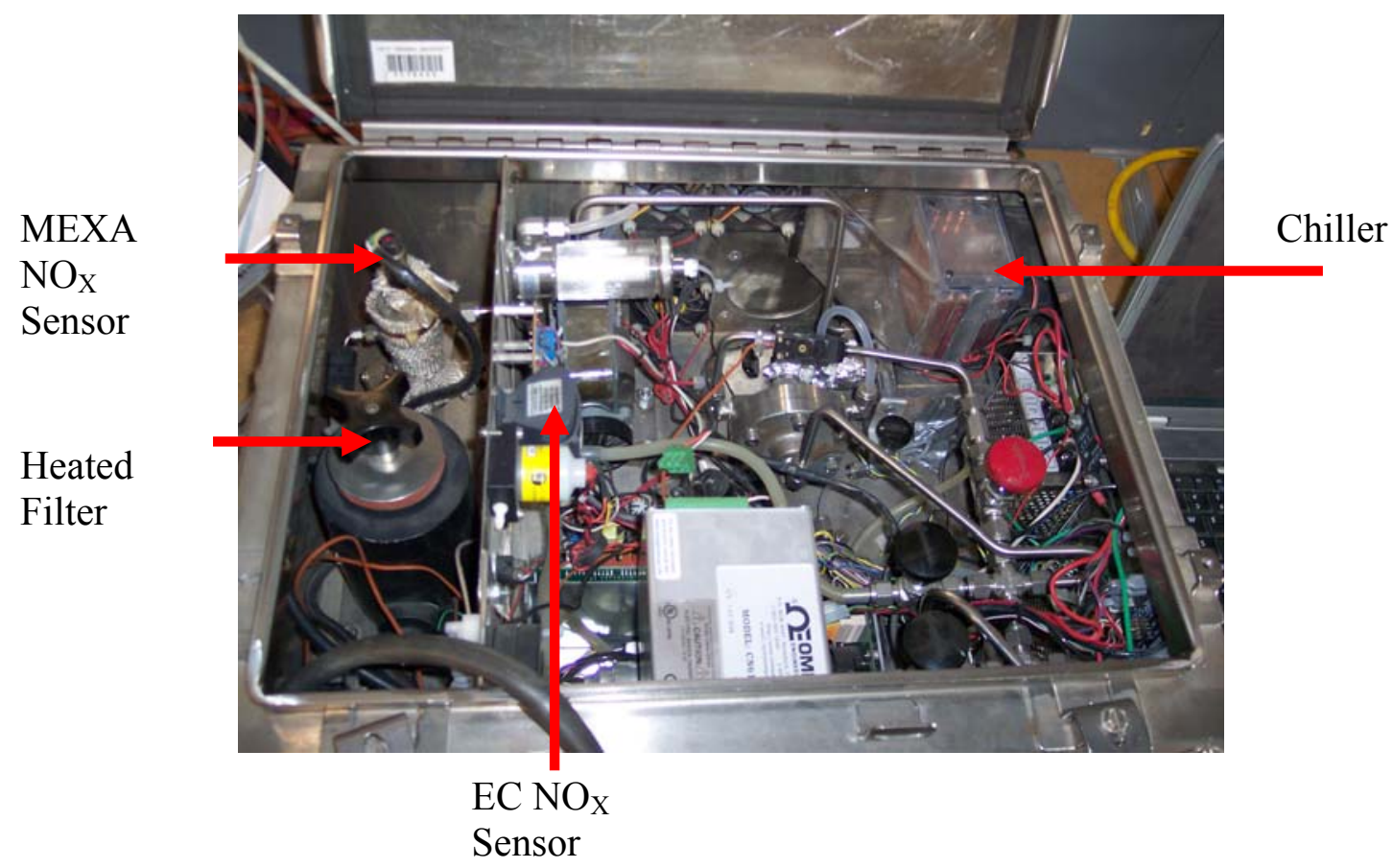

Figure 3 - Emissions Box Components

At the Emissions Box, the exhaust sample was passed through a heated filter to maintain the sample above the dewpoint and remove the particulate matter from the sample. A heated $\mathrm{NO}_{\mathrm{X}}$ converter converted all $\mathrm{NO}_{2}$ to $\mathrm{NO}$ so as to provide a more readily analyzable sample. At this point, the exhaust sample was analyzed by a Horiba MEXA-120 $\mathrm{NO}_{\mathrm{X}}$ analyzer. This heated conversion was necessary because the $\mathrm{NO}_{2}$ is very soluble in water, and any moisture in the sample can alter the measured emissions concentrations.

With the $\mathrm{NO}_{\mathrm{X}}$ converted, the sample passed through a Pelletier element chiller which used electrical current to lower the sample temperature to remove the water from the sample. The sample is then further analyzed for $\mathrm{CO}_{2}$ and $\mathrm{CO}$ using a Horiba BE-140 analyzer. After the chiller, the sample is "dry" so that the analyzer outputs must be 
corrected to ensure agreement of percent volume calculations before and after moisture changes to the sample.

While all of this was taking place, a personal computer with National Instruments data acquisition equipment was recording instantaneous data values. Also, the data acquisition acquired the ECU data, including engine speed, engine percent load, engine fueling rate, and vehicle speed. During the data reduction, this information was used to correlate the emissions data with the corresponding engine events.

WVU had prepared data reduction software that takes raw data from the data acquisition and generates plots and data tables in engineering units. This software utilized known constants for the system as well as all necessary calibration and correction factors for exhaust gas measurement.

\subsection{Test Setup}

For this research, one vehicle was utilized in order to obtain in-use emissions data that can be compared and contrasted over various tests. The vehicle chosen was a 1996 Peterbilt Tractor belonging to the WVU Research Corporation. This truck utilized a Caterpillar 3406E engine fitted to an 18-speed Eaton transmission. This engine had six cylinders in an inline configuration and had a total displacement of 14.6 liters. The engine was programmed to produce 550 horsepower. The torque output of the engine along with the corresponding engine speed can be seen in Figure 4.

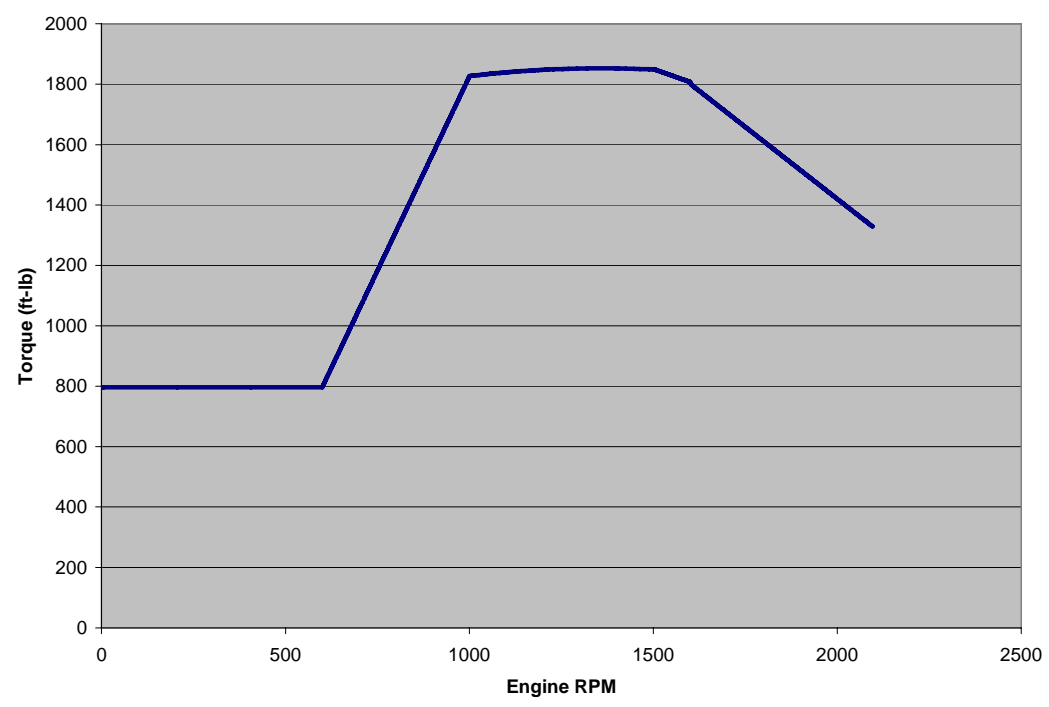

Figure 4 - Engine Lug Curve for 1996 Peterbilt Test Vehicle 
Also, the vehicle used the SAE J1587 protocol for its ECU communication with the on-board emissions measurement system. The vehicle is shown in Figure 5 with the emissions testing equipment installed.

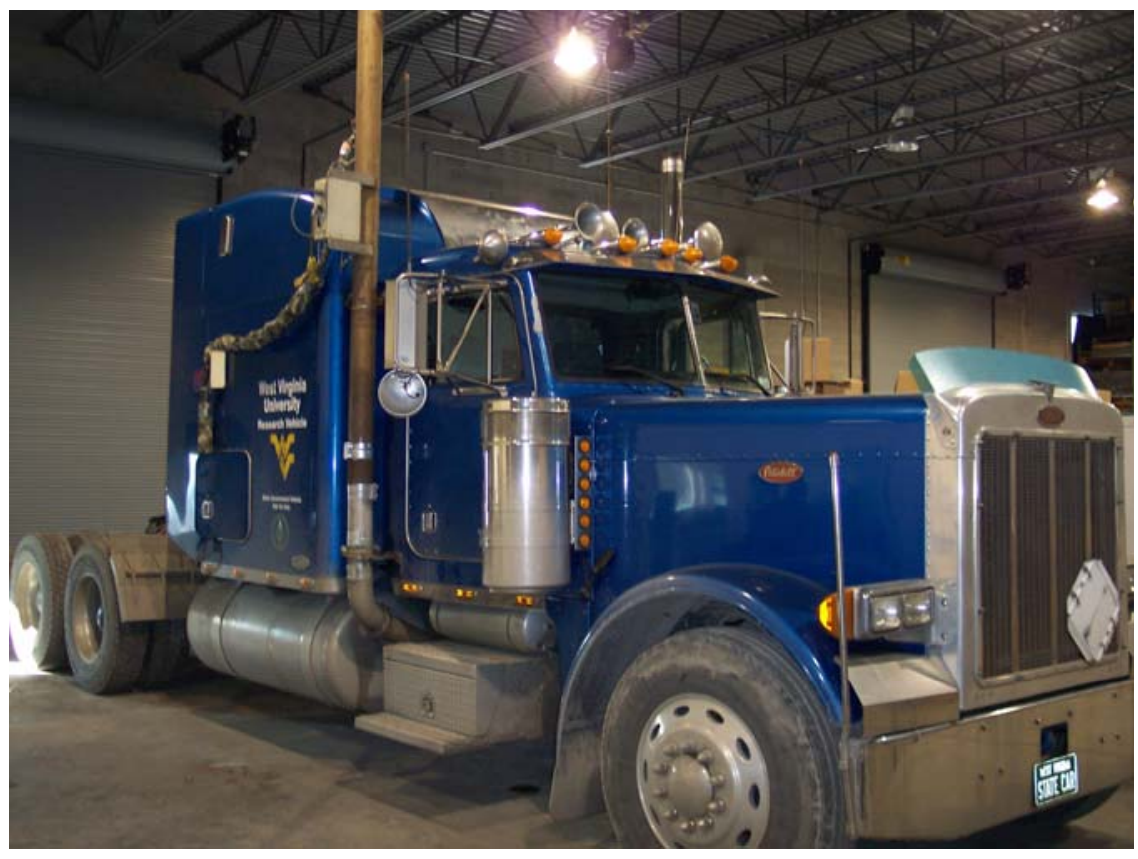

Figure 5 - 1996 Peterbilt with MEMS System Installed

Specifically, to explore the relationships between emissions and gross vehicle weight for an in-use Heavy Heavy-Duty Diesel Truck (HHDDT), a test matrix was constructed to obtain the necessary data. Four routes were chosen as well as four different gross vehicle weights. The four routes were selected in such a way that the truck would be required to traverse varied terrain. The routes were given names in order to differentiate among them within the test data. Bruceton and Saltwell were chosen as the names for the two routes originating from the WVU laboratory in Westover, WV. PA 43 was chosen as the name for the route that traveled over Route 43 in Pennsylvania, and Stop-n-go was selected due to the transient behavior of the vehicle in city driving. These routes are described in more detail following the test plan.

To correlate the gross vehicle weight to emissions, differing loadings were driven over each separate route. The weights of 20,740 lb., 34,640 lb., 61,520 lb., and 79,700 lb. were chosen as test weights at which to drive the truck. The 20,740 lb. test weight estimate was chosen because this is the weight of the truck during bobtail operation. This 17 
serves as an emissions baseline to which to compare the rest of the emissions measurements for the other test weights. The 34,640 lb. test weight was determined by adding an empty trailer to the truck itself. This simulated a driver utilizing the truck during a deadheading operation. It was desired that the other two test weights be determined by using approximately $75 \%$ and $100 \%$ of the gross vehicle weight rating of the 1996 Peterbilt used in the testing. The Flat and Stop-n-go routes only utilized two different weights. Table 2 shows the test matrix and illustrates the weights and routes used for this research.

Table 2 - Completed Testing

\begin{tabular}{|c|r|r|r|r|}
\hline Westover to Bruceton - Uphill & $20,740 \mathrm{lb}$ & $34,640 \mathrm{lb}$ & $61,520 \mathrm{lb}$ & $79,700 \mathrm{lb}$ \\
\hline Bruceton to Westover - Downhill & $20,740 \mathrm{lb}$ & $34,640 \mathrm{lb}$ & $61,520 \mathrm{lb}$ & $79,700 \mathrm{lb}$ \\
\hline Westover to Saltwell & $20,740 \mathrm{lb}$ & $34,640 \mathrm{lb}$ & $61,520 \mathrm{lb}$ & $79,700 \mathrm{lb}$ \\
\hline Saltwell to Westover & $20,740 \mathrm{lb}$ & $34,640 \mathrm{lb}$ & $61,520 \mathrm{lb}$ & $79,700 \mathrm{lb}$ \\
\hline PA 43 - 1 & & $34,640 \mathrm{lb}$ & & $79,700 \mathrm{lb}$ \\
\hline PA 43 - 2 & & $34,640 \mathrm{lb}$ & & $79,700 \mathrm{lb}$ \\
\hline Stop-n-go & & $34,640 \mathrm{lb}$ & & $79,700 \mathrm{lb}$ \\
\hline
\end{tabular}

The first route, called Bruceton, consists of interstate driving from Westover, WV to Bruceton Mills, WV. Part of this route includes a very long hill climb into the WV mountains via Interstate 68 east. Data were also gathered on the return trip so as to compare emissions even across the same route. A map for this route is shown in Figure 6.

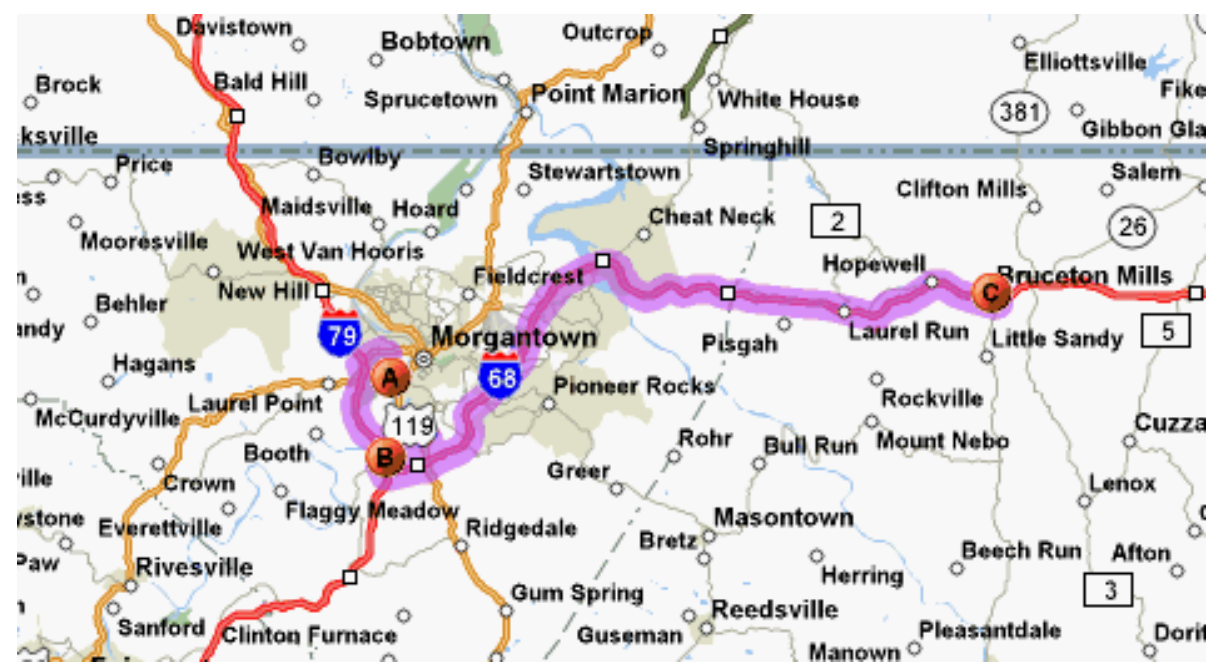

Figure 6 - Bruceton Route Map [24] 
This route included a large hill climb to the Coopers Rock area. This difficult section of terrain was utilized to compare the emissions at different vehicle loadings to determine the effect of road grade on the emissions. A plot of the elevation changes on this route is shown in Figure 7. This data was obtained though GPS data and verified using a road grade estimation that is described in Section 4.7.4.

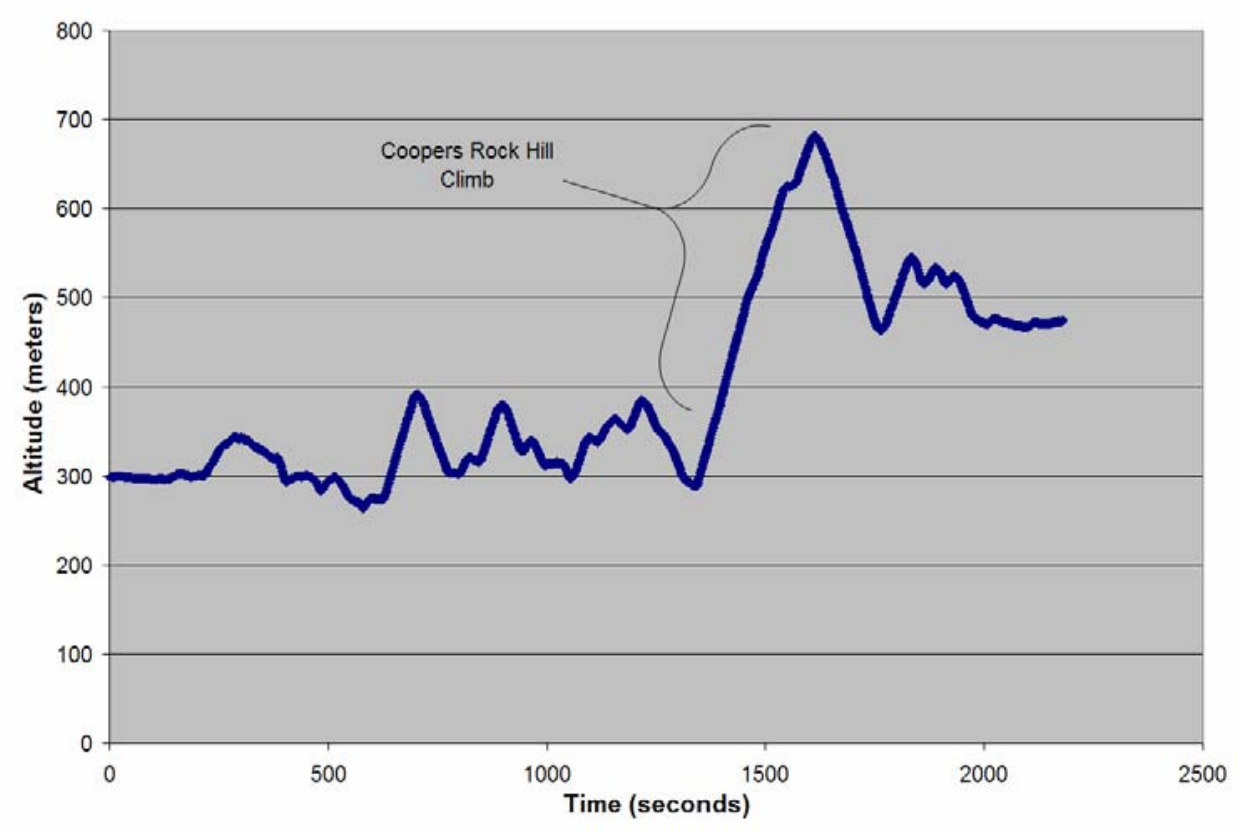

Figure 7 - Bruceton Route Altitude Profile

For the route, the truck was driven in a similar manner for each test. Statistical data shown in Table 3 illustrates the similarities of the tests to one another. General statistics were examined for each route such as average speed and the distance traveled. Additionally, the stops per mile were calculated to provide a measure of comparison with dynamometer test routes. The only major statistical difference exists in the stops per mile category. This is a result of the $20,740 \mathrm{lb}$. test from Bruceton to Westover encountering some heavy traffic when returning to the starting location at the end of the test run. All of the other test runs have between three and four stops for the entire route, where this run contained seven such stops. The cruise portion of the test route was defined as the period over which the speed of the vehicle exceeded $50 \mathrm{mph}$ for over two minutes. For statistical analysis, the period continued until the vehicle dropped below $50 \mathrm{mph}$ for more than two minutes. In some test runs, there was a weigh station that required a stop in the 
middle of a test, so those transient portions were not considered in the analysis of the statistical data for the cruise portion.

Table 3 - Statistical Data for Bruceton Test Runs

\begin{tabular}{|c|c|c|c|c|}
\hline \multicolumn{7}{|c|}{ Westover to Bruceton } \\
\hline Test Weight & $\mathbf{2 0 , 7 4 0 ~} \mathbf{~ b .}$ & $\mathbf{3 4 , 6 4 0 ~} \mathbf{~ b .}$ & $\mathbf{6 1 , 5 2 0 ~} \mathbf{~ b .}$ & $\mathbf{7 9 , 7 0 0 ~} \mathbf{~ b .}$ \\
\hline Avg Speed (overall) [MPH] & 50.18 & 49.77 & 46.77 & 41.20 \\
\hline Avg Speed (cruise) [MPH] & 69.70 & 69.94 & 60.09 & 55.36 \\
\hline Standard Deviation [MPH] & 26.49 & 26.50 & 22.30 & 21.18 \\
\hline Standard Deviation (cruise) [MPH] & 4.49 & 4.29 & 11.18 & 12.17 \\
\hline Stops & 3.00 & 3.00 & 4.00 & 3.00 \\
\hline Distance [Miles] & 29.53 & 29.94 & 30.00 & 30.01 \\
\hline Test Duration [Seconds] & 2170.60 & 2210.60 & 2351.20 & 2668.60 \\
\hline Stops per mile & 0.10 & 0.10 & 0.13 & 0.10 \\
\hline
\end{tabular}

\begin{tabular}{|c|c|c|c|c|}
\hline \multicolumn{7}{|c|}{ Bruceton to Westover } \\
\hline Test Weight & $\mathbf{2 0 , 7 4 0 ~} \mathbf{~ b}$. & $\mathbf{3 4 , 6 4 0} \mathbf{~ l b}$. & $\mathbf{6 1 , 5 2 0} \mathbf{~ l b}$. & $\mathbf{7 9 , 7 0 0 ~} \mathbf{~ b .}$ \\
\hline Avg Speed (overall) [MPH] & 49.22 & 49.39 & 45.09 & 43.27 \\
\hline Avg Speed (cruise) [MPH] & 68.62 & 68.34 & 61.21 & 59.28 \\
\hline Standard Deviation [MPH] & 25.51 & 25.21 & 22.77 & 21.22 \\
\hline Standard Deviation (cruise) [MPH] & 5.14 & 3.21 & 8.89 & 9.87 \\
\hline Stops & 7.00 & 4.00 & 4.00 & 3.00 \\
\hline Distance [Miles] & 29.11 & 29.22 & 29.27 & 29.31 \\
\hline Test Duration [Seconds] & 2208.80 & 2176.40 & 2381.60 & 2486.20 \\
\hline Stops per mile & 0.24 & 0.14 & 0.14 & 0.10 \\
\hline
\end{tabular}

Secondly, a route called Saltwell was utilized and included interstate driving from Westover, WV to Saltwell Road which is approximately 30 miles. Data were collected during both the outbound and returning trips in order to be compared and contrasted. Although the trips do not show an "uphill" and "downhill" section as distinctly as the Bruceton route, the outbound trip from Morgantown to Saltwell will be referred to as the uphill portion of the route since the ending altitude is 50 meters above the beginning altitude. Conversely, the return trip will be called a "downhill" route, but the undulations of the terrain cause both hill climbs and hill descents throughout the test route. Figure 8 shows this route on an interstate map.

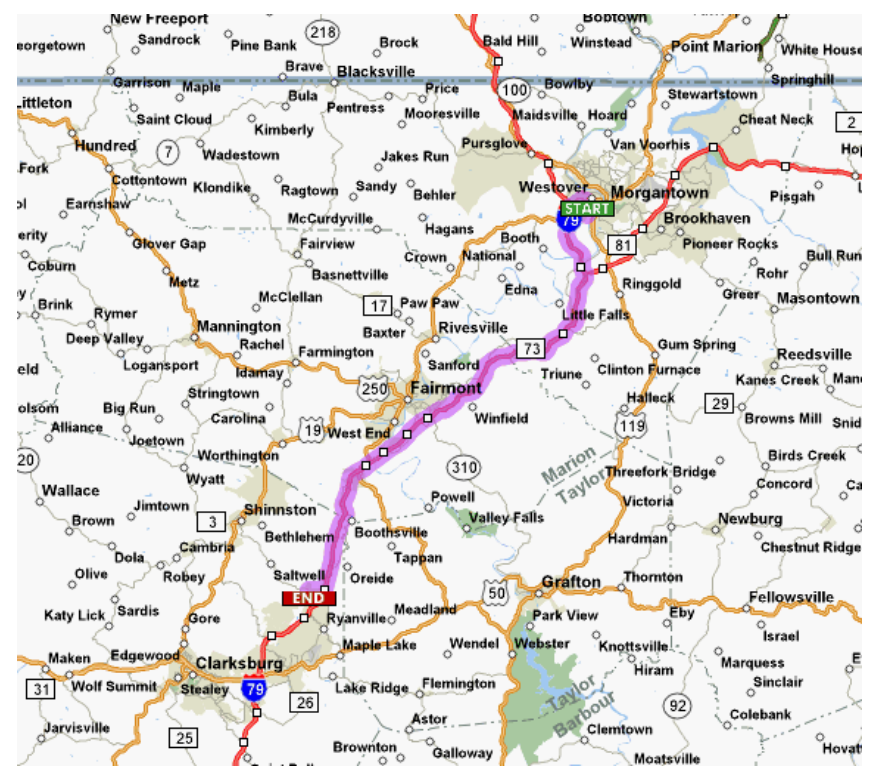

Figure 8 - Saltwell Route Map [25] 
The terrain for this section is more rolling smaller hills, and the terrain could be described as "undulating" as it progresses along the route. A plot of these elevation changes can be found in Figure 9. The magnitude of the altitude oscillations on this route is much less than those on the Bruceton route. This particular run has the tallest hill climb of approximately $100 \mathrm{~m}$, whereas the Bruceton route contained a climb of almost $400 \mathrm{~m}$.

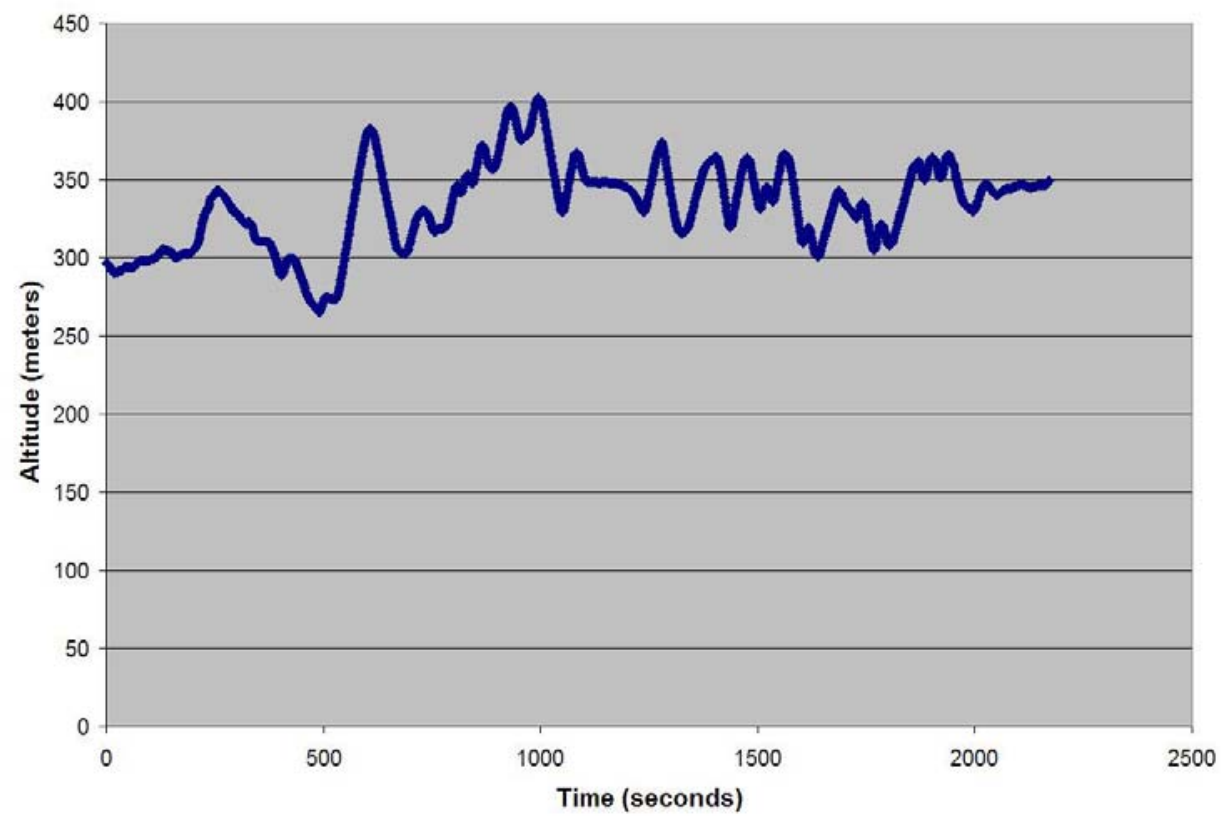

Figure 9 - Saltwell- Uphill Altitude Profile

The test routes to and from Saltwell Road resulted in very comparable statistical data for the test routes. These data are shown in Table 4.

Table 4 - Statistical Data for Saltwell Test Runs

\begin{tabular}{|c|c|c|c|c|}
\hline \multicolumn{5}{|c|}{ Westover to Saltwell } \\
\hline Test Weight & $\mathbf{2 0 , 7 4 0} \mathbf{~ l b}$. & $\mathbf{3 4 , 6 4 0} \mathbf{~ b .}$ & $\mathbf{6 1 , 5 2 0} \mathbf{~ b .}$ & $\mathbf{7 9 , 7 0 0 ~} \mathbf{~ b .}$ \\
\hline Avg Speed (overall) [MPH] & 51.47 & 52.05 & 40.50 & 43.36 \\
\hline Avg Speed (cruise) [MPH] & 67.80 & 56.40 & 58.67 & 59.01 \\
\hline Standard Deviation [MPH] & 24.07 & 26.89 & 23.67 & 22.71 \\
\hline Standard Deviation (cruise) [MPH] & 5.16 & 24.45 & 7.75 & 11.24 \\
\hline Stops & 4.00 & 5.00 & 6.00 & 6.00 \\
\hline Distance [Miles] & 30.18 & 30.30 & 30.70 & 30.74 \\
\hline Test Duration [Seconds] & 2208.80 & 2136.00 & 2776.60 & 2593.00 \\
\hline Stops per mile & 0.13 & 0.17 & 0.20 & 0.20 \\
\hline
\end{tabular}

\begin{tabular}{|c|c|c|c|c|}
\hline \multicolumn{5}{|c|}{ Saltwell to Westover } \\
\hline Test Weight & $20,740 \mathrm{lb}$. & $34,640 \mathrm{lb}$. & $61,520 \mathrm{lb}$. & $79,700 \mathrm{lb}$. \\
\hline Avg Speed (overall) [MPH] & 50.24 & 49.77 & 48.50 & 49.21 \\
\hline Avg Speed (cruise) [MPH] & 66.07 & 69.94 & 61.24 & 60.42 \\
\hline Standard Deviation [MPH] & 24.29 & 26.50 & 21.22 & 20.46 \\
\hline Standard Deviation (cruise) [MPH] & 6.36 & 4.29 & 6.11 & 7.87 \\
\hline Stops & 4.00 & 3.00 & 4.00 & 3.00 \\
\hline Distance [Miles] & 29.51 & 29.94 & 29.86 & 29.90 \\
\hline Test Duration [Seconds] & 2208.80 & 2210.60 & 2258.80 & 2226.80 \\
\hline
\end{tabular}


Next, Pennsylvania Route 43 (or PA 43) was driven to obtain data from driving conditions with limited gradients. This section was a four-lane divided highway that included long stretches of constant speed on level roadway. The map of the route is found in Figure 10.

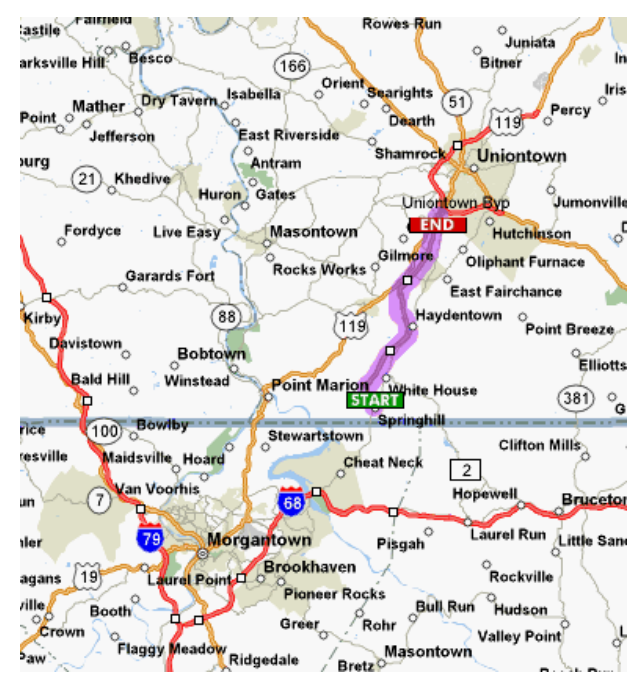

Figure 10 - PA 43 Route Map [26]

Sections of PA 43 were used to examine the road load of driving on a flat road with no hill or terrain effects. The plot of the altitude along this route is shown in Figure 11.

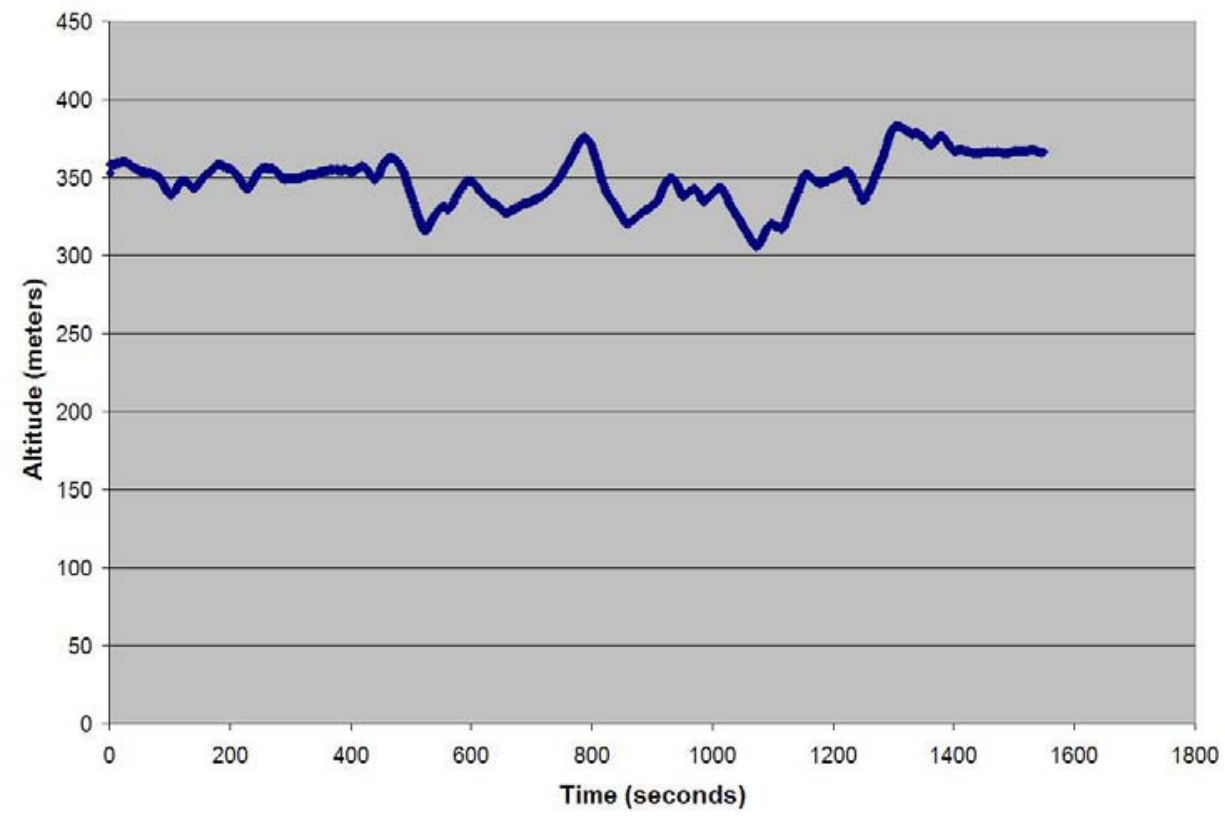

Figure 11 - PA 43 Altitude Profile 
For the PA 43 test runs, statistical data illustrates the comparability of the various test runs which were performed. Given the less mountainous nature of this test route, the average speed could be maintained from the empty trailer weight to the fully loaded vehicle weight. These and other data are displayed in Table 5.

Table 5 - Statistical Data for PA 43 Test Runs

\begin{tabular}{|c|c|c|}
\hline \multicolumn{3}{|c|}{ PA 43 - Outbound } \\
\hline Test Weight & $\mathbf{3 4 , 6 4 0 ~} \mathbf{~ b .}$ & $\mathbf{7 9 , 7 0 0 ~} \mathbf{~ l b}$. \\
\hline Avg Speed (overall) [MPH] & 46.55 & 46.89 \\
\hline Avg Speed (cruise) [MPH] & 62.45 & 62.78 \\
\hline Standard Deviation [MPH] & 25.13 & 23.84 \\
\hline Standard Deviation (cruise) [MPH] & 3.58 & 5.04 \\
\hline Stops & 3.00 & 3.00 \\
\hline Distance [Miles] & 19.49 & 19.56 \\
\hline Test Duration [Seconds] & 1540.00 & 1528.00 \\
\hline Stops per mile & 0.15 & 0.15 \\
\hline
\end{tabular}

\begin{tabular}{|c|c|c|}
\hline \multicolumn{3}{|c|}{ PA 43 - Inbound } \\
\hline Test Weight & $\mathbf{3 4 , 6 4 0 ~} \mathbf{~ b .}$ & $\mathbf{7 9 , 7 0 0 ~} \mathbf{~ b .}$ \\
\hline Avg Speed (overall) [MPH] & 46.60 & 49.39 \\
\hline Avg Speed (cruise) [MPH] & 61.31 & 68.34 \\
\hline Standard Deviation [MPH] & 23.77 & 25.21 \\
\hline Standard Deviation (cruise) [MPH] & 3.89 & 3.21 \\
\hline Stops & 5.00 & 4.00 \\
\hline Distance [Miles] & 19.27 & 29.22 \\
\hline Test Duration [Seconds] & 1520.80 & 2176.40 \\
\hline
\end{tabular}

Finally, a route through the city of Morgantown, called the Stop-n-go route was driven to obtain the effects of driving in traffic. These tests were used to determine the emissions and behavior of a HHDDT during in-city operation. By driving through town, the effect of starting and stopping could be compared with the highway testing data. A cartographic representation of this route can be found in Figure 12.

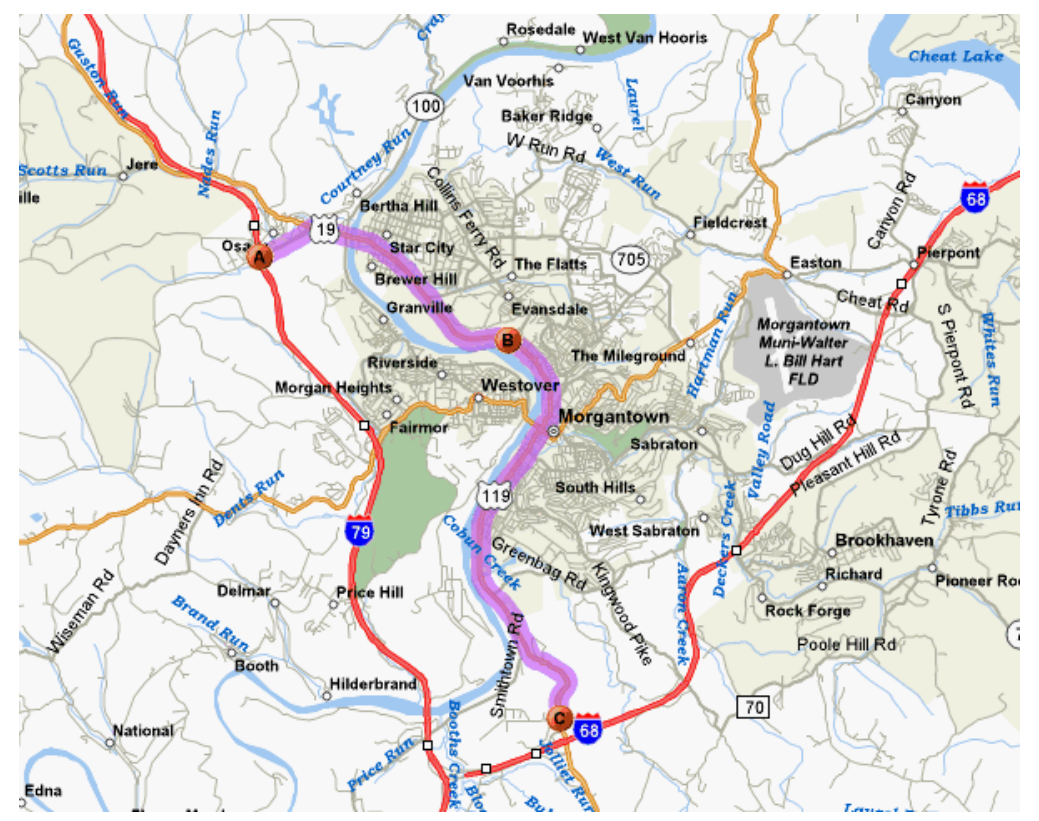

Figure 12 - Stop-n-go Route Map [27] 
For the transient, in-town testing, the statistical data was far less conclusive than the highway data. The nature of the test route included the fact that the vehicle would have to stop a different number of times depending on the traffic lights and other vehicles during a given test. Although the tests were conducted on different days, the time of day was similar in both cases in order to experience approximately the same traffic flow and congestion. Still, the data were comparable in terms of average speed for both tests. The data can be seen in Table 6.

Table 6 - Statistical Data for Stop-n-go Test Runs

\begin{tabular}{|c|c|c|}
\hline \multicolumn{3}{|c|}{ Stop-n-go } \\
\hline Test Weight & $\mathbf{3 4 , 6 4 0 ~ \mathbf { ~ b } .}$ & $\mathbf{7 9 , 7 0 0 ~ \mathbf { ~ b } .}$ \\
\hline Avg Speed (overall) [MPH] & 29.02 & 27.58 \\
\hline Avg Speed (cruise) [MPH] & NA & NA \\
\hline Standard Deviation [MPH] & 20.32 & 14.68 \\
\hline Standard Deviation (cruise) [MPH] & NA & NA \\
\hline Stops & 9.00 & 5.00 \\
\hline Distance [Miles] & 14.93 & 15.05 \\
\hline Test Duration [Seconds] & 1895.80 & 2002.20 \\
\hline Stops per mile & 0.60 & 0.33 \\
\hline
\end{tabular}

\subsection{System Calibration}

Prior to each segment of testing, a system calibration was performed in order to ensure proper data collection. To do this, a compressed gas mixture of approximately $12 \% \mathrm{CO}_{2}$ and $2000 \mathrm{ppm} \mathrm{NO}_{\mathrm{X}}$ was passed through the exhaust gas sampling system. The voltage outputs of the sensors were recorded and used to check system response to known gases. By calibrating prior to each test, errors were minimized.

\subsection{Data Collection}

For the MEMS equipment, specific data were collected for each run. The data displayed in this section of the thesis all come from a Saltwell route driven at a gross vehicle weight of $34,640 \mathrm{lb}$. The same data were taken for each test, but this data is shown to illustrate the categories of data that were obtained.

First, the differential pressure was measured using an annubar flowmeter. Through an electronic transducer, this value was measured as a voltage and stored in the Data Acquisition Unit (DAQ) along with constants that were used to determine the engineering 
value in inches of water. Figure 13 shows the differential pressure during the test versus time elapsed.

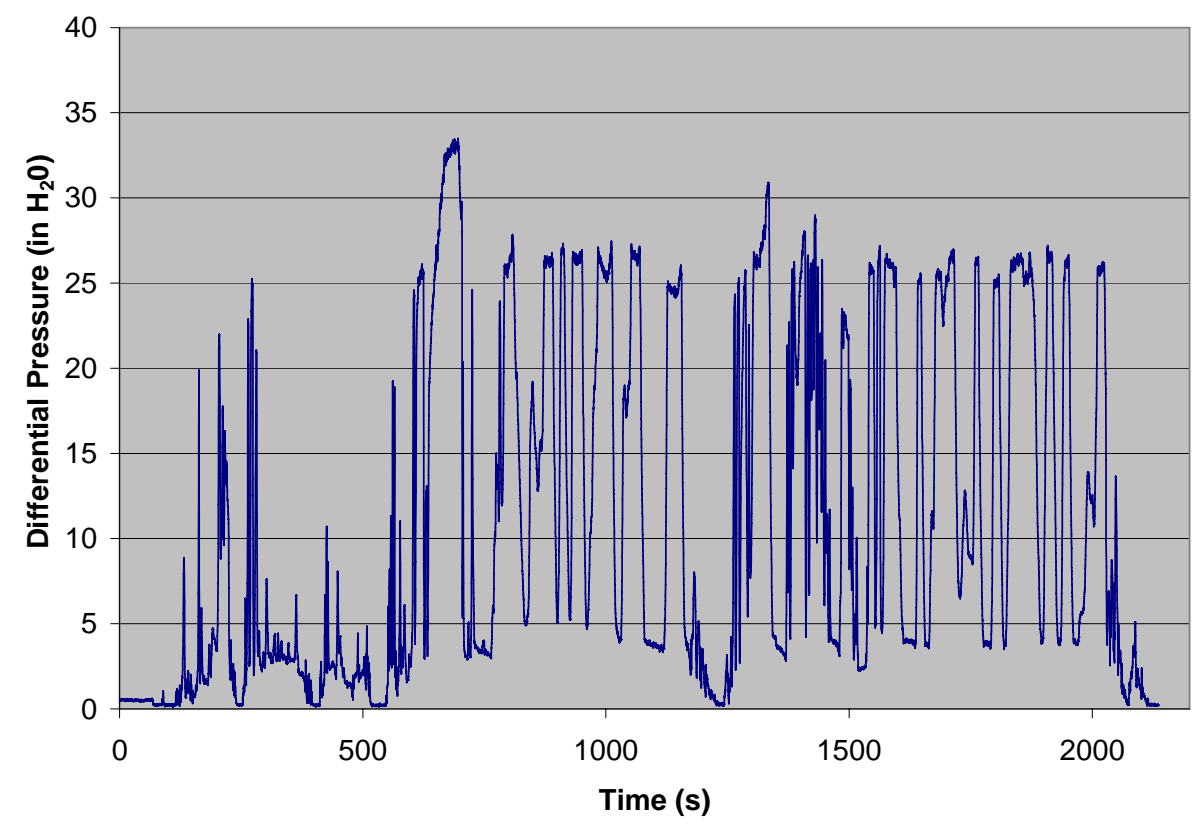

Figure 13 - Differential Pressure versus Time for Saltwell Route at 34,640 lb.

Next, the temperature of the exhaust flow was measured near the annubar flow obstruction. Figure 14 shows the temperature profile over the course of the test.

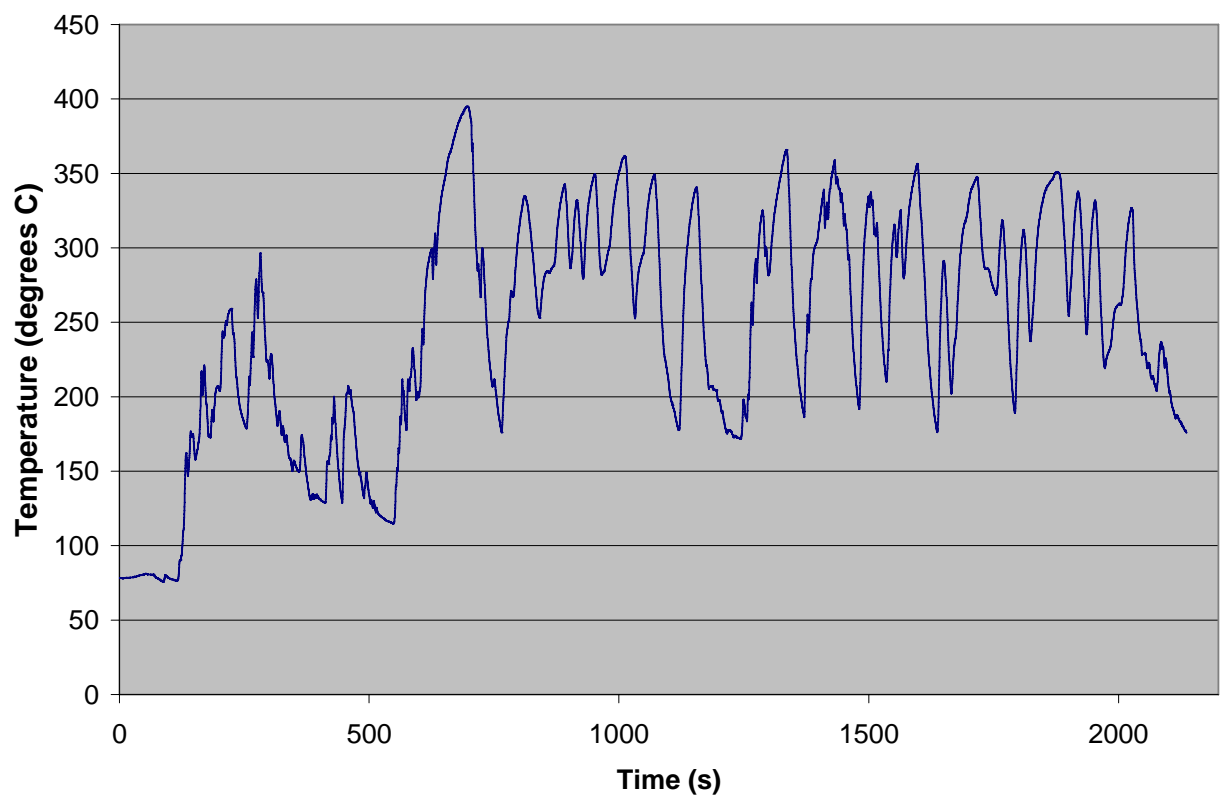

Figure 14 - Exhaust Temperature versus Time for Saltwell Route at 34,640 lb. 
In addition to the temperatures, the absolute pressure in the exhaust tube was also recorded. The plot of absolute pressure was used in determining the flowrate in the pipe. Also, the absolute pressure can be used to derive the slope of the road being traveled by the vehicle. Figure 15 shows the absolute pressure data inside the exhaust tube. This absolute pressure measurement also indicated the relative road grade for the trip. The absolute pressure was found to be inversely proportional to the road grade. The fluctuations seen in Figure 15 can be directly related to the hills and valleys on the vehicle's test routes. Also, the noise present in the data sample caused issues in the determination of the road inclination angle, as seen in section 4.7.3.

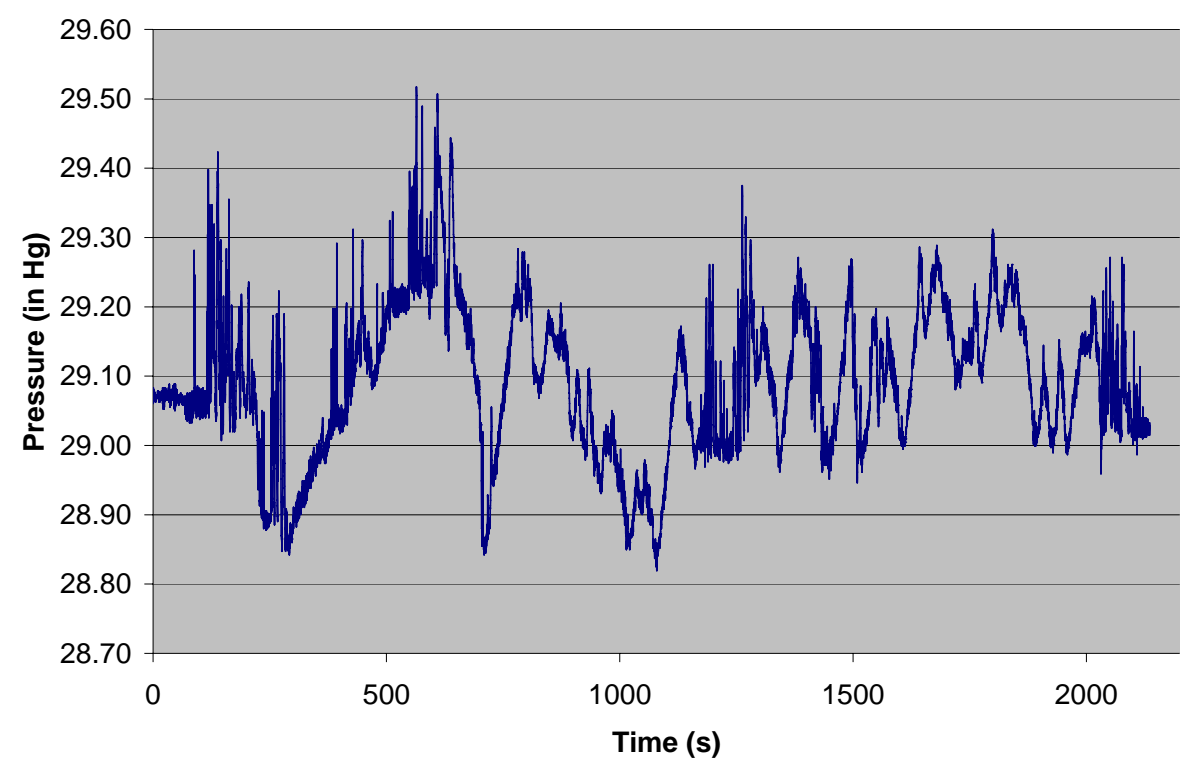

Figure 15 - Annubar Absolute Pressure for Saltwell Route at 34,640 lb.

Once the previous parameters are reduced, all the data can be combined to result in an overall calculation of flow in standard feet per minute, as shown in Figure 16. In the SAE Paper on the subject, Gautam, et. al. [12] described the MEMS system in more detail including the various sensors and components utilized in the data collection. 


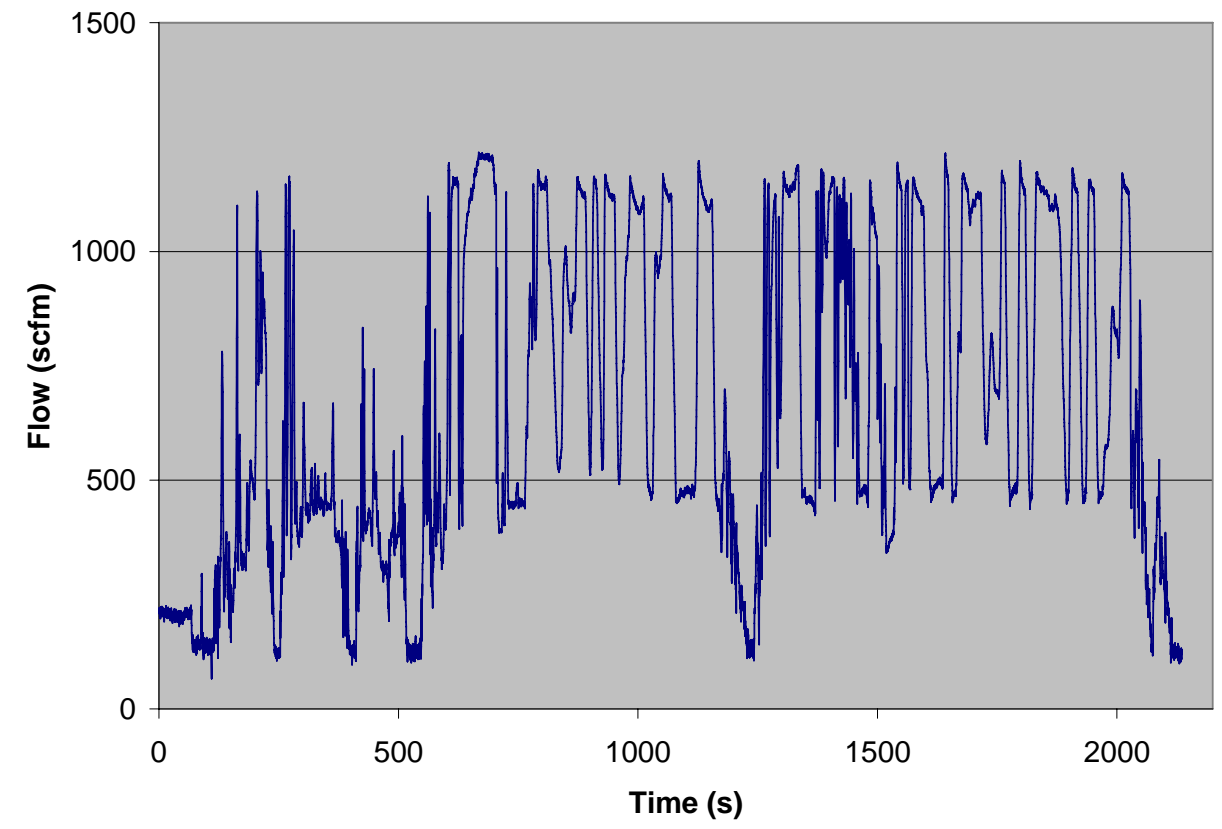

Figure 16 - Exhaust Flowrate at Standard Conditions versus Time for Saltwell Route at $34,640 \mathrm{lb}$.

In Figure 17, the ECU fueling rate has been plotted. This value, when it increases during engine loading, also corresponds to an increase in exhaust flowrate. This value can be integrated over the entire test or certain NTE regions to determine the fuel economy for the vehicle.

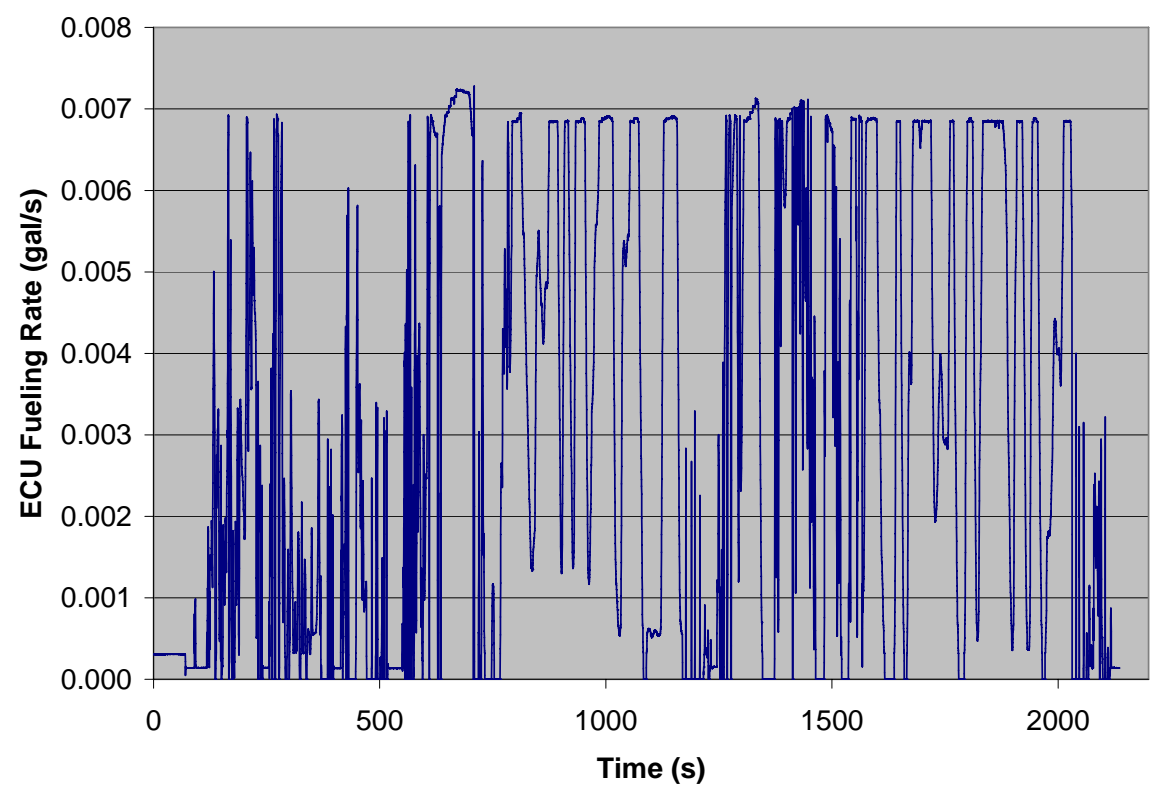

Figure 17 - ECU Fueling Rate versus Time for Saltwell Route at 34,640 lb. 
The instantaneous emissions values for $\mathrm{NO}_{\mathrm{X}}$ can be utilized to determine the flowrate of that emissions constituent. Because the sample that was analyzed by the MEMS equipment was not diluted, the product of the flowrate and the concentration, along with conversion factors, can be used directly to achieve a mass emissions flowrate. Additionally, a correction factor was applied to the $\mathrm{NO}_{\mathrm{X}}$ measurements according to the atmospheric conditions of the day. Also, delays in the sampling system and its electronic response require the data to be time-shifted according to known parameters of the MEMS system in order to correlate engine events with exhaust analysis events. The shifting takes place within the software using a specified time interval that had been determined through experimental verification. These data were compared with engine events to verify the data was shifted by the right amount of time. Figure 18 shows the resulting corrected and shifted $\mathrm{NO}_{\mathrm{X}}$ flowrate as used in the brake-specific, distance-specific, and NTE emissions levels to be calculated later.

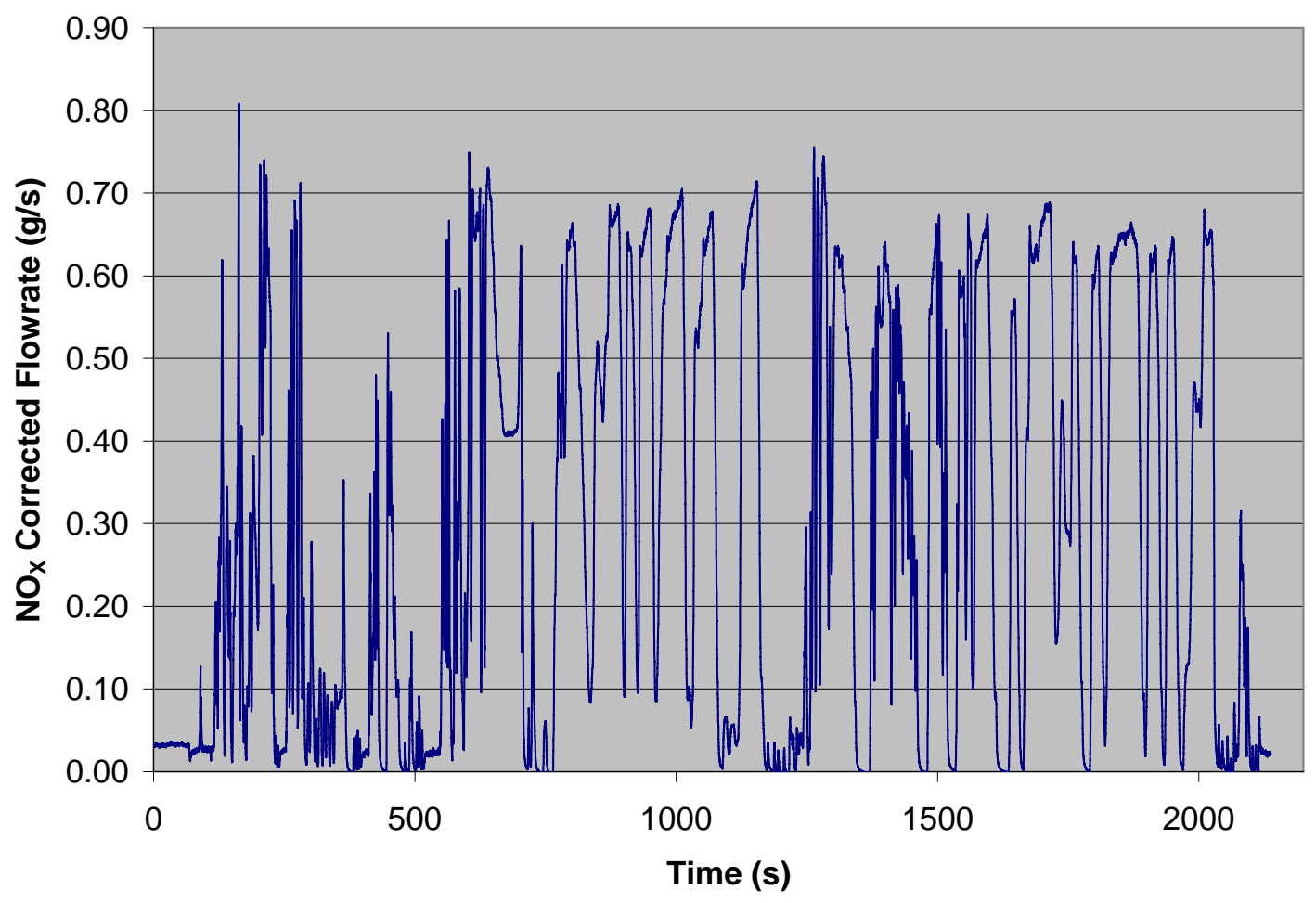

Figure $18-\mathrm{NO}_{x}$ Corrected Flowrate versus Time for Saltwell Route at 34,640 lb. 
Although the instantaneous data are interesting to examine for the entire test, they are averaged over a moving thirty-second window to further examine engine events. To illustrate the necessity of the moving thirty-second average, Figure 19 shows the broadcast fueling versus the $\mathrm{NO}_{\mathrm{X}}$ flowrate. The vertical axis contains data from the MEXA $\mathrm{NO}_{\mathrm{X}}$ sensor that had been corrected for the given weather conditions of the day and shifted to the proper time interval. The relationship should be direct and lie on a line. Although the data is time-shifted to obtain the best correlation, sampling delays allow a few fueling events to be reported by the ECU prior to recognizing the actual emissions data.

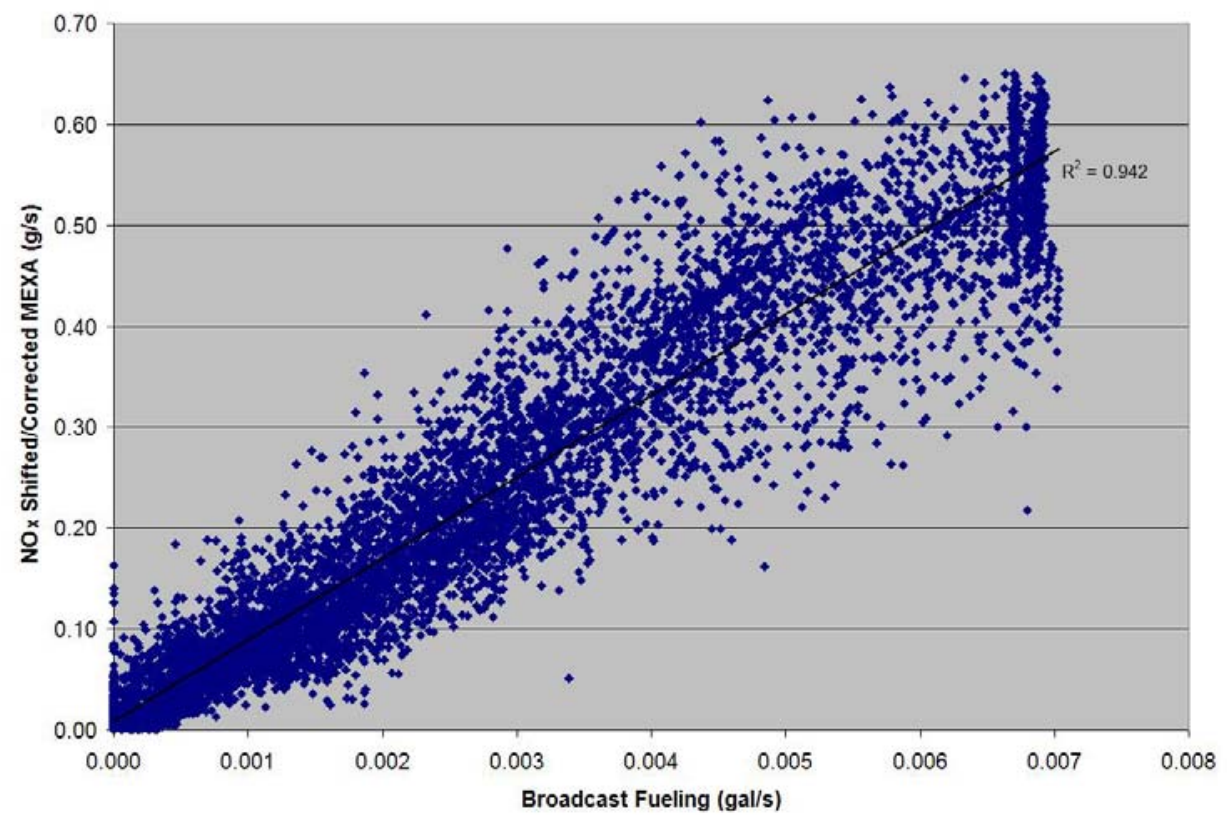

Figure 19 - Broadcast Fueling versus Shifted and Corrected MEXA NO Flowrate $^{-}$

In a similar manner to the $\mathrm{NO}_{\mathrm{X}}$ flowrate shown in Figure 18 , the carbon dioxide $\left(\mathrm{CO}_{2}\right)$ flowrate is also calculated after shifting and correcting the instantaneous values obtained from the Horiba BE-140 module located in the Emissions Box. Figure 20 shows the carbon dioxide flowrate throughout the duration of the test run. 


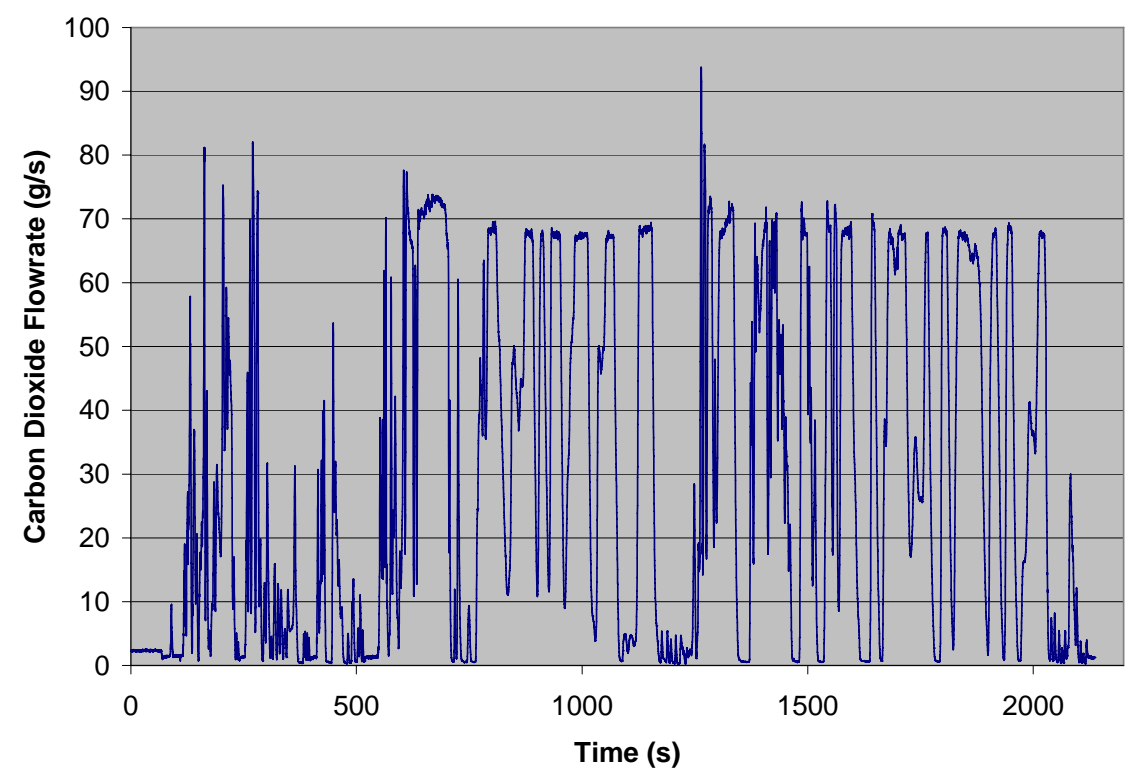

Figure 20 - Carbon Dioxide Flowrate versus Time for Saltwell Route at $\mathbf{3 4 , 6 4 0 ~ l b . ~}$

In addition, the $\mathrm{CO}_{2}$ flowrate is directly proportional to the fueling rate of the engine of the truck. This trend can be seen in Figure 21.

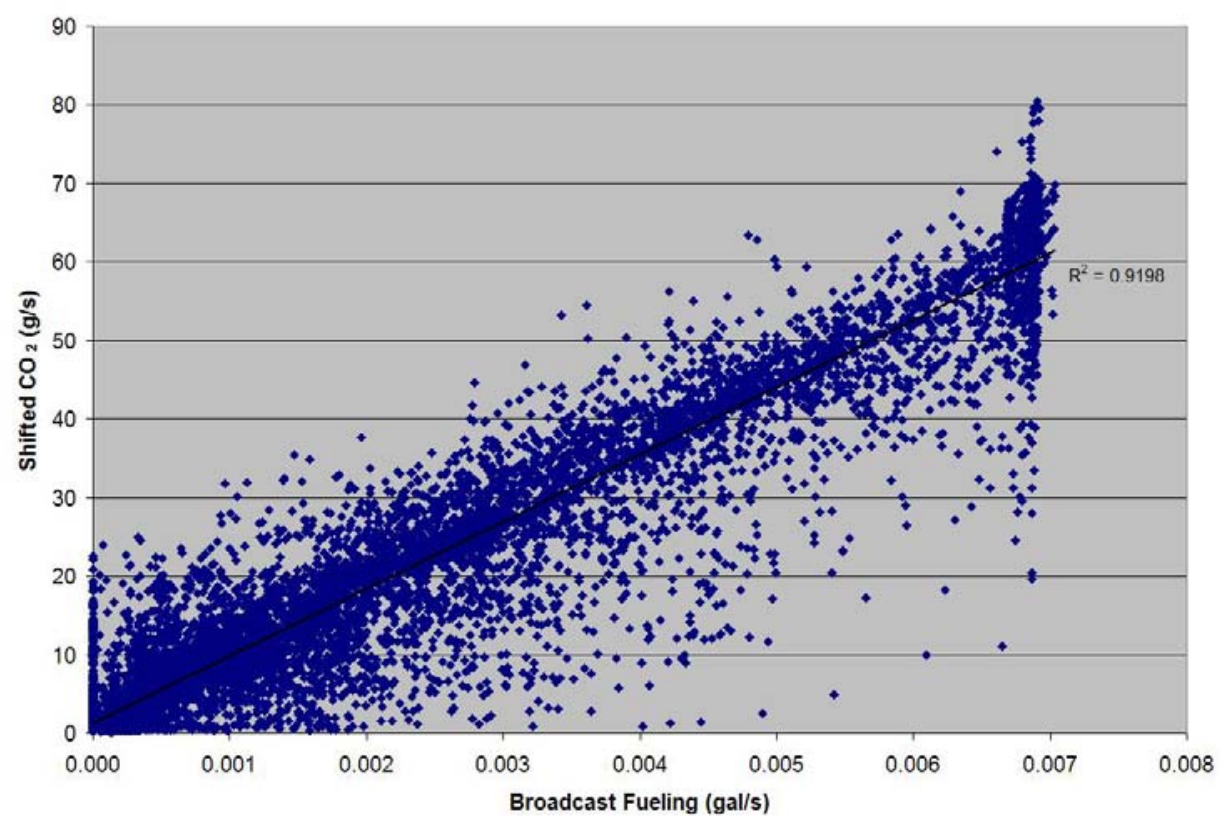

Figure 21 - Broadcast Fueling versus Shifted $\mathrm{CO}_{2}$ Flowrate

Per the CFR, the main regions in which emissions are most critically monitored are called Not-to-exceed zones [5]. These are detailed in 65 Fed. Reg. 59896, Oct. 6, 2000 and consist of certain periods of engine operation for which the emissions must not 
exceed a specified level. To determine whether the vehicle is operating in the NTE zone, the engine speed, horsepower, and torque are required. Figure 1 shows the NTE zone as defined by the government for the testing of diesel powered trucks. In this study, the vehicle's behavior within the NTE zone has been examined along with the various ways a vehicle can enter and exit the region. Section 4 will provide details on the vehicle's emissions behavior over the various test routes.

Figure 22 illustrates the engine speed for the duration of the test route. From this plot, it can be noticed that a large portion of the route consisted of steady state operation of the engine around $1700 \mathrm{rpm}$. This was due to the fact that this route consists of a large amount of highway driving with no changes in gear selection.

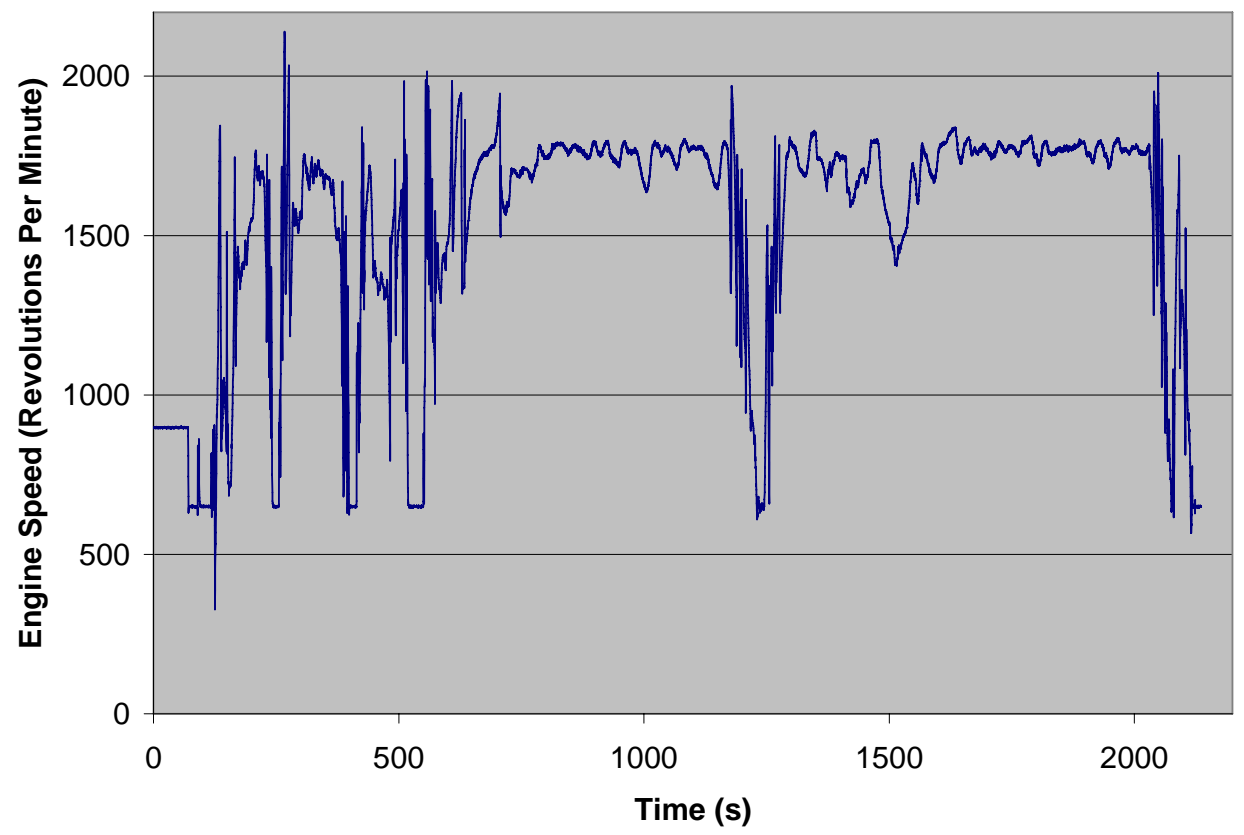

Figure 22 - Engine Speed versus Time for Saltwell Route at 34,640 lb.

Because this truck does not broadcast torque from its Engine Control Unit (ECU), percent load is instead utilized to determine an "inferred torque" value and a horsepower value that are derived from the percent load of the engine and a torque curve that is based upon idling data as well as factory engine specifications. The percent load values for the test route are shown in Figure 23. 


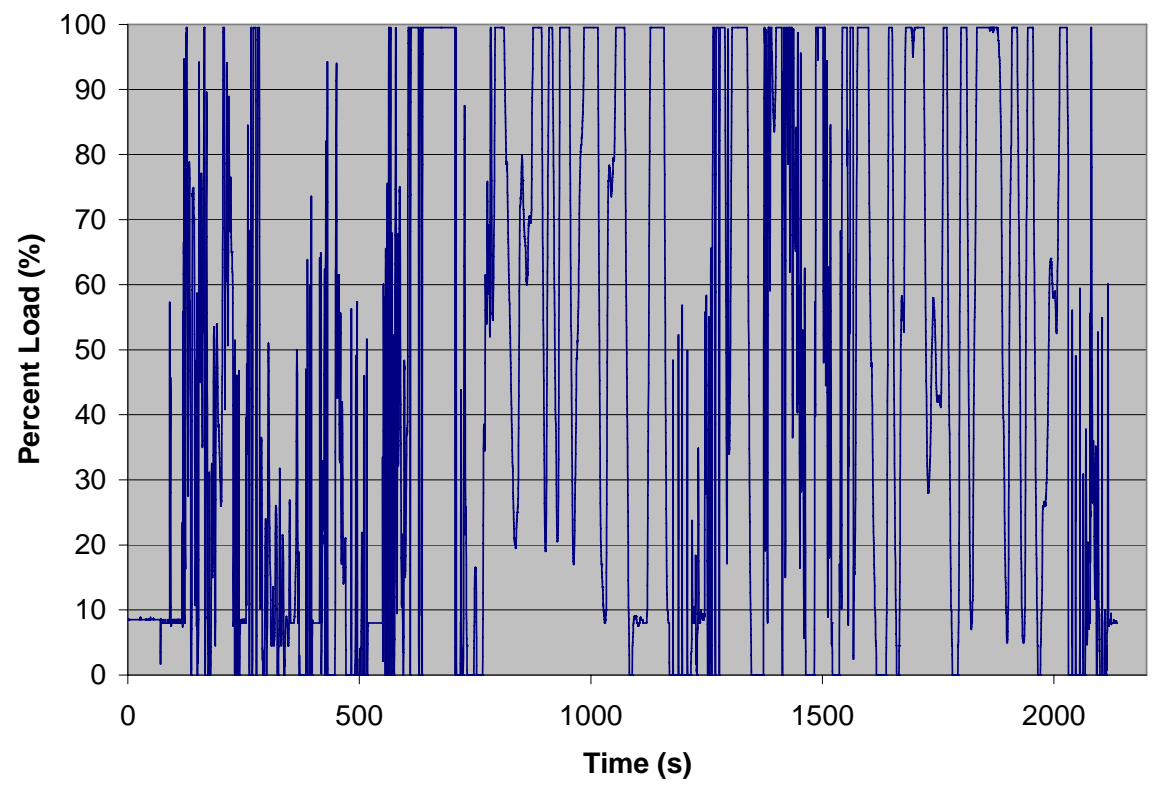

Figure 23 - Percent Load versus Time for Saltwell Route at $34,640 \mathrm{lb}$.

Once the values of percent load are correlated with their respective horsepower and torque values from the engine lug curve, those two values are also found. Figure 24 displays the horsepower values for the test.

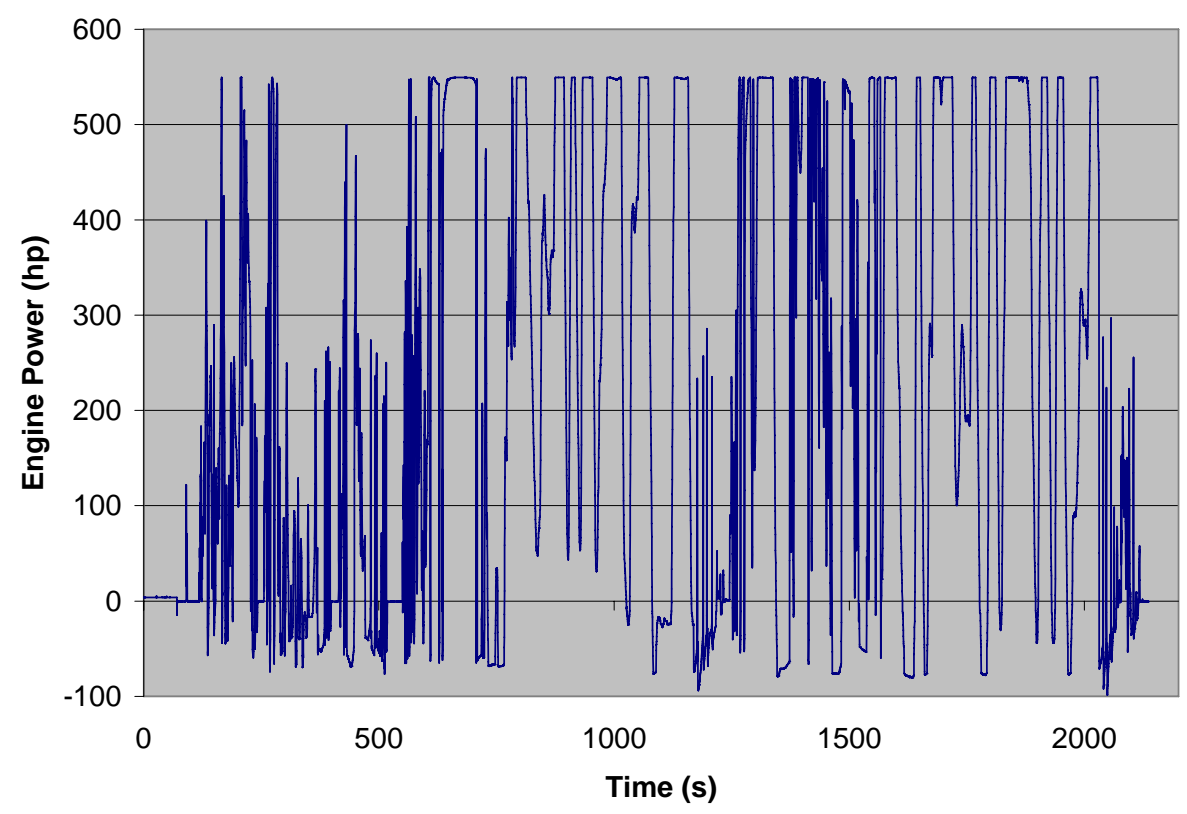

Figure 24 - Engine Power versus Time for Saltwell Route at 34,640 lb. 
Along with the engine power data in Figure 24, the torque values shown in Figure 25 are used to determine the engine work done for the test cycle as well as the instantaneous work being done inside each NTE window.

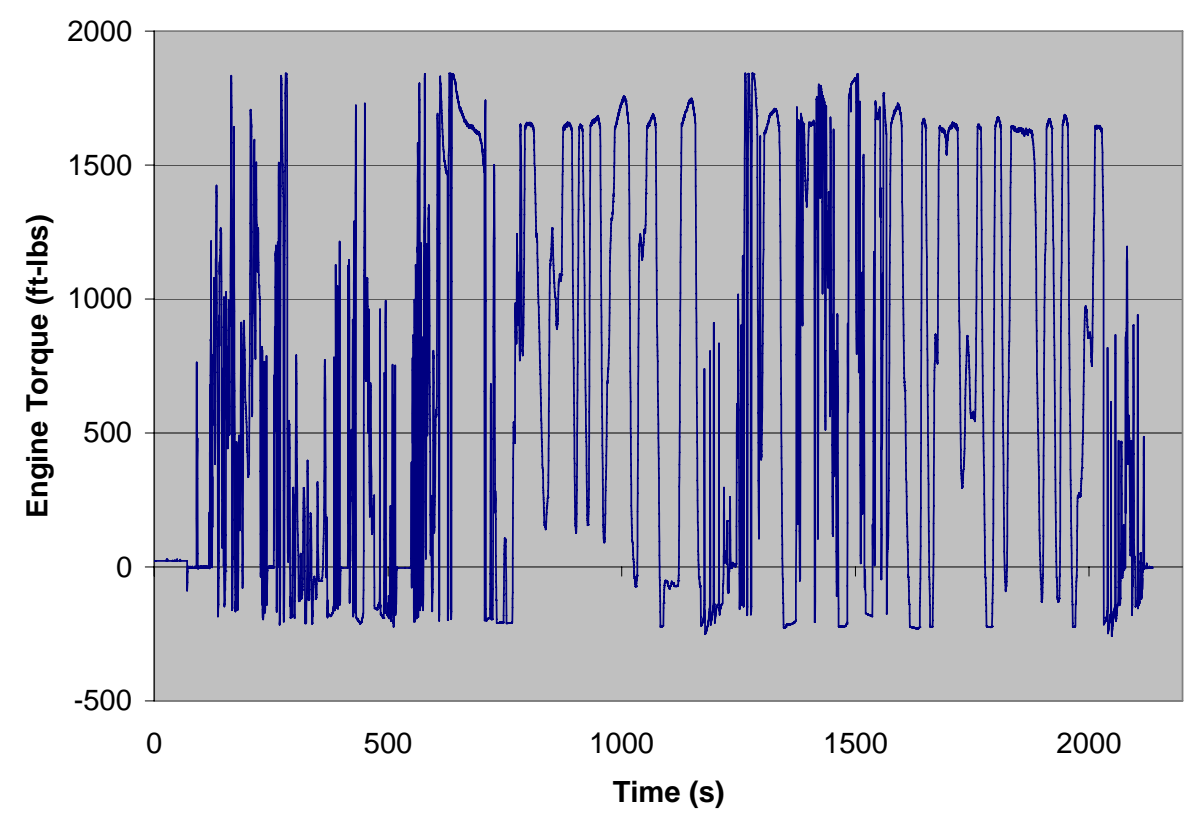

Figure 25 - Engine Torque versus Time for Saltwell Route at $34,640 \mathrm{lb}$.

To determine the vehicle's speed throughout the test, a Global Positioning System (GPS) receiver is used along with the vehicle's on-board speed sensor. These two data streams provide a quality control assurance as well as valuable data that are useful in determining the vehicle's total distance traveled. The ECU readings are plotted in Figure 26 for the entire test run. 


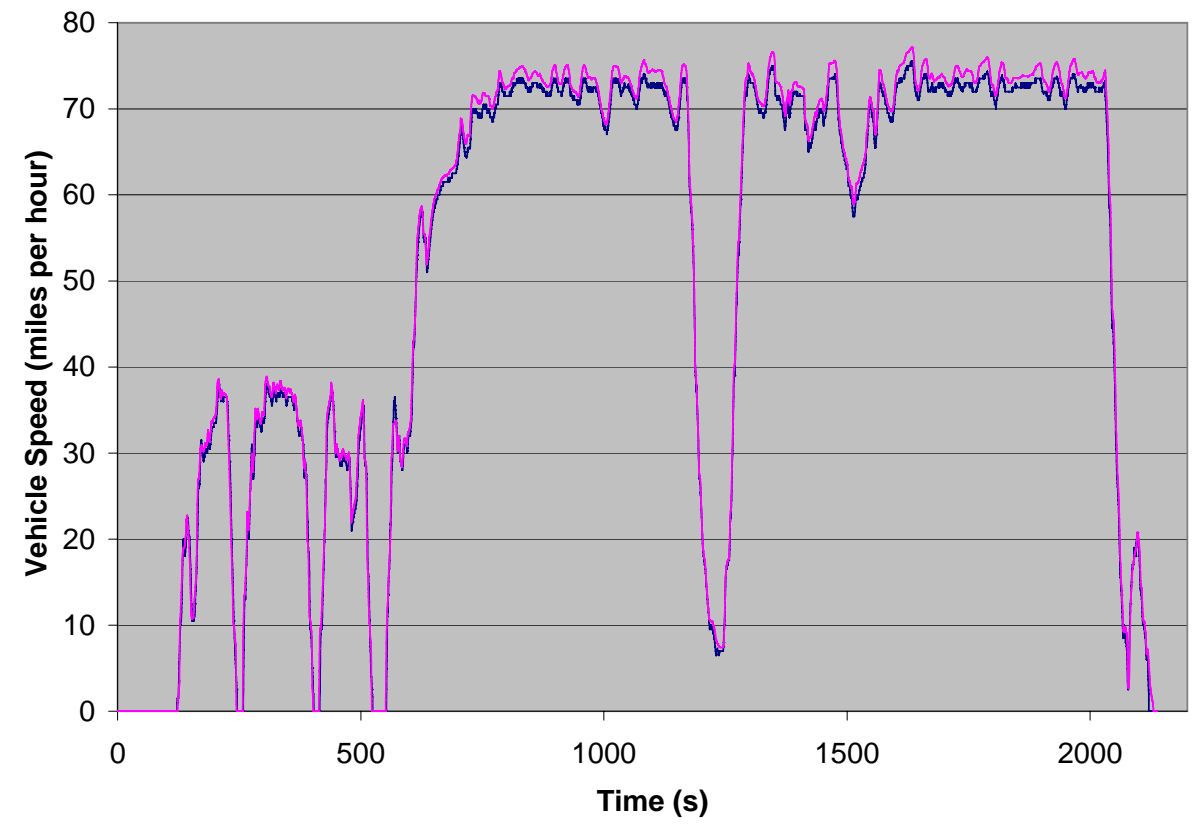

Figure 26 - ECU Vehicle Speed versus Time for Saltwell Route at 34,640 lb.

At this point, all the data in Figure 13 to Figure 26 can be used to determine the brake-specific and distance specific emissions values over the course of each test. The values can also be calculated for the NTE regions of the tests. 


\section{Test Results}

\subsection{Bruceton Tests}

First, the Bruceton route was examined at the four gross vehicle weights tested. This route, as previously described, consisted of interstate driving over mountainous terrain, including a very large hill climb to the top of Cooper's Rock on Interstate 68 East outside of Morgantown, WV. The amount of time spent in the NTE zone by the vehicle as well as the percentage of the total test time spent in the NTE can be found in Table 7 . Also in this table, the amount of time the vehicle spent at $100 \%$ load and $0 \%$ load can be found.

Table 7 - NTE Zone Data Bruceton Runs

\begin{tabular}{|c|c|c|c|c|c|}
\hline \multirow[b]{2}{*}{ Test Weight } & \multicolumn{5}{|c|}{ Uphill Test Route } \\
\hline & $\begin{array}{l}\text { Total } \\
\text { Time }\end{array}$ & $\begin{array}{l}\text { Time in } \\
\text { NTE } \\
\text { (seconds) }\end{array}$ & $\begin{array}{c}\text { Percentage } \\
\text { of Time in } \\
\text { NTE }\end{array}$ & $\begin{array}{c}\text { Percentage } \\
\text { of Time at } \\
100 \% \text { Load }\end{array}$ & $\begin{array}{c}\text { Percentage } \\
\text { of Time at } \\
0 \% \text { Load }\end{array}$ \\
\hline 20,740 & 2170.6 & 90.0 & $4.15 \%$ & $8.13 \%$ & $14.24 \%$ \\
\hline 34,640 & 2210.6 & 409.4 & $18.52 \%$ & $21.08 \%$ & $17.73 \%$ \\
\hline 61,520 & 2351.2 & 409.6 & $17.42 \%$ & $39.18 \%$ & $22.83 \%$ \\
\hline 79,700 & 2668.6 & 596.8 & $22.36 \%$ & $41.21 \%$ & $23.90 \%$ \\
\hline \multirow[b]{2}{*}{ Test Weight } & \multicolumn{5}{|c|}{ Downhill Test Route } \\
\hline & $\begin{array}{l}\text { Total } \\
\text { Time }\end{array}$ & $\begin{array}{c}\text { Time in } \\
\text { NTE } \\
\text { (seconds) }\end{array}$ & $\begin{array}{c}\text { Percentage } \\
\text { of Time in } \\
\text { NTE }\end{array}$ & $\begin{array}{c}\text { Percentage } \\
\text { of Time at } \\
100 \% \text { Load }\end{array}$ & $\begin{array}{c}\text { Percentage } \\
\text { of Time at } \\
0 \% \text { Load }\end{array}$ \\
\hline 20,740 & 2350.8 & 86.6 & $3.68 \%$ & $4.67 \%$ & $17.09 \%$ \\
\hline 34,640 & 2176.4 & 243.4 & $11.18 \%$ & $14.80 \%$ & $25.66 \%$ \\
\hline & 2381.6 & 312.4 & $13.12 \%$ & $30.81 \%$ & $29.85 \%$ \\
\hline 79,700 & 2486.2 & 228.6 & $9.19 \%$ & $30.97 \%$ & $30.07 \%$ \\
\hline
\end{tabular}

Within the NTE zone, the emissions were calculated for each NTE event. For the test weights, the average values for the brake-specific $\mathrm{NO}_{\mathrm{X}}$ can be found in Figure 27. The values for this emissions measure consisted of a total amount of $\mathrm{NO}_{\mathrm{X}}$ emitted divided by the work completed during the test. Therefore, the actual values do not vary a great deal from test to test. There is no distinct trend versus test weight in the uphill or downhill direction. 


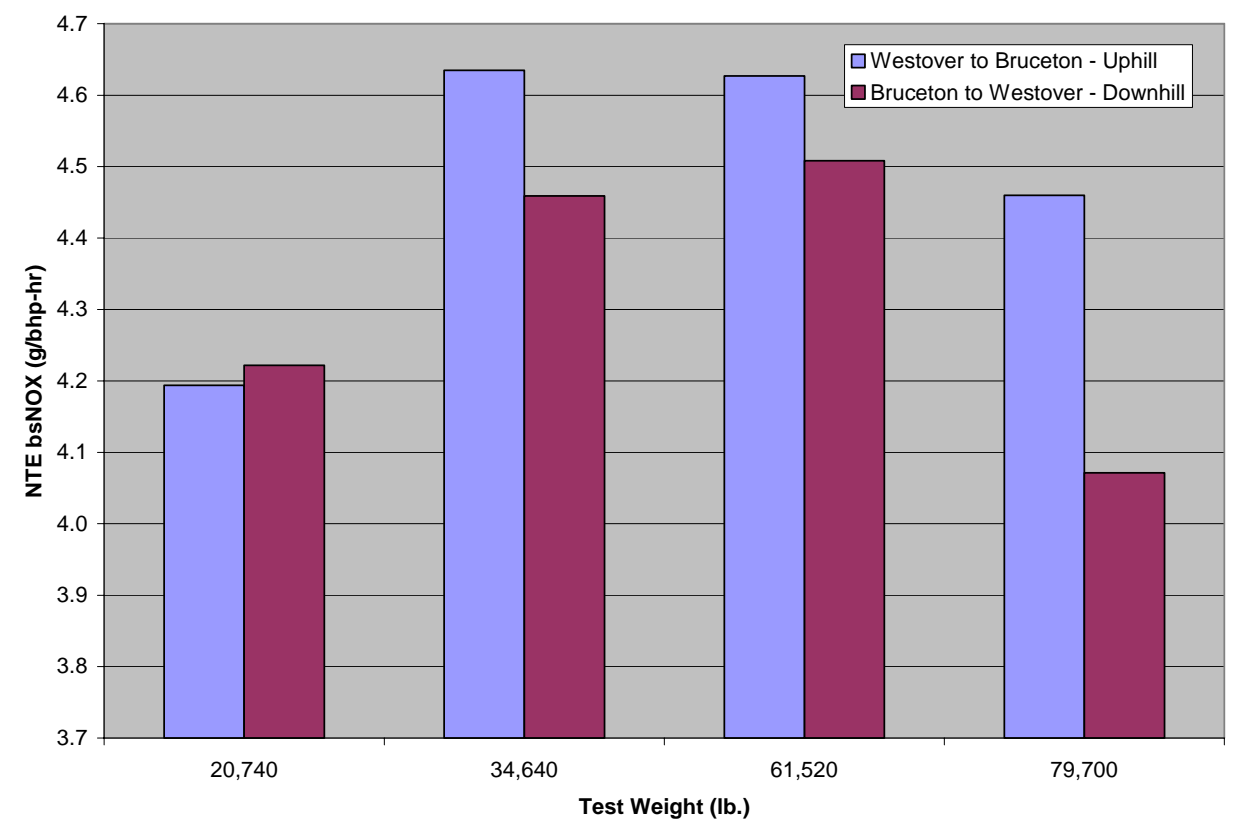

Figure 27 - Bruceton Average NTE bsNO versus Test Weight (Note expanded scale on the emissions axis)

For the same test weights, the carbon dioxide emissions were recorded on a brakespecific basis as well. These values are reported as the average emissions over the NTE events for the individual routes. Although the brake-specific $\mathrm{CO}_{2}$ increased almost linearly over the test weights for the downhill trips, the uphill portions did not exhibit the same trend. However, the uphill portions do show an overall increase in the emissions, but no linear trend. These results are shown in Figure 28. 


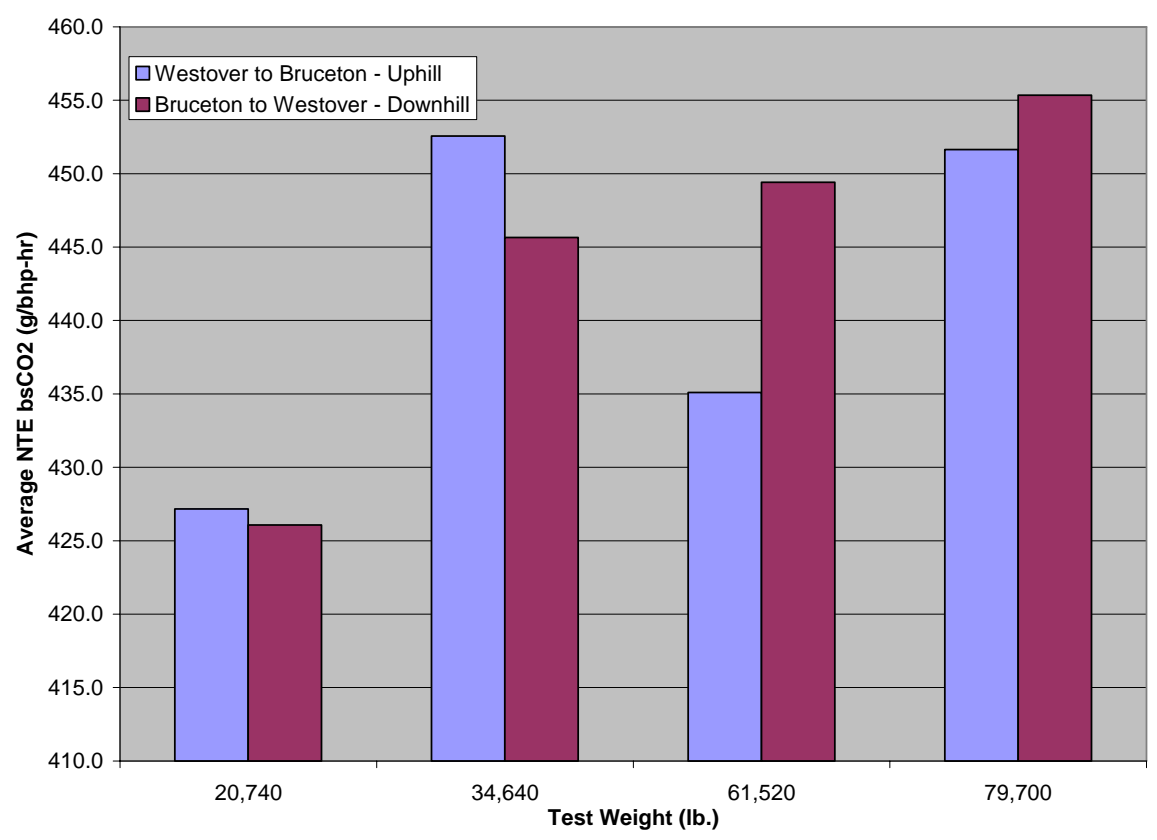

Figure 28 - Bruceton Average NTE $\mathrm{bsCO}_{2}$ versus Test Weight (Note expanded scale on the emissions axis)

In addition to brake-specific emissions over each route, more telling statistics are the distance-specific emissions. Figure 29 illustrates the increasing trend in distancespecific $\mathrm{NO}_{\mathrm{X}}$ emissions over the test weights. Although the route is the same distance in both uphill and downhill directions, the uphill portion produces more emissions due to the effects of road grade on the vehicle load. The difference between the emissions produced for the uphill and downhill trips increases as the weight increases. If vehicles are tested in only one direction (i.e. uphill or downhill), then the overall emissions from the route could be skewed. 


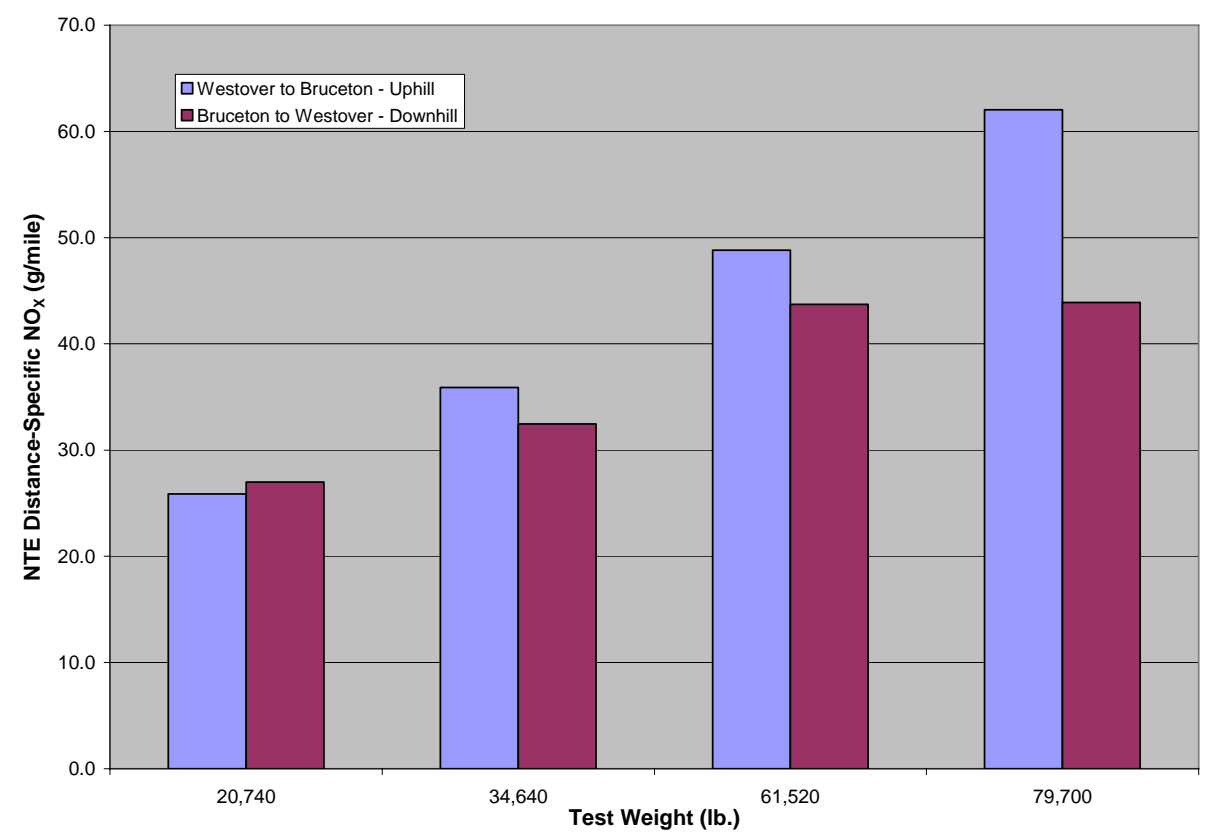

Figure 29 - Bruceton Distance-Specific NTE NO $\mathrm{N}_{x}$ versus Test Weight (Note expanded scale on the emissions axis)

The $\mathrm{NO}_{\mathrm{X}}$ results of this study were very similar to Gajendran and Clark's [21] study of vehicle operating weight on diesel emissions. Their work developed a formula that predicted that for every $\mathrm{X} \%$ increase in weight, there would be an $\mathrm{X} / 2 \%$ increase in $\mathrm{NO}_{\mathrm{X}}$ emissions. The data from this study was very comparable for the Uphill test route, while only somewhat comparable for the downhill route. Table 8 compares these data against one another. The predicted values are based upon the 20,740 lb. baseline value.

Table 8 - Bruceton Theoretical and Actual NTE $\mathrm{NO}_{\mathrm{x}}$ Data Comparison

\begin{tabular}{|c|c|c|c|c|}
\hline \multicolumn{5}{|c|}{ Uphill Route } \\
\hline Test Weight & $\begin{array}{c}\text { Weight Increase } \\
(\%)\end{array}$ & $\begin{array}{c}\text { Actual NTE NO } \\
\text { Emissions } \\
\text { (g/mile })\end{array}$ & $\begin{array}{l}\text { Predicted } \mathrm{NO}_{\mathrm{x}} \\
\quad(\mathrm{g} / \mathrm{mile})\end{array}$ & $\begin{array}{c}\text { Percent } \\
\text { Difference }\end{array}$ \\
\hline 20,740 & - & 25.870 & - & - \\
\hline 34,640 & $67.02 \%$ & 35.891 & 34.539 & $3.77 \%$ \\
\hline 61,520 & $77.60 \%$ & 48.816 & 49.817 & $2.05 \%$ \\
\hline 79,700 & $29.55 \%$ & 62.049 & 56.029 & $9.70 \%$ \\
\hline \multicolumn{5}{|c|}{ Downhill Route } \\
\hline Test Weight & $\begin{array}{c}\text { Weight Increase } \\
(\%)\end{array}$ & $\begin{array}{c}\text { Actual NTE } \mathrm{NO}_{\mathrm{x}} \\
\text { Emissions } \\
\text { (g/mile) }\end{array}$ & $\begin{array}{l}\text { Predicted } \mathrm{NO}_{\mathrm{x}} \\
\text { (g/mile) }\end{array}$ & $\begin{array}{c}\text { Percent } \\
\text { Difference }\end{array}$ \\
\hline 20,740 & - & 26.996 & - & - \\
\hline 34,640 & $67.02 \%$ & 32.463 & 36.042 & $11.03 \%$ \\
\hline 61,520 & $77.60 \%$ & 43.707 & 45.058 & $3.09 \%$ \\
\hline 79,700 & $29.55 \%$ & 43.895 & 50.165 & $14.28 \%$ \\
\hline
\end{tabular}

In the same manner as $\mathrm{NO}_{\mathrm{X}}$, the carbon dioxide emissions can be examined on a distance specific basis as well. These emissions exhibit a similar increasing trend as the 
$\mathrm{NO}_{\mathrm{X}}$ emissions. The distance-specific emissions for the Bruceton runs are found in Figure 30 .

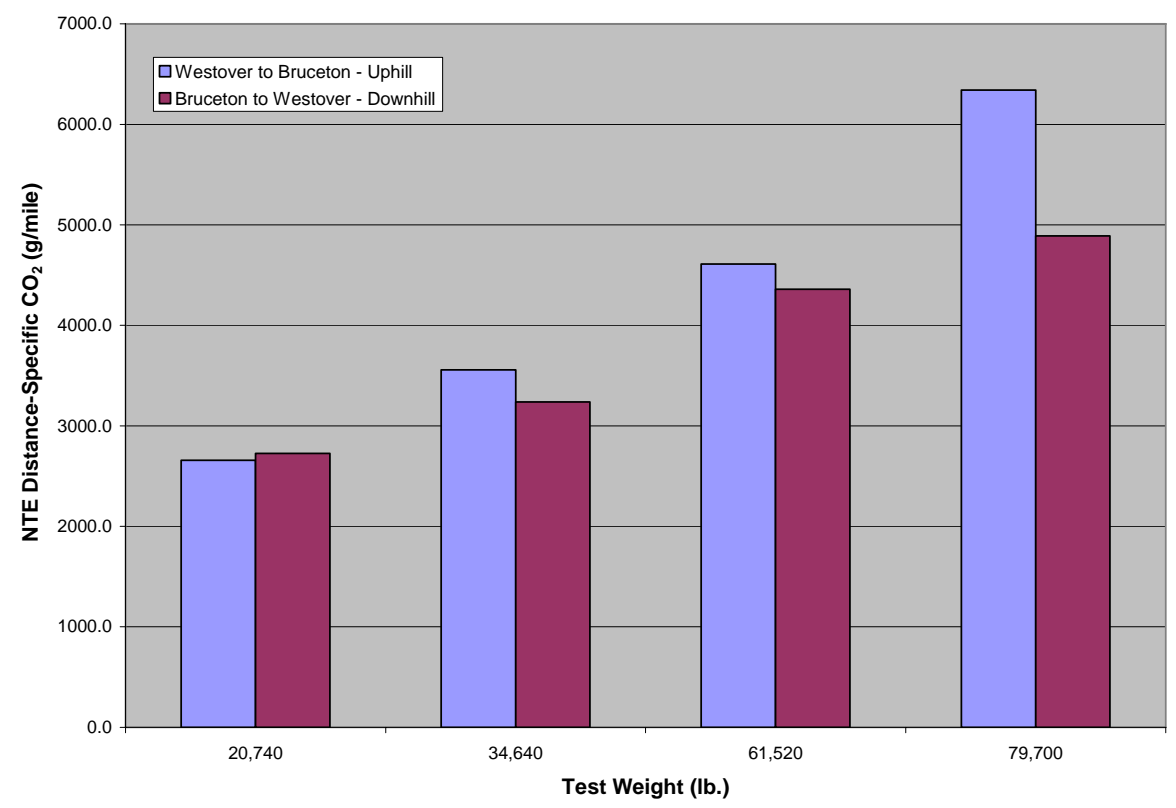

Figure 30 - Bruceton Distance-Specific NTE $\mathrm{CO}_{2}$ versus Test Weight (Note expanded scale on the emissions axis)

The fuel economy in the NTE region is inversely proportional to the vehicle test weight, and Figure 31 shows the NTE fuel economy for the Bruceton runs. These values of fuel economy are based upon the ECU fueling information. After the MEMS data acquisition process, this value was verified by comparing the total fuel used during the test and the actual amount of carbon dioxide measured by the Horiba BE-140. All the values for the percent difference for this measurement were found to be less than $10 \%$, which is the acceptable limit for the MEMS on-road testing. The fuel economy for the heaviest test weight shows a difference in the NTE regions of almost 0.5 miles/gallon. 


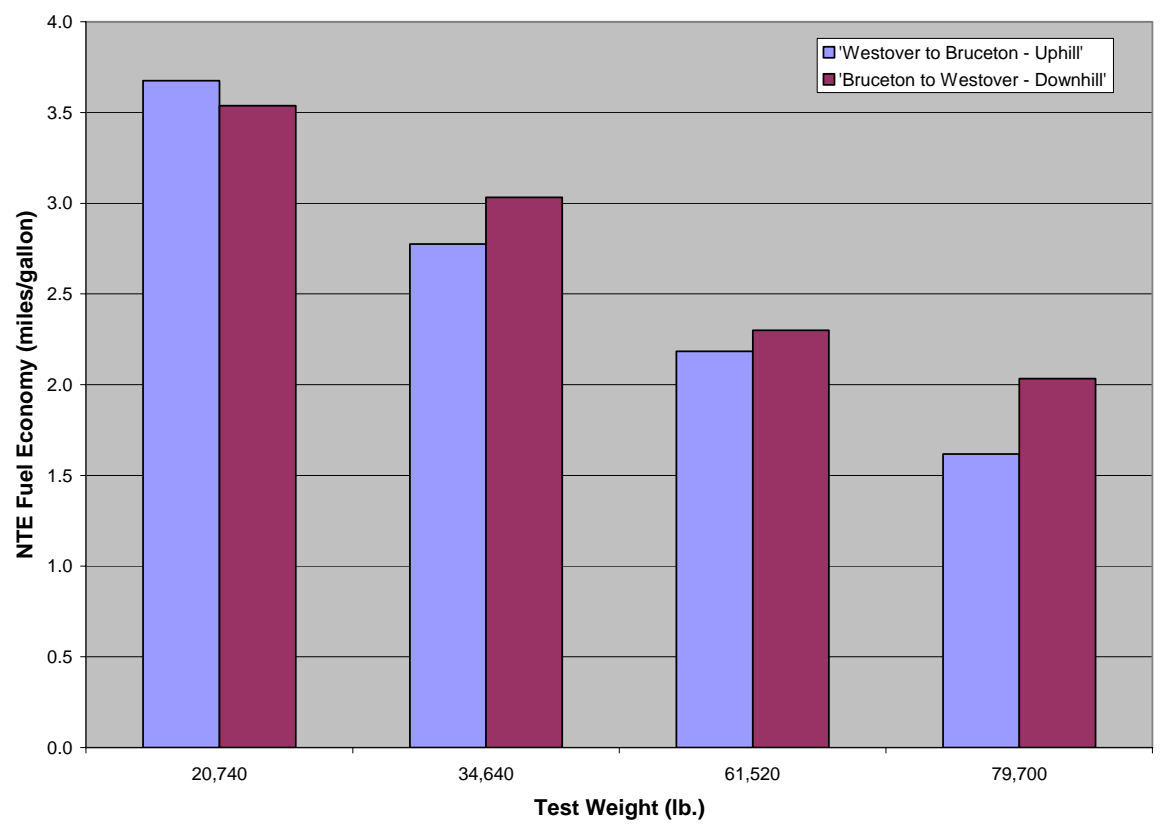

Figure 31 - Bruceton NTE Fuel Economy versus Test Weight

During the duration of the Bruceton test runs, the overall fuel economy exhibited a similar decrease as shown in Figure 31 for NTE vehicle operation. The overall fuel economy is shown in Figure 32 according to test weight. As the test weight increased by $15,000 \mathrm{lb}$., the fuel economy decreased at approximately $0.5 \mathrm{miles} / \mathrm{gallon}$. Because of the tougher terrain for the Uphill route, the fuel economy for this route was lower than the Downhill route. The rate of decrease over each route was nearly the same. 


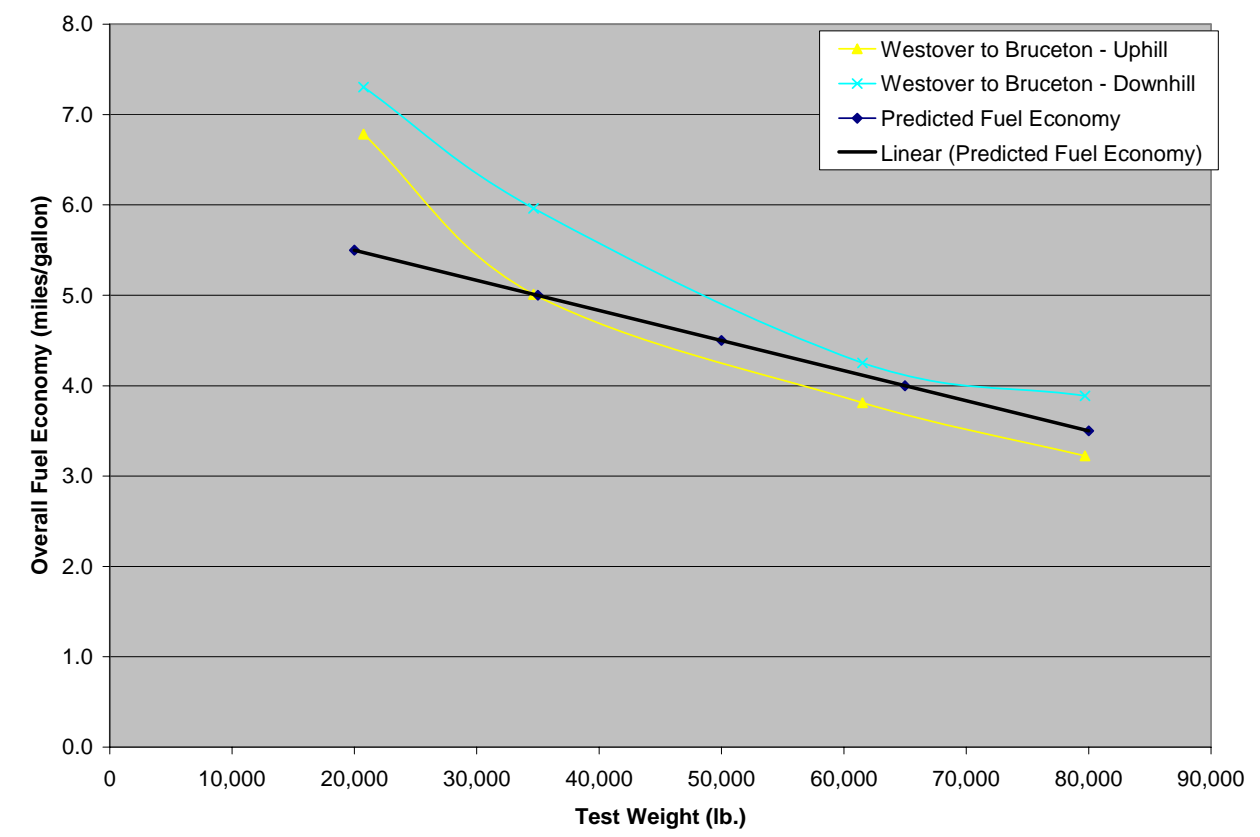

Figure 32 - Overall Bruceton Fuel Economy versus Test Weight

\subsection{Saltwell Tests}

For the Saltwell route, similar results were obtained as in the Bruceton runs.

Table 9 shows the amount of time the vehicle spent in the NTE zone as compared with the time duration for the entire run.

Table 9 - NTE Zone Data for Saltwell Runs

\begin{tabular}{|c|c|c|c|c|c|}
\hline \multirow{2}{*}{ Test Weight } & \multicolumn{5}{|c|}{ Uphill } \\
\cline { 2 - 6 } & $\begin{array}{c}\text { Total } \\
\text { Time }\end{array}$ & $\begin{array}{c}\text { Time in } \\
\text { NTE } \\
\text { (seconds) }\end{array}$ & $\begin{array}{c}\text { Percentage } \\
\text { of Time in } \\
\text { NTE }\end{array}$ & $\begin{array}{c}\text { Percentage } \\
\text { of Time at } \\
\mathbf{1 0 0 \%} \text { Load }\end{array}$ & $\begin{array}{c}\text { Percentage } \\
\text { of Time at } \\
\text { 0\% Load }\end{array}$ \\
\hline 20,740 & 2165.2 & 4.0 & $0.18 \%$ & $3.16 \%$ & $12.33 \%$ \\
\hline 34,640 & 2136 & 224.2 & $10.50 \%$ & $24.95 \%$ & $15.74 \%$ \\
\hline 61,520 & 2776.6 & 221.0 & $7.96 \%$ & $26.94 \%$ & $18.81 \%$ \\
\hline 79,700 & 2593 & 255.4 & $9.85 \%$ & $38.88 \%$ & $22.31 \%$ \\
\hline & \multicolumn{5}{|c|}{ Downhill } \\
\cline { 2 - 7 } Test Weight & Total & $\begin{array}{c}\text { Time in } \\
\text { NTE }\end{array}$ & $\begin{array}{c}\text { Percentage } \\
\text { of Time in } \\
\text { NTE }\end{array}$ & $\begin{array}{c}\text { Percentage } \\
\text { of Time at } \\
\mathbf{1 0 0 \% ~ L o a d ~}\end{array}$ & $\begin{array}{c}\text { Percentage } \\
\text { of Time at } \\
\mathbf{0} \% \text { Load }\end{array}$ \\
\hline 20,740 & 2208.8 & 9.2 & $0.42 \%$ & $2.35 \%$ & $14.34 \%$ \\
\hline 34,640 & 1952 & 157.4 & $8.06 \%$ & $22.00 \%$ & $22.56 \%$ \\
\hline 61,520 & 2258.8 & 36.0 & $1.59 \%$ & $25.55 \%$ & $25.32 \%$ \\
\hline 79,700 & 2226.8 & 89.4 & $4.01 \%$ & $38.12 \%$ & $26.69 \%$ \\
\hline
\end{tabular}

Average values for the $\mathrm{NO}_{\mathrm{X}}$ during the NTE events of the runs, the average $\mathrm{NO}_{\mathrm{X}}$ values on a brake-specific basis can be found. Figure 33 shows the average brakespecific values over the Saltwell tests. 


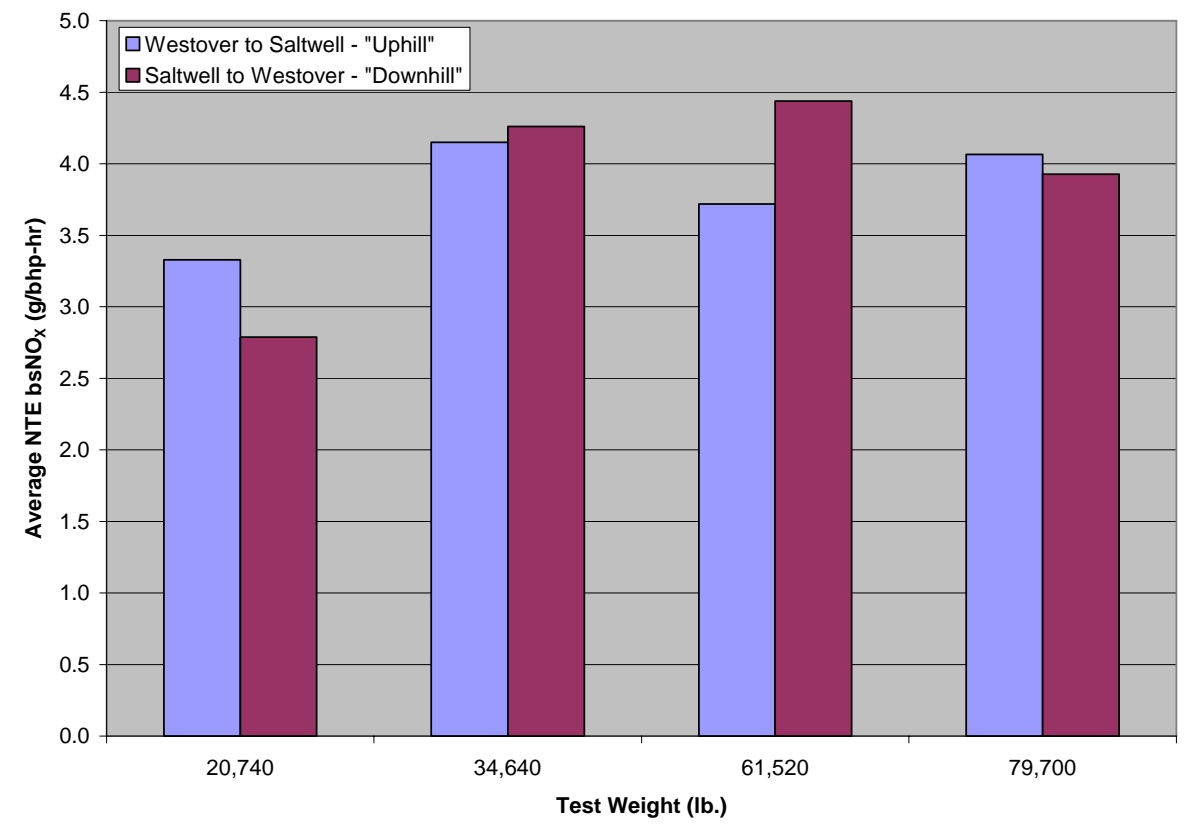

Figure 33 - Saltwell Average NTE bsNO ${ }_{x}$ versus Test Weight (Note expanded scale on the emissions axis)

Similarly, the average $\mathrm{CO}_{2}$ emissions can be compared for the NTE regions across the varying test weights. These data are shown in Figure 34.

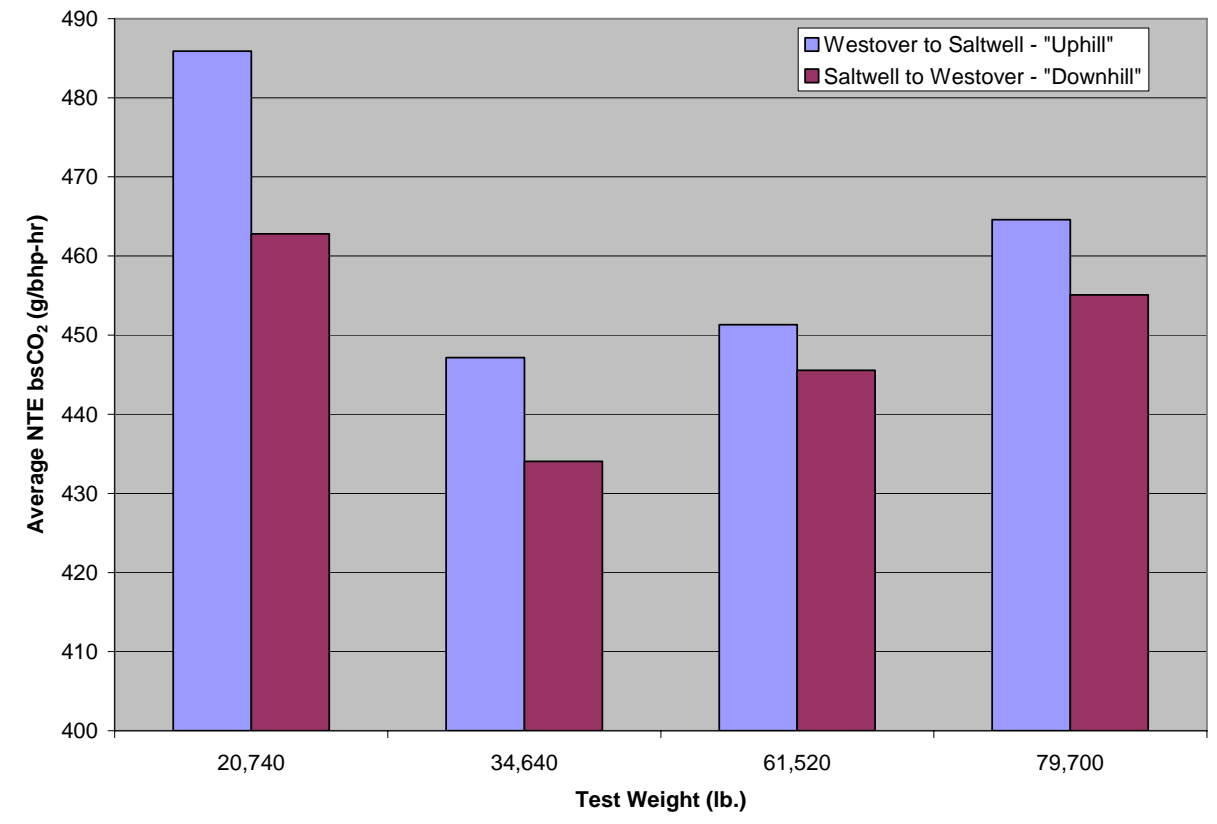

Figure 34 - Saltwell Average NTE $\mathrm{bsCO}_{2}$ versus Test Weight 
Again, for the Saltwell route, the distance-specific emissions values illustrated the effects of increased vehicle weight on the vehicle emissions. Figure 35 shows this increasing trend for the $\mathrm{NO}_{\mathrm{X}}$ emissions. The overall values for these emissions, however, were lower than the values recorded for the Bruceton runs as shown in Figure 29. The trend, though, was the same with an almost linear increase with vehicle weight. At 79,700 lb., the downhill emissions decrease even though the weight was at its peak. This was most likely due to the downhill nature of the route. The heavier truck could use less fuel due to its momentum when descending hills on the route.

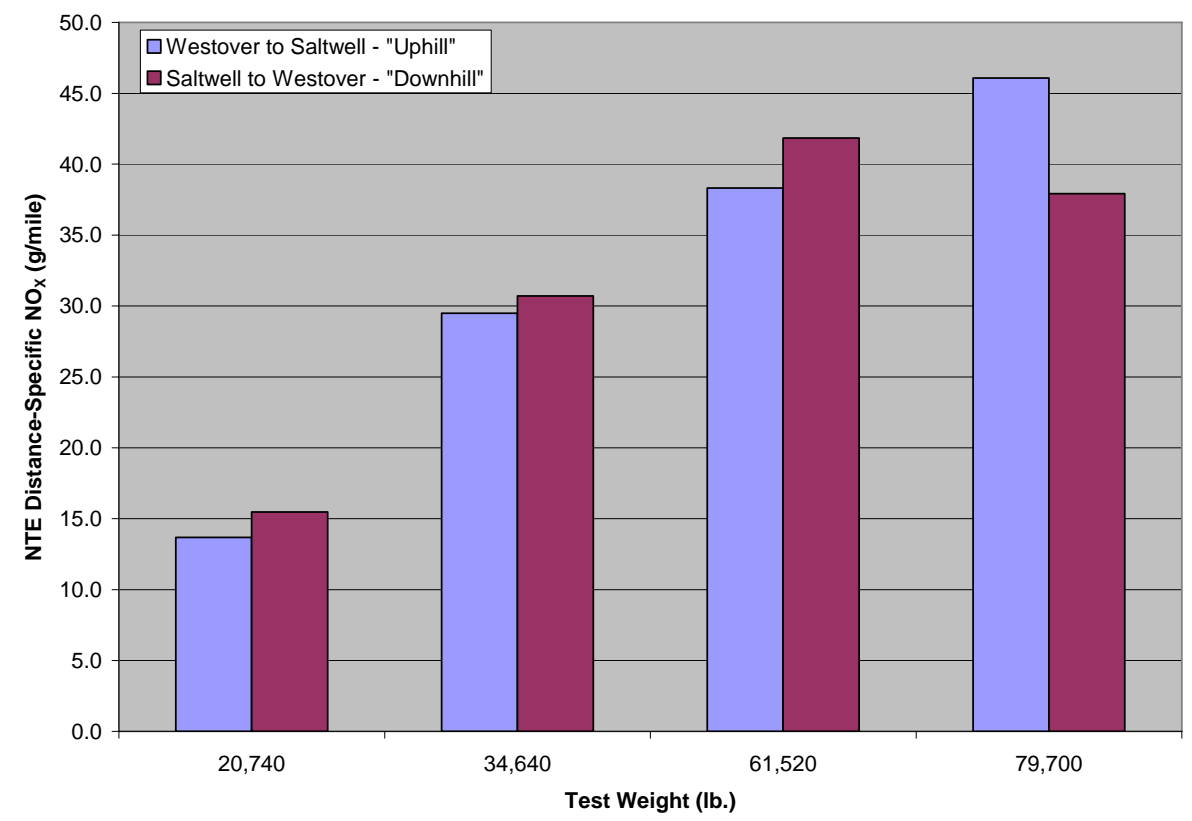

Figure 35 - Saltwell Distance-Specific NTE NO $x$ versus Test Weight

Also, the data on the uphill runs were comparable to the work by Gajendran and Clark [21]. These results are shown in Table 10. The actual data did show some differences from the predicted values, but these were abnormally large. These calculations were able to predict emissions changes for varying vehicle weight based upon data from the $20,740 \mathrm{lb}$. test. 


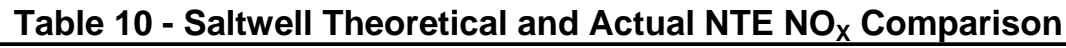

\begin{tabular}{|c|c|c|c|c|}
\hline \multicolumn{5}{|c|}{ Uphill } \\
\hline Test Weight & $\begin{array}{c}\text { Weight Increase } \\
\mathbf{( \% )}\end{array}$ & $\begin{array}{c}\text { Actual NTE NO } \\
\text { Emissions } \\
\text { (g/mile) }\end{array}$ & $\begin{array}{c}\text { Predicted NO } \\
\text { (g/mile) }\end{array}$ & $\begin{array}{c}\text { Percent } \\
\text { Difference }\end{array}$ \\
\hline 20,740 & - & 13.682 & - & - \\
\hline 34,640 & $67.02 \%$ & 29.494 & 18.267 & $38.07 \%$ \\
\hline 61,520 & $77.60 \%$ & 38.316 & 40.938 & $6.84 \%$ \\
\hline 79,700 & $29.55 \%$ & 46.085 & 43.978 & $4.57 \%$ \\
\hline \multicolumn{5}{|c|}{ Downhill } \\
\hline Test Weight & $\begin{array}{c}\text { Weight Increase } \\
\text { (\%) }\end{array}$ & $\begin{array}{c}\text { Actual NTE NO } \\
\text { Emissions } \\
\text { (g/mile) }\end{array}$ & $\begin{array}{c}\text { Predicted NO } \\
\text { (g/mile) }\end{array}$ & $\begin{array}{c}\text { Percent } \\
\text { Difference }\end{array}$ \\
\hline 20,740 & - & 15.472 & - & - \\
\hline 34,640 & $67.02 \%$ & 30.698 & 20.656 & $32.71 \%$ \\
\hline 61,520 & $77.60 \%$ & 41.845 & 42.609 & $1.82 \%$ \\
\hline 79,700 & $29.55 \%$ & 37.920 & 48.028 & $26.66 \%$ \\
\hline
\end{tabular}

The $\mathrm{CO}_{2}$ data, when divided into a distance-specific value, clearly illustrated the effect of increased vehicle weight on emissions. Figure 36 illustrates this phenomenon.

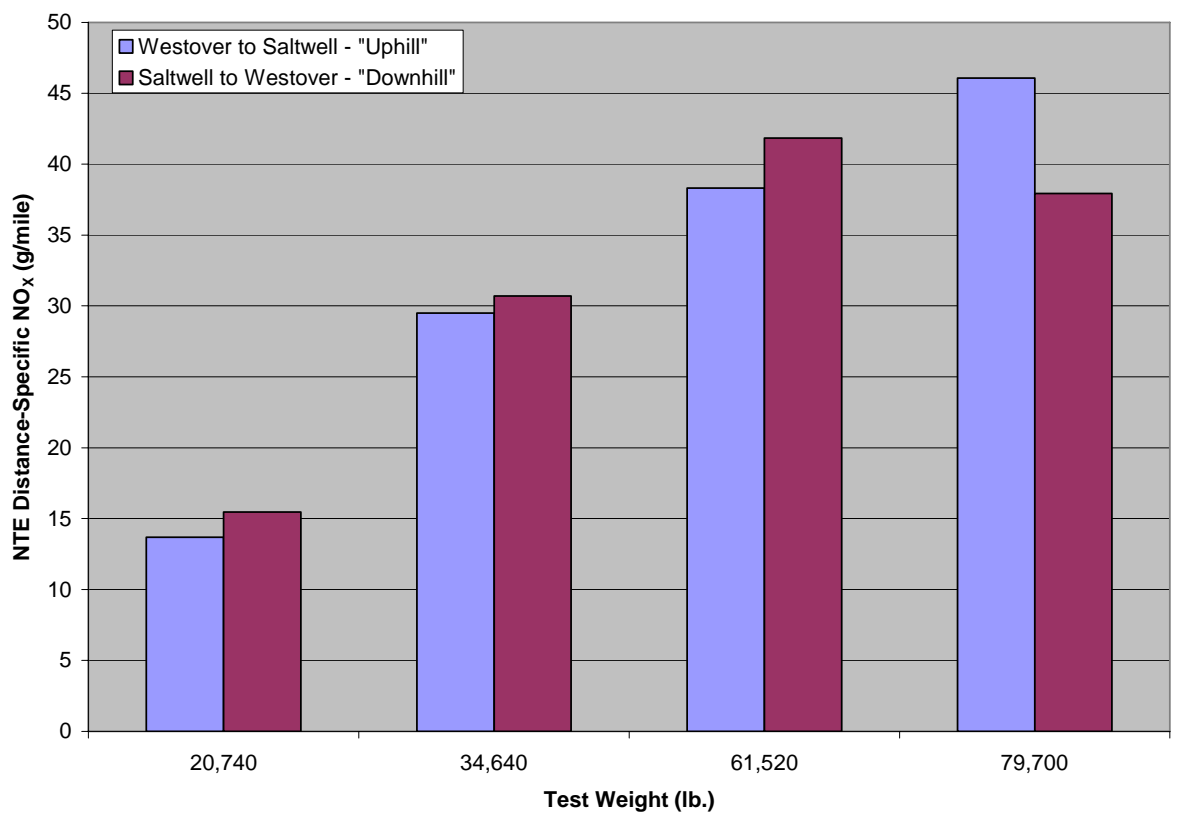

Figure 36 - Saltwell Distance-Specific NTE $\mathrm{CO}_{2}$ versus Test Weight

As shown previously for the Bruceton route, the fuel economy decreased as the vehicle weight increases. This was again true for the Saltwell test runs and is shown in Figure 37. 


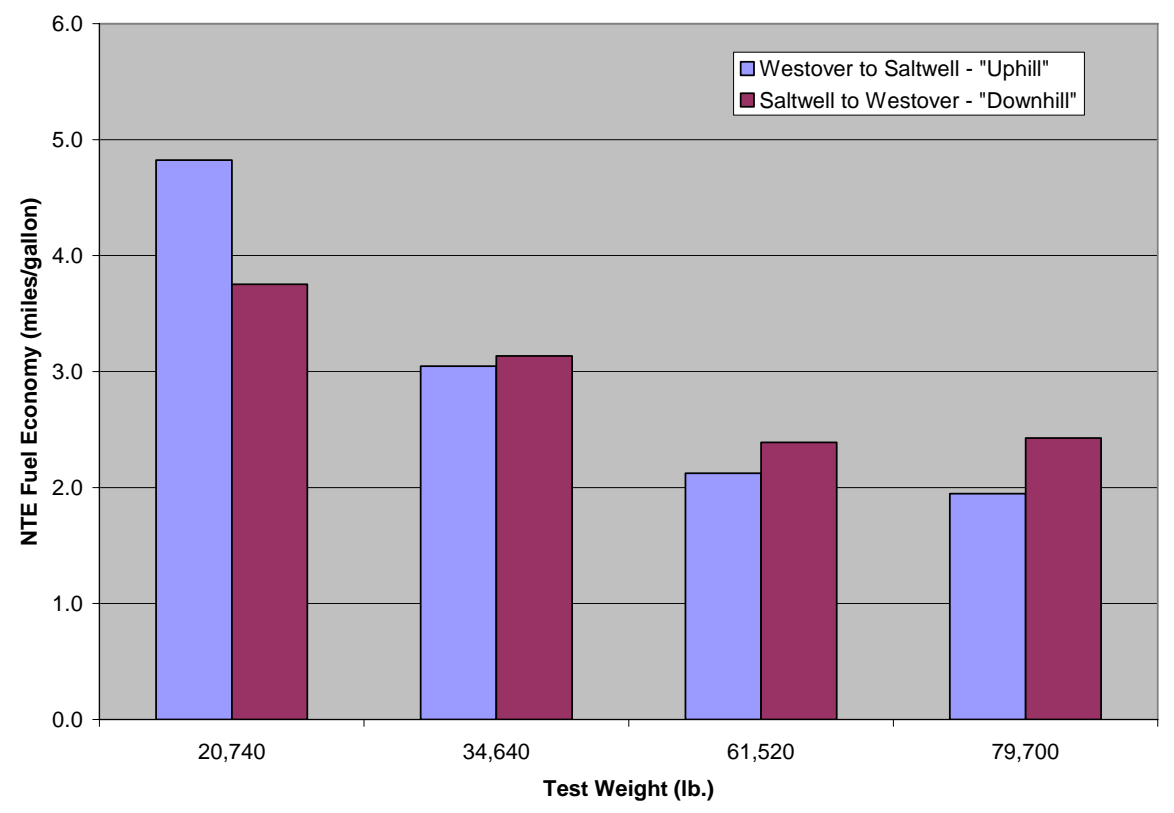

Figure 37 - Saltwell NTE Fuel Economy versus Test Weight

In the same manner, the overall fuel economy for all of the Saltwell tests in their entirety also declined as vehicle weight increases. As the vehicle weight increased from $20,740 \mathrm{lb}$. to 79,700 lb., the fuel economy was cut in half from $8 \mathrm{miles} / \mathrm{gallon}$ to 4 miles/gallon. Also, the tests in which the trailer was used (34,640 lb., 61,520 lb., and 79,700 lb.) showed a linear decrease. The relationship indicated a 0.5 miles/gallon decrease for every 15,000 lb. increase in test weight. This is shown in Figure 38. 


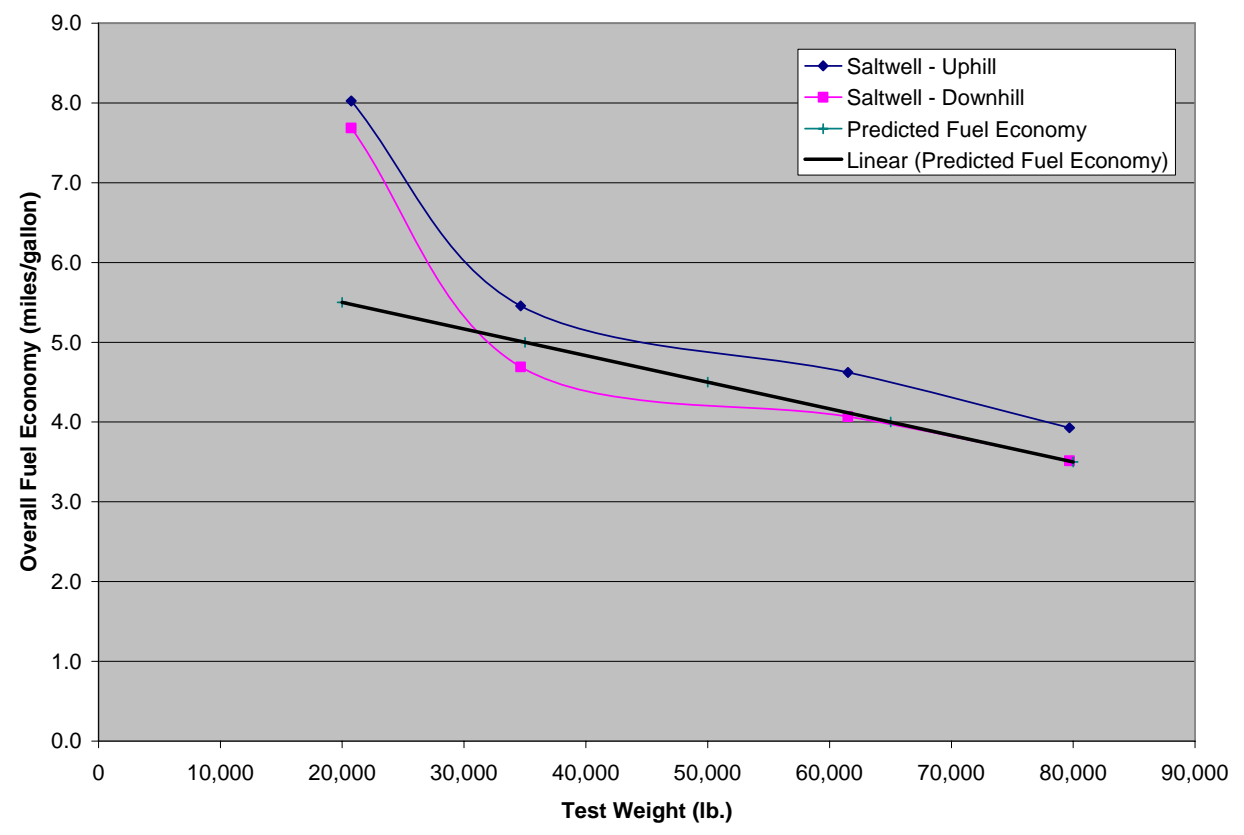

Figure 38 - Overall Saltwell Fuel Economy versus Test Weight

\subsection{PA 43 Route Tests}

For the PA 43 route, there were only two weights tested. The results from these tests follow in the same format as the Bruceton and Saltwell test data.

During the test, the vehicle spent less time, on average, in the NTE zone for this route. This can probably be attributed to the road grade being more flat for this route. However, the time in the NTE zone still increased from the lighter weight to the heavier gross vehicle weight. Table 11 shows the time spent in the NTE zone and its corresponding percentage of the total test time.

Table 11 - NTE Zone Data for PA 43 Runs

\begin{tabular}{|c|c|c|c|c|c|}
\hline \multirow{2}{*}{ Test Weight } & \multicolumn{5}{|c|}{ Outbound } \\
\cline { 2 - 6 } & $\begin{array}{c}\text { Total } \\
\text { Time }\end{array}$ & $\begin{array}{c}\text { Time in } \\
\text { NTE } \\
\text { (seconds) }\end{array}$ & $\begin{array}{c}\text { Percentage } \\
\text { of Time in } \\
\text { NTE }\end{array}$ & $\begin{array}{c}\text { Percentage } \\
\text { of Time at } \\
\mathbf{1 0 0 \%} \text { Load }\end{array}$ & $\begin{array}{c}\text { Percentage } \\
\text { of Time at } \\
\text { 0\% Load }\end{array}$ \\
\hline 34,640 & 1520.8 & 136.2 & $8.96 \%$ & $2.39 \%$ & $10.66 \%$ \\
\hline 79,700 & 1592.4 & 133.6 & $8.39 \%$ & $21.31 \%$ & $15.29 \%$ \\
\hline \multirow{5}{*}{ Test Weight } & \multicolumn{5}{|c|}{ Inbound } \\
\cline { 2 - 7 } & $\begin{array}{c}\text { Total } \\
\text { Time }\end{array}$ & $\begin{array}{c}\text { Time in } \\
\text { NTE } \\
\text { (seconds) }\end{array}$ & $\begin{array}{c}\text { Percentage } \\
\text { of Time in } \\
\text { NTE }\end{array}$ & $\begin{array}{c}\text { Percentage } \\
\text { of Time at } \\
\text { 100\% Load }\end{array}$ & $\begin{array}{c}\text { Percentage } \\
\text { of Time at } \\
\text { 0\% Load }\end{array}$ \\
\hline 34,640 & 1952 & 157.4 & $8.06 \%$ & $1.96 \%$ & $6.59 \%$ \\
\hline 79,700 & 2226.8 & 89.4 & $4.01 \%$ & $20.77 \%$ & $10.26 \%$ \\
\hline
\end{tabular}


While the engine is operating in the NTE region, the emissions were considered most critical since the bulk of the engine's power is created in this region. The $\mathrm{NO}_{\mathrm{X}}$ values for these NTE regions are shown for the PA 43 runs in Figure 39.

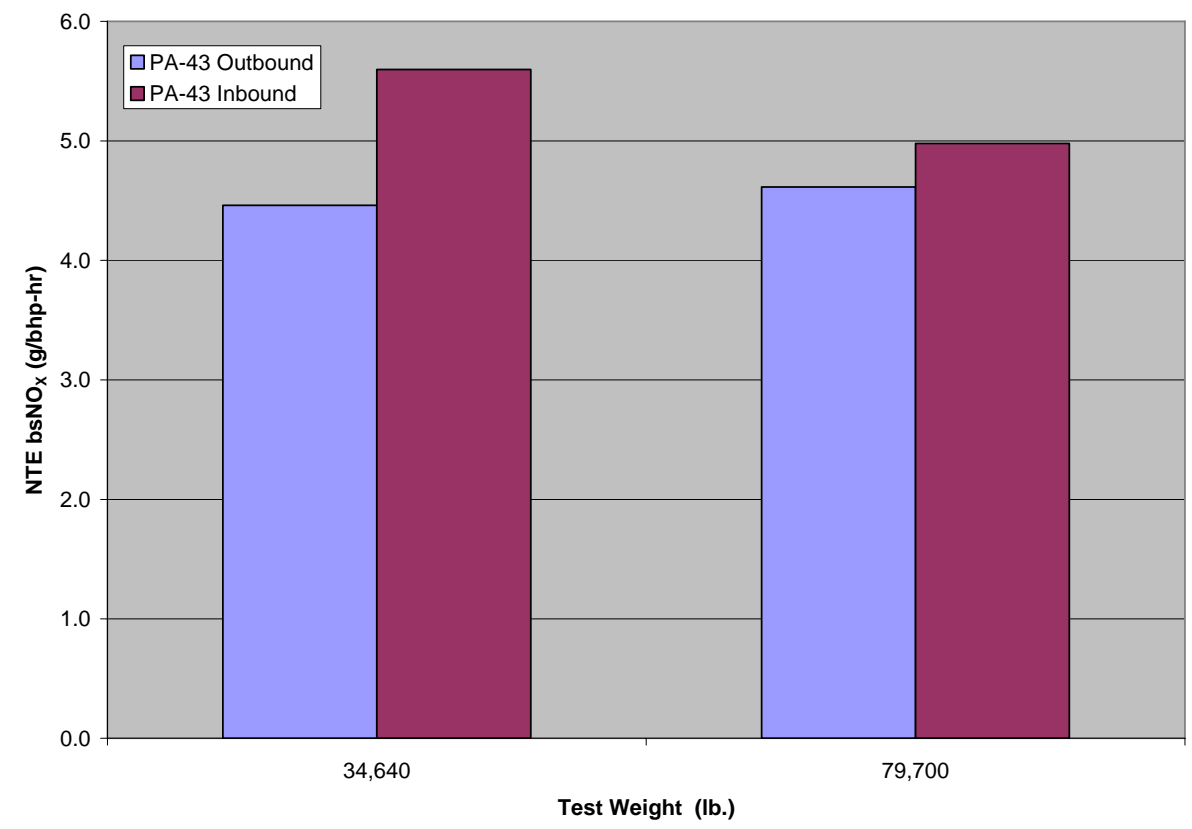

Figure 39 - PA 43 Average NTE bsNO ${ }_{x}$ versus Test Weight

Also, the brake-specific values for $\mathrm{CO}_{2}$ were of importance when examining the NTE emissions for heavy duty diesel vehicles. Figure 40 shows these values for the NTE region on the PA 43 test runs. 


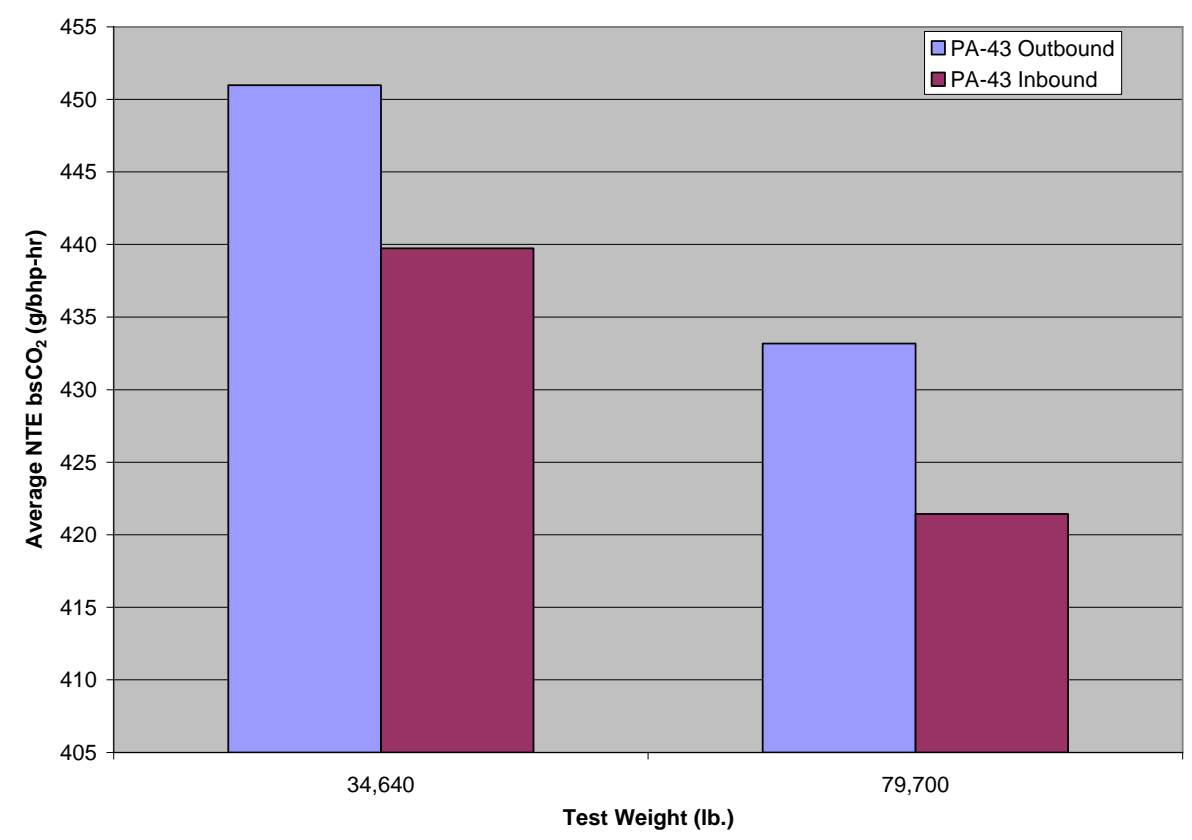

Figure 40 - PA 43 Average NTE bsCO $_{2}$ versus Test Weight

Again, for the PA 43 test runs, the distance-specific emissions values exhibit the greatest gross vehicle weight effects. Figure 41 shows the distance-specific values for $\mathrm{NO}_{\mathrm{X}}$ for the testing. These values were dramatically lower than those taken on the more mountainous terrain of the Bruceton and Saltwell runs. 


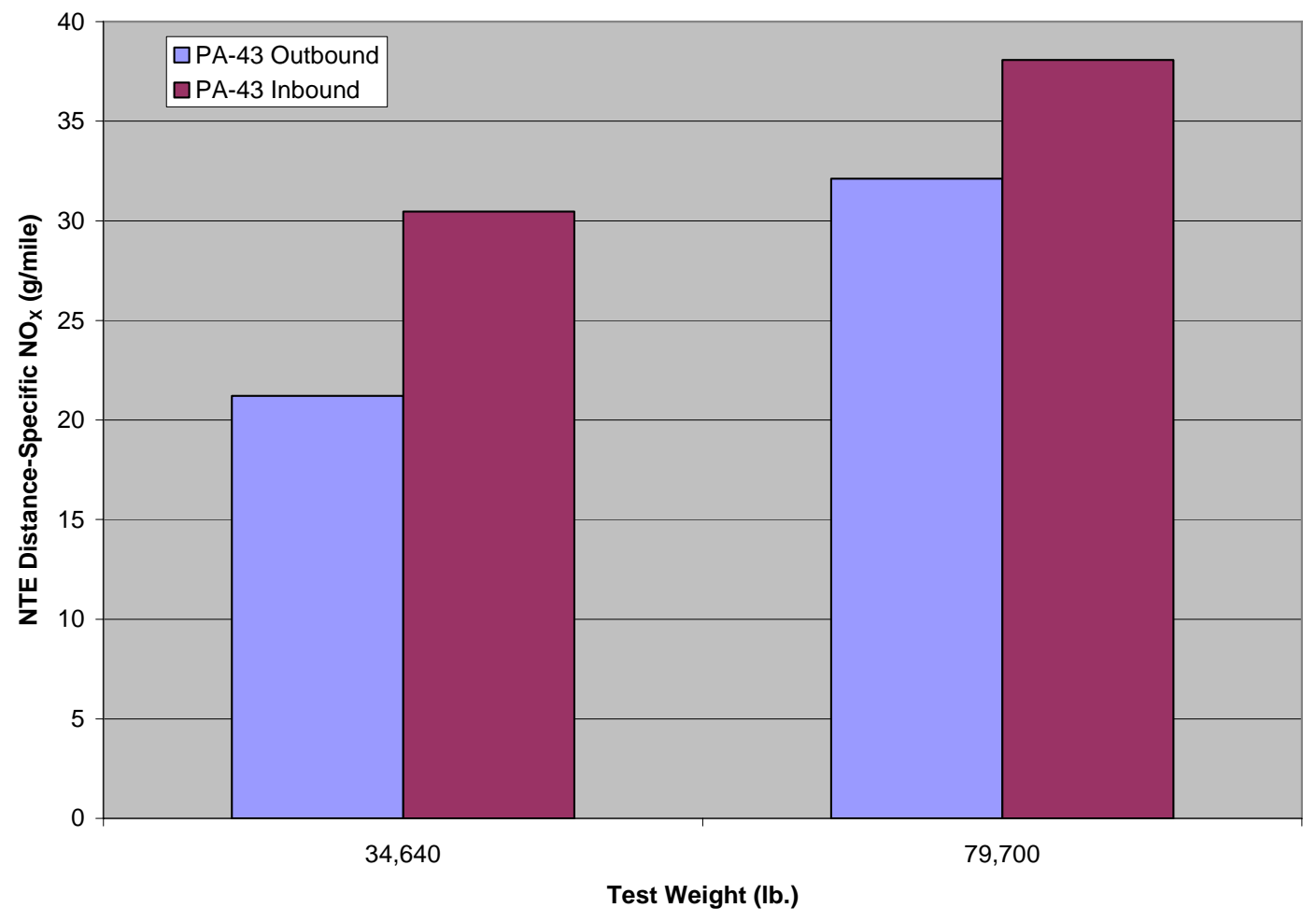

Figure 41 - PA 43 Distance-Specific NTE NO $x$ versus Test Weight

The difference in distance-specific emissions versus other test routes was due to the average power demand being lower for the PA 43 routes than the other test routes. Figure 42 illustrates the average work performed (bhp-hr) divided by the mileage of each route. This measure gives an indication of the terrain effects for each test route. 


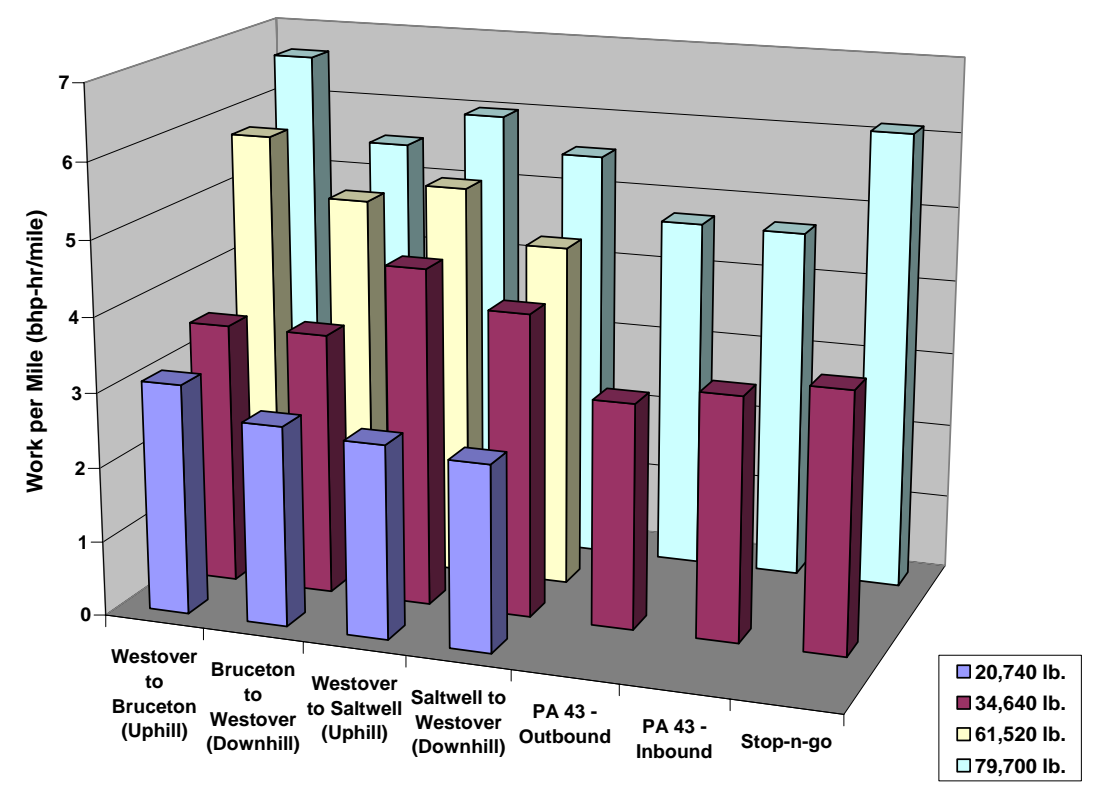

Figure 42- Average Power Demand per Mile (bhp-hr/mile) for All Routes

Also, the values for the $\mathrm{CO}_{2}$ on a distance-specific basis illustrated the effects of gross vehicle weight on emissions. Figure 43 shows these results for the PA 43 tests.

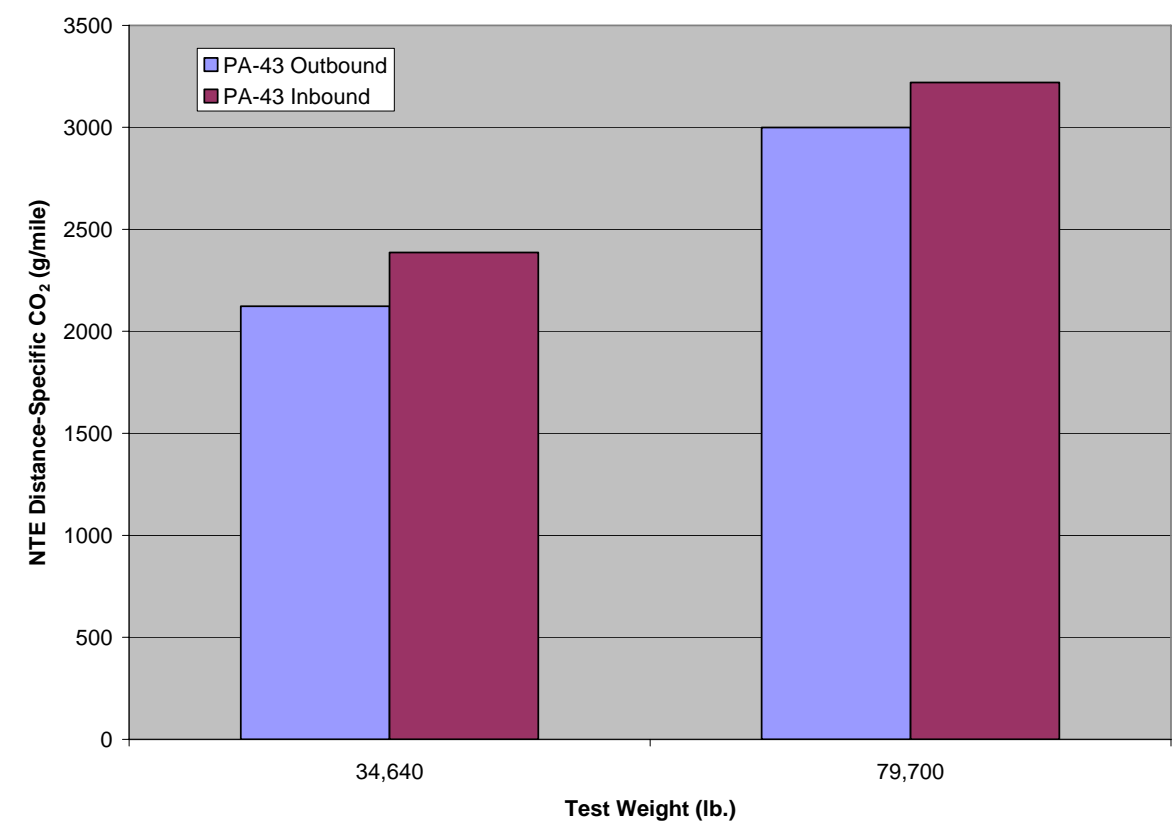

Figure 43 - PA 43 Distance-Specific NTE $\mathrm{CO}_{2}$ versus Test Weight 
Figure 44 shows the fuel economy in the NTE region against the vehicle test weight.

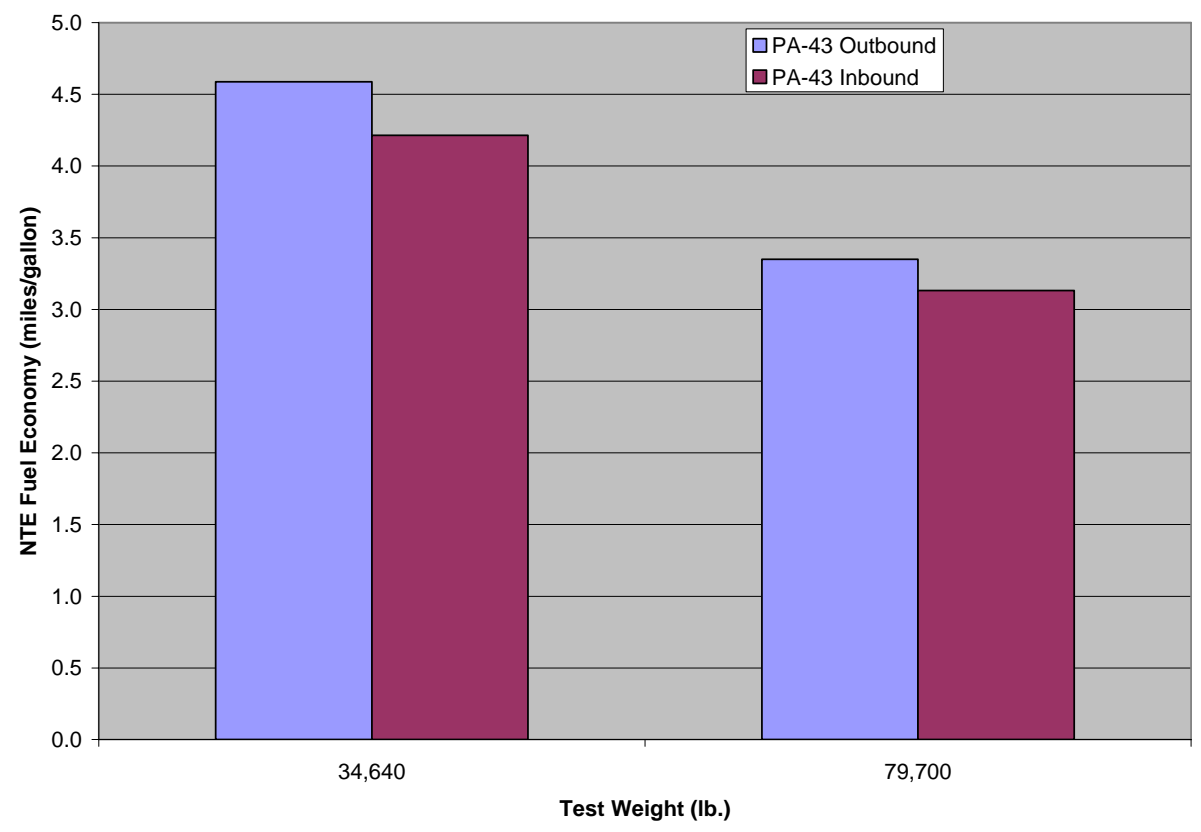

Figure 44 - PA 43 NTE Fuel Economy versus Test Weight

Inside the NTE region, the fuel economy was generally lower than it is during the overall test run. The fuel economies for the Outbound and Inbound routes were very similar. Data for the NTE region were used to create a formula for the NTE fuel economy which is shown in Equation 1. This formula is very similar to the relationship discovered for the Bruceton and Saltwell routes, with the intercept being the major difference.

NTE Fuel Economy $($ miles/gallon $)=-2.58 * 10^{-5} *($ vehicle weight $[1 \mathrm{~b}])+5.29$

\section{Equation 1}

Overall, the fuel economy was inversely proportional to the vehicle weight. The fuel economy decline was similar to the results found for the Bruceton and Saltwell routes. An approximate 0.5 miles/gallon decrease was noted for each 15,000 lb. change in test weight. However, the magnitude of the fuel economies for PA 43 were each approximately 1.2 miles/gallon higher than the corresponding test on a more mountainous Bruceton or Saltwell route. These values are shown in Figure 45. 


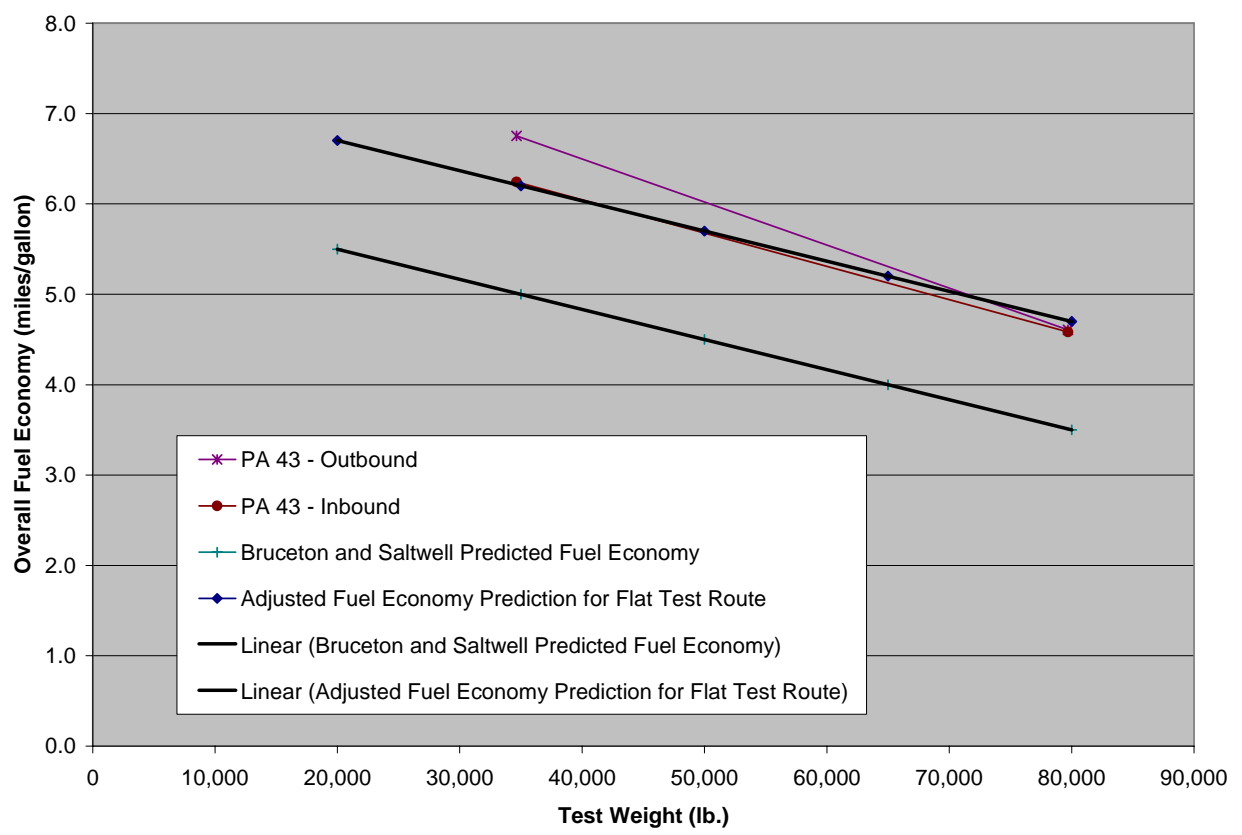

Figure 45 - Overall PA 43 Fuel Economy versus Test Weight

The data for the test route were similar to those within the NTE region. These data were used to create a formula for the fuel economy which is shown in

Equation 2.

Overall Fuel Economy $($ miles/gallon $)=-4.225 * 10^{-5} *($ vehicle weight $[\mathrm{lb}])+7.961$

\section{Equation 2}

\subsection{Stop-n-go Test Runs}

Finally, the Stop-n-go route was utilized to simulate driving through city traffic. This route included many traffic lights and other traffic items that would be encountered in any city driving scenario. Table 12 shows the amount and percentages of time spent in the NTE region for the Stop-n-go Route. Also shown are the percentages of time spent at $100 \%$ load and $0 \%$ load

Table 12- NTE Zone Data for Stop-n-go Runs

\begin{tabular}{|c|c|c|c|c|c|}
\hline \multirow{3}{*}{ Test Weight } & \multicolumn{5}{|c|}{ Stop - $\mathrm{n}$ - go } \\
\cline { 2 - 6 } & $\begin{array}{c}\text { Total } \\
\text { Time }\end{array}$ & $\begin{array}{c}\text { Time in } \\
\text { NTE } \\
\text { (seconds) }\end{array}$ & $\begin{array}{c}\text { Percentage } \\
\text { of Time in } \\
\text { NTE }\end{array}$ & $\begin{array}{c}\text { Percentage } \\
\text { of Time at } \\
\mathbf{1 0 0 \%} \text { Load }\end{array}$ & $\begin{array}{c}\text { Percentage } \\
\text { of Time at } \\
\text { o\% Load }\end{array}$ \\
\hline 34,640 & 1895.8 & 35.0 & $1.85 \%$ & $6.37 \%$ & $21.75 \%$ \\
\hline 79,700 & 2002.2 & 48.2 & $2.41 \%$ & $18.44 \%$ & $29.25 \%$ \\
\hline
\end{tabular}


For the brake-specific emissions on the Stop-n-go route, comparing the values to the vehicle weight resulted in a direct relationship. The $\mathrm{NO}_{\mathrm{X}}$ values, on average, increased from $3.8 \mathrm{~g} / \mathrm{bhp}$-hr to about $4.5 \mathrm{~g} / \mathrm{bhp}-\mathrm{hr}$ when the test weight increased from $34,640 \mathrm{lb}$. to $79,700 \mathrm{lb}$.

The $\mathrm{CO}_{2}$ values for the NTE region also increased when the test weight was changed. The values for this went from $443 \mathrm{~g} / \mathrm{bhp}-\mathrm{hr}$ at the first weight to $448 \mathrm{~g} / \mathrm{bhp}-\mathrm{hr}$ at the heavier weight.

The distance-specific $\mathrm{NO}_{\mathrm{X}}$ value of $62.4 \mathrm{~g} /$ mile was almost $20 \mathrm{~g} /$ mile greater than the test conducted at 79,700 lb. on PA 43. However, the value for the lighter weight, $26.4 \mathrm{~g} / \mathrm{mile}$, was nearly equivalent to the value shown on a standard testing route. This is probably due to the varying idling time that occurs during normal city driving.

Because distance-specific measurements account for changes in route length, these values should be comparable for the Stop-n-go route and the highway driving routes. Although the emissions per mile increase with test weight, the magnitudes of these values were very comparable to previously discussed data. The Stop-n-go testing resulted in values of $3058.18 \mathrm{~g} / \mathrm{mile}$ for the lower test weight and $6326.7 \mathrm{~g} / \mathrm{mile}$ at 79,700 lb.

Due to the traffic lights and other traffic holdups, the Stop-n-go route results in slightly lower fuel economy than some of the Bruceton and Saltwell runs. At 34,640 lb. the fuel economy in the NTE region was measured to be 3.2 miles per gallon. This value was lower than the fuel economy on the PA 43 route by about 1 mile per gallon. A similar trend was illustrated during the $79,700 \mathrm{lb}$. test where the Stop-n-go route resulted in a value of 1.7 miles per gallon.

Overall, the fuel economy of the vehicle declined as the weight increased even in city driving. At the lower test weight, the data showed fuel economy of 5.5 miles per gallon. For the higher weight, a fuel economy of 3.3 miles per gallon was shown for the Stop-n-go test route.

\subsection{Entrance and Exit of the NTE Region}

Because the NTE region is defined by engine speed and engine torque, a vehicle may enter and exit the region by the way of a gear change or by other changes in the 
operation of the vehicle. These changes could be an engine speed change or engine torque change. In a manual transmission vehicle, shifting can cause one or both of these parameters to move temporarily outside the NTE region. With the coming regulations of in-use emissions, a vehicle's emissions will be closely monitored while in the NTE zone as well as the amount of time spent in the zone itself. This entrance and exit issue was of importance because frequent shifting may cause the vehicle to have few NTE events.

For each of the test routes, two-axis plots were created with the result of Equation 3 along the left $x$-axis, and a " 1 " or " 0 " indicating whether the vehicle was operating inside or outside of the NTE region.

$$
\frac{\text { vehicle speed }(\mathrm{mph})}{\text { engine speed }(\mathrm{rpm})}=\text { constant when in gear, unstable when shifting }
$$

\section{Equation 3}

The entrance and exit to the NTE region can be linked at this point to whether it is the result of a gear change or not. If so, the entrance or exit point will lie directly on top of an unstable region near a gear change in the ratio from Equation 3. If not, the entrance or exit will simply fall during a constant period in the ratio, indicating the vehicle has been operating in the same gear. An NTE event was defined during this research as a continuous period of 30 seconds during which the vehicle operated within the NTE region. In terms of entering and exiting the region, Figure 46 illustrates this point for an example test route. 


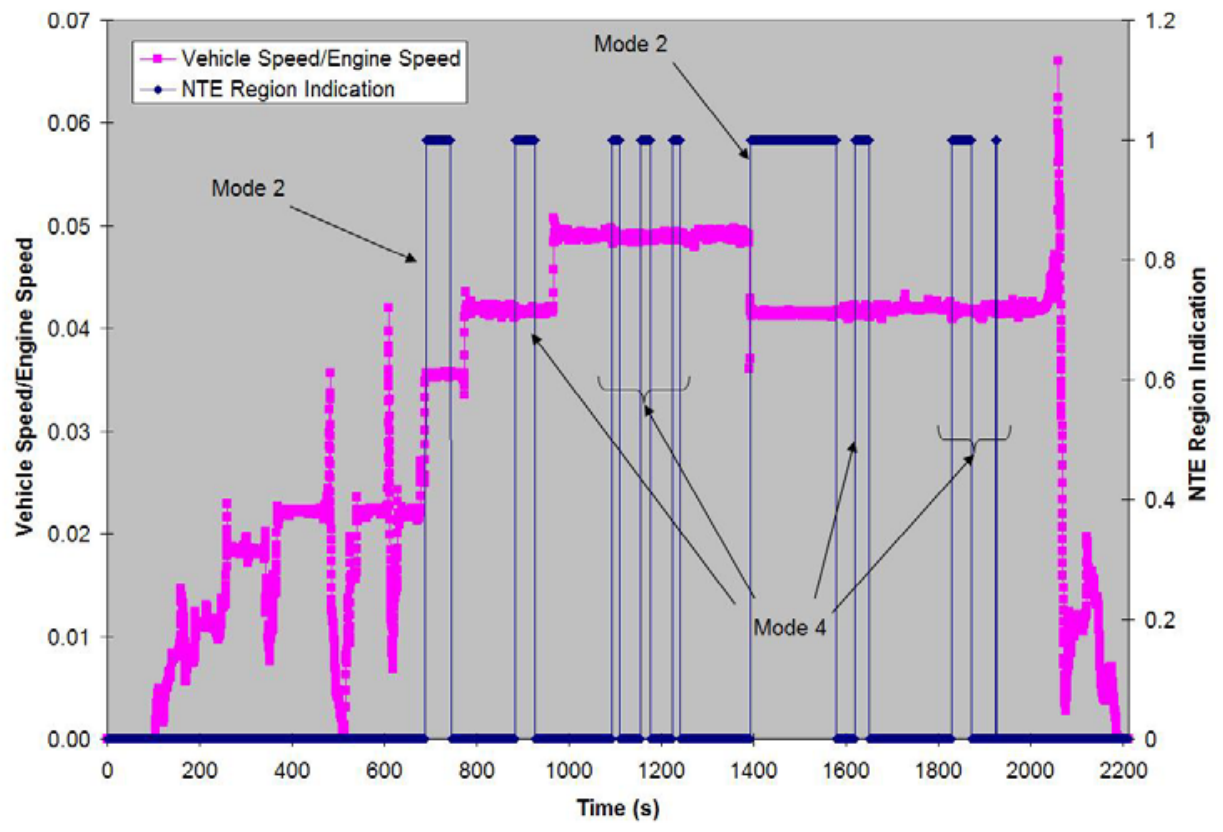

Figure 46 - NTE Entrance and Exit for $34,640 \mathrm{lb}$. Westover to Bruceton Test Run These options create four "modes" for entering and exiting the NTE region which are listed in Table 13.

Table 13 - Modes for Entering and Exiting NTE Region

\begin{tabular}{|c|c|c|c|}
\hline Mode 1 & Mode 2 & Mode 3 & Mode 4 \\
\hline $\begin{array}{c}\text { Enter NTE due to gear } \\
\text { change, leave NTE due } \\
\text { to gear change }\end{array}$ & $\begin{array}{c}\text { Enter NTE due to gear } \\
\text { change, leave in a } \\
\text { constant gear }\end{array}$ & $\begin{array}{c}\text { Enter NTE while in a } \\
\text { constant gear, leave due } \\
\text { to gear change }\end{array}$ & $\begin{array}{c}\text { Enter NTE while in a } \\
\text { constant gear, leave in a } \\
\text { constant gear }\end{array}$ \\
\hline
\end{tabular}

In some routes, the vehicle does not spend much time in the NTE region. Figure 47 shows the NTE region information plotted along with the gear shift pattern. 


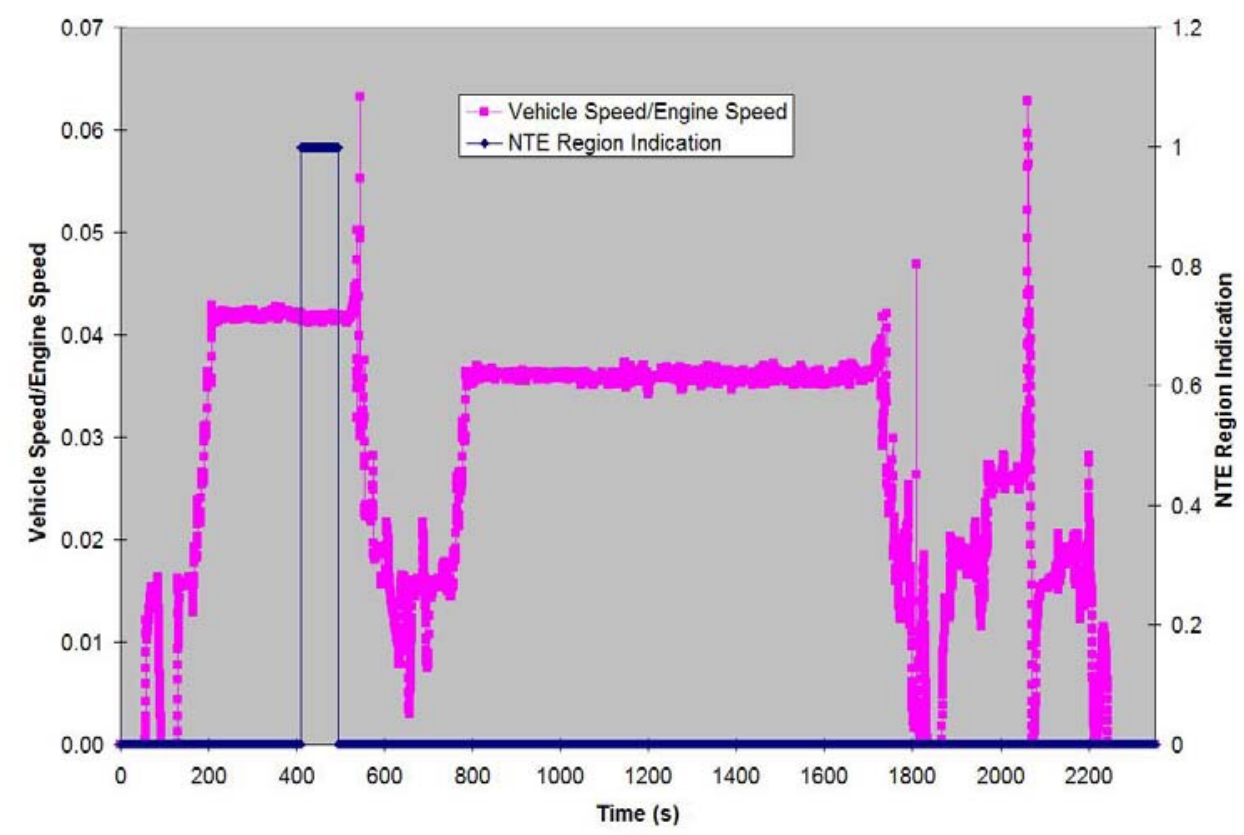

Figure 47 - NTE Entrance and Exit for 20,740 lb. Westover to Bruceton Test Run

For test weights closer to the $80,000 \mathrm{lb}$. rating of the tractor, the vehicle spent additional time within the NTE region and had more NTE events. Figure 48 shows this pattern for a test from Westover to Saltwell at 79,700 lb.

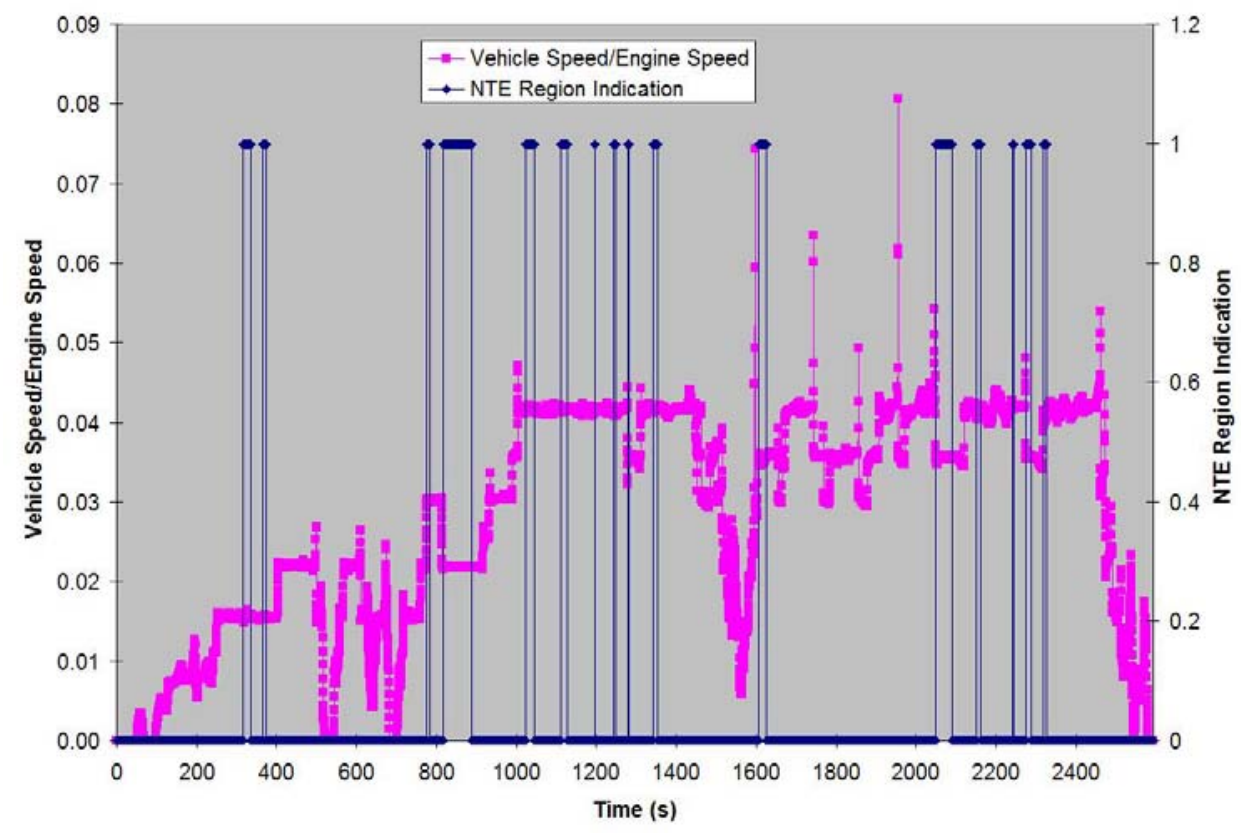

Figure 48 - NTE Entrance and Exit for 79,700 lb. Westover to Saltwell Test Run 
For each test route, an analysis was performed that determined which modes exist in each test route. The results of this analysis are shown in Table 14. Overall, most of the entrances and exits of the NTE region occurred for reasons other than a gear change. However, Mode 2, in which the vehicle enters the NTE region due to a gear change, was shown to be the reason in almost a quarter of the cases examined in this study. This scenario may allow an NTE event to be lost due to a short gear change. However, vehicles with automatic transmissions would not experience this situation. Future NTE regulations may need to address this issue when examining emissions within the NTE region.

Table 14 - NTE Entrance and Exit Mode Data

\begin{tabular}{|c|c|c|c|c|c|c|c|}
\hline Test Route & Test ID & Test Weight & Mode 1 & Mode 2 & Mode 3 & Mode 4 & $\begin{array}{c}\text { Total NTE } \\
\text { Occurrences }\end{array}$ \\
\hline \multirow{4}{*}{$\begin{array}{c}\text { Westover to } \\
\text { Bruceton }\end{array}$} & M130097-1 & 20,740 & 0 & 0 & 0 & 3 & 3 \\
\hline & M130104-2 & 34,640 & 0 & 2 & 0 & 7 & 9 \\
\hline & M130098-4 & 61,520 & 2 & 5 & 0 & 7 & 14 \\
\hline & M130099-2 & 79,700 & 2 & 3 & 1 & 6 & 12 \\
\hline \multirow{4}{*}{$\begin{array}{l}\text { Bruceton to } \\
\text { Westover }\end{array}$} & M130097-2 & 20,740 & 0 & 0 & 0 & 1 & 1 \\
\hline & M130104-5 & 34,640 & 0 & 3 & 0 & 7 & 10 \\
\hline & M130098-5 & 61,520 & 0 & 5 & 1 & 4 & 10 \\
\hline & M130099-3 & 79,700 & 0 & 4 & 0 & 6 & 10 \\
\hline \multirow{4}{*}{$\begin{array}{c}\text { Westover To } \\
\text { Saltwell }\end{array}$} & M130097-3 & 20,740 & 0 & 0 & 0 & 1 & 1 \\
\hline & M130102-1 & 34,640 & 0 & 1 & 0 & 10 & 11 \\
\hline & M130098-2 & 61,520 & 3 & 0 & 0 & 10 & 13 \\
\hline & M130099-6 & 79,700 & 2 & 5 & 1 & 8 & 16 \\
\hline \multirow{4}{*}{$\begin{array}{l}\text { Saltwell to } \\
\text { Westover }\end{array}$} & M130097-4 & 20,740 & 0 & 0 & 0 & 1 & 1 \\
\hline & M130102-2 & 34,640 & 0 & 0 & 0 & 7 & 7 \\
\hline & M130098-3 & 61,520 & 2 & 2 & 0 & 3 & 7 \\
\hline & M130099-7 & 79,700 & 3 & 2 & 0 & 4 & 9 \\
\hline \multirow{2}{*}{ PA $43-1$} & M130104-3 & 34,640 & 0 & 1 & 0 & 5 & 6 \\
\hline & M130101-4 & 79,700 & 0 & 1 & 0 & 8 & 9 \\
\hline \multirow{2}{*}{ PA $43-2$} & M130104-4 & 34,640 & 0 & 0 & 0 & 6 & 6 \\
\hline & M130101-5 & 79,700 & 1 & 2 & 0 & 3 & 6 \\
\hline \multirow{2}{*}{ Stop-n-go } & M130104-6 & 34,640 & 0 & 0 & 0 & 1 & 1 \\
\hline & M130099-9 & 79,700 & 0 & 2 & 0 & 0 & 2 \\
\hline \multicolumn{3}{|c|}{ Total Occurrences Per Mode } & 15 & 38 & 3 & 108 & 164 \\
\hline
\end{tabular}




\subsection{Cooper's Rock Hillclimb Section}

Within the Bruceton test route, there was a large section of that climbs an area known as Coopers Rock. This section consists of a constant hill that rises from $300 \mathrm{~m}$ to almost $700 \mathrm{~m}$. Also, the hill covers approximately 4 miles of roadway. Specifically, the data from $300 \mathrm{~m}$ to $600 \mathrm{~m}$ was examined where the road has an approximate grade of approximately $3.5 \%$. For the given test weights, the speeds up the hill section decreased as the weight increased. This trend can be seen in Figure 49.

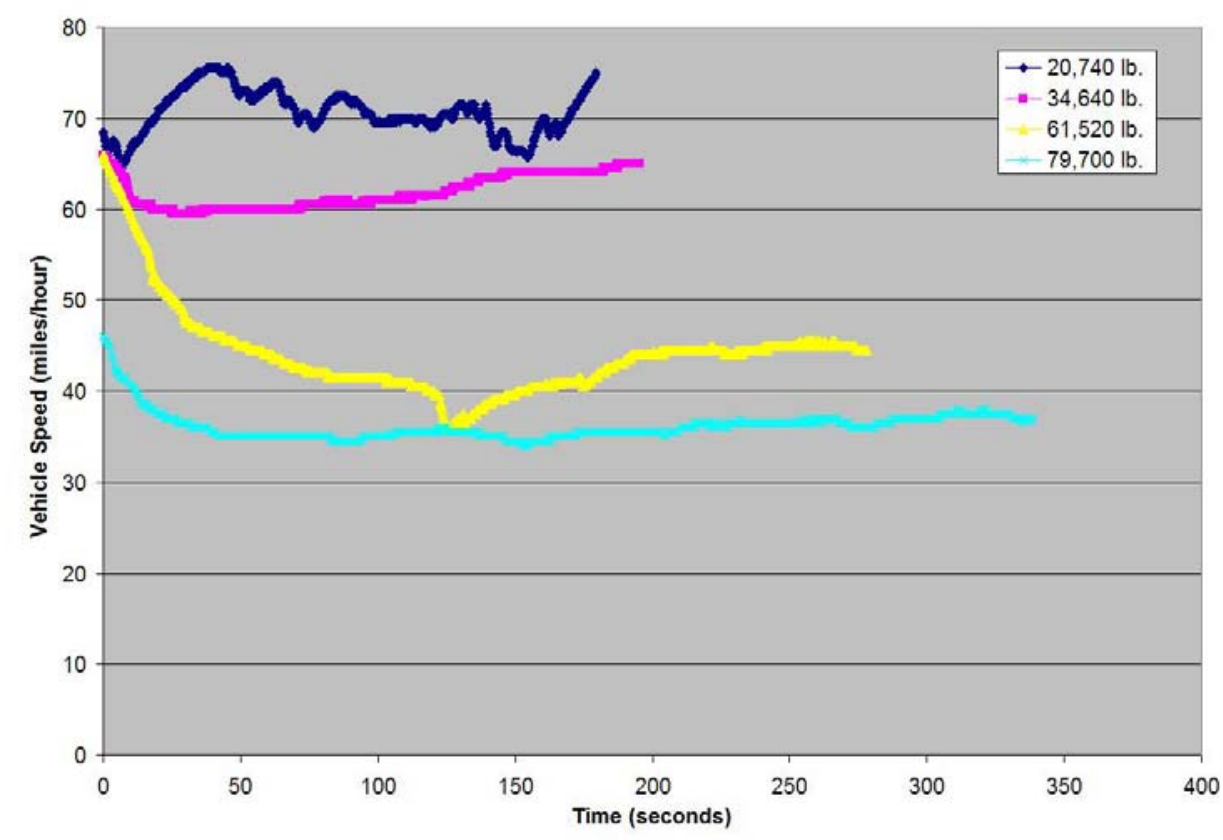

Figure 49 - Speed versus Time for Cooper's Rock Section

As the test weight increases, the continuous emissions also showed an increase. The mass flowrate of $\mathrm{NO}_{\mathrm{X}}$ is shown in Figure 50, and the described pattern can be seen. However, there were some areas in which the $\mathrm{NO}_{\mathrm{X}}$ flowrate for a test weight was higher than that of a higher test weight. 


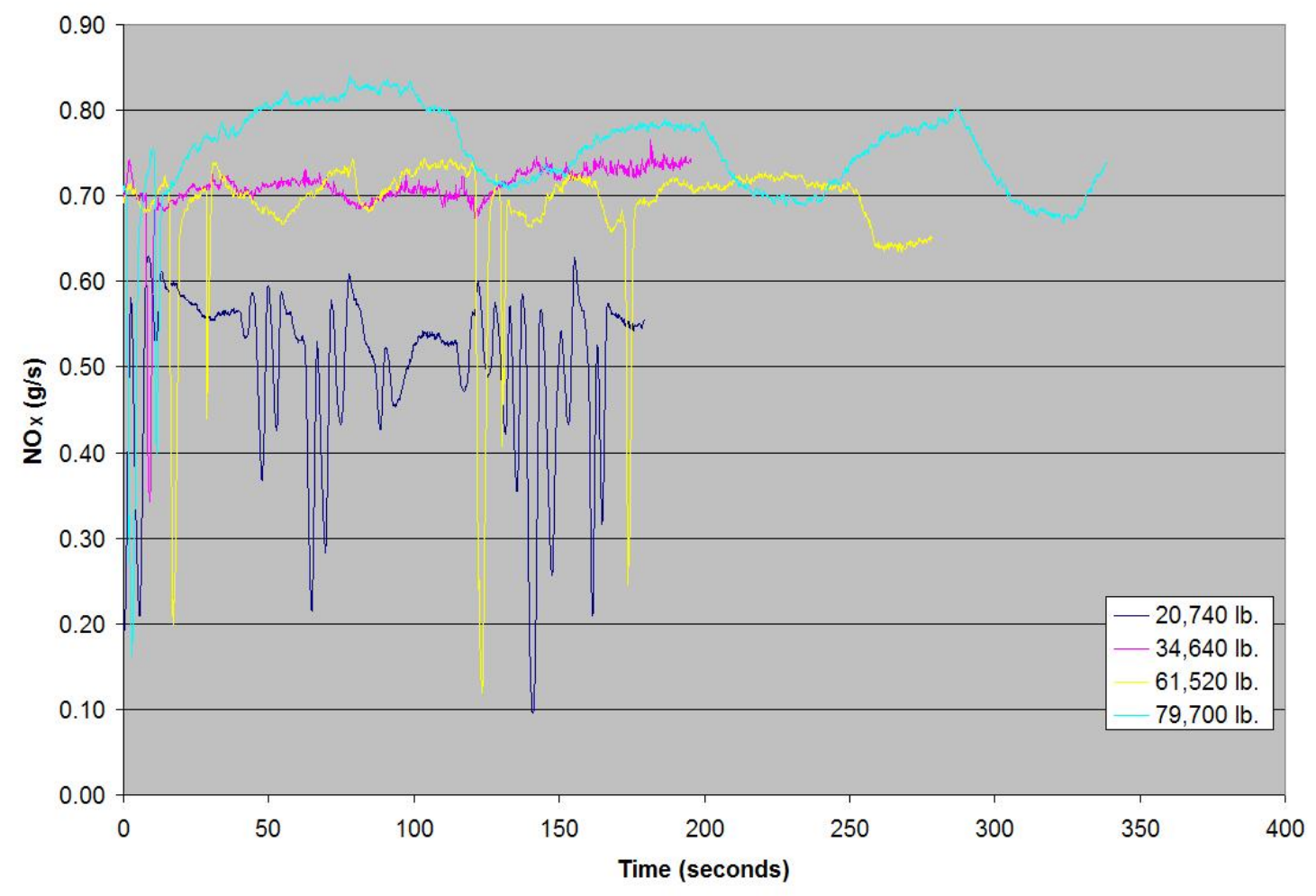

Figure 50 - Instantaneous $\mathrm{NO}_{x}$ Flowrate versus Time

Because of the engine power required to scale the hill at Cooper's Rock, the vehicle performed much of the trip in the NTE region. Table 15 shows the amounts of time spent in the NTE for the various test weights. As expected, a very high percentage of the time elapsed in the NTE region, especially when compared with the original percentages for these test routes shown in Table 7.

Table 15 - NTE Region Data for Cooper's Rock Section

\begin{tabular}{|c|c|c|c|}
\hline $\begin{array}{c}\text { Test } \\
\text { Weight }\end{array}$ & $\begin{array}{c}\text { Total Time } \\
\text { (seconds) }\end{array}$ & $\begin{array}{c}\text { Time in } \\
\text { NTE } \\
\text { (seconds) }\end{array}$ & $\begin{array}{c}\text { Percentage } \\
\text { of Time in } \\
\text { NTE }\end{array}$ \\
\hline $20,740 \mathrm{lb}$. & 179.4 & 72.8 & $40.58 \%$ \\
\hline $34,640 \mathrm{lb}$. & 195.4 & 185.6 & $94.98 \%$ \\
\hline $61,520 \mathrm{lb}$. & 278.4 & 178.6 & $64.15 \%$ \\
\hline $79,700 \mathrm{lb}$. & 338.8 & 325.8 & $96.16 \%$ \\
\hline
\end{tabular}


For the test route, the distance-specific $\mathrm{NO}_{\mathrm{X}}$ production can be calculated by dividing the mass of exhaust constituent measured by the distance traveled. The instantaneous plot of the distance-specific $\mathrm{NO}_{\mathrm{X}}$ value is shown in Figure 51. For each test weight, the vehicle's $\mathrm{NO}_{\mathrm{X}}$ output increased, finally culminating in an average value of $74.8 \mathrm{~g} / \mathrm{mile}$ at the highest test weight.

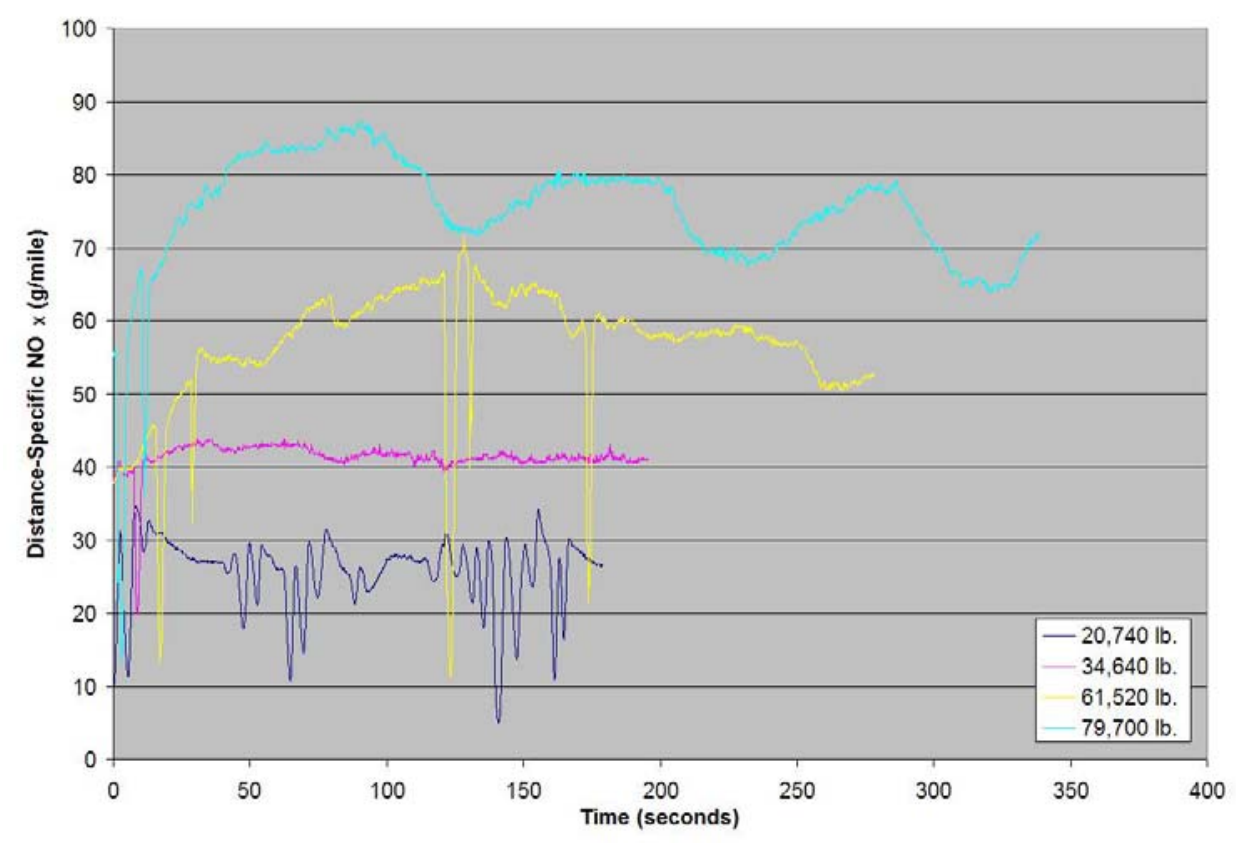

Figure 51 - Distance-Specific $\mathrm{NO}_{x}$ versus Time for Cooper's Rock Section

In comparison to the federal emissions standards, $\mathrm{NO}_{\mathrm{X}}$ measures must be computed on a work basis, or grams per brake-horsepower hour. Figure 52 shows these values for the various test weights on the hill at Cooper's Rock. The quantities shown occured in the NTE region, and they increased with the increase in test weight. At 79,700 lb., the engine produced brake-specific $\mathrm{NO}_{\mathrm{X}}$ values that were near $5.0 \mathrm{~g} / \mathrm{bhp}-\mathrm{hr}$, the standard emissions level for a 1996 tractor. 


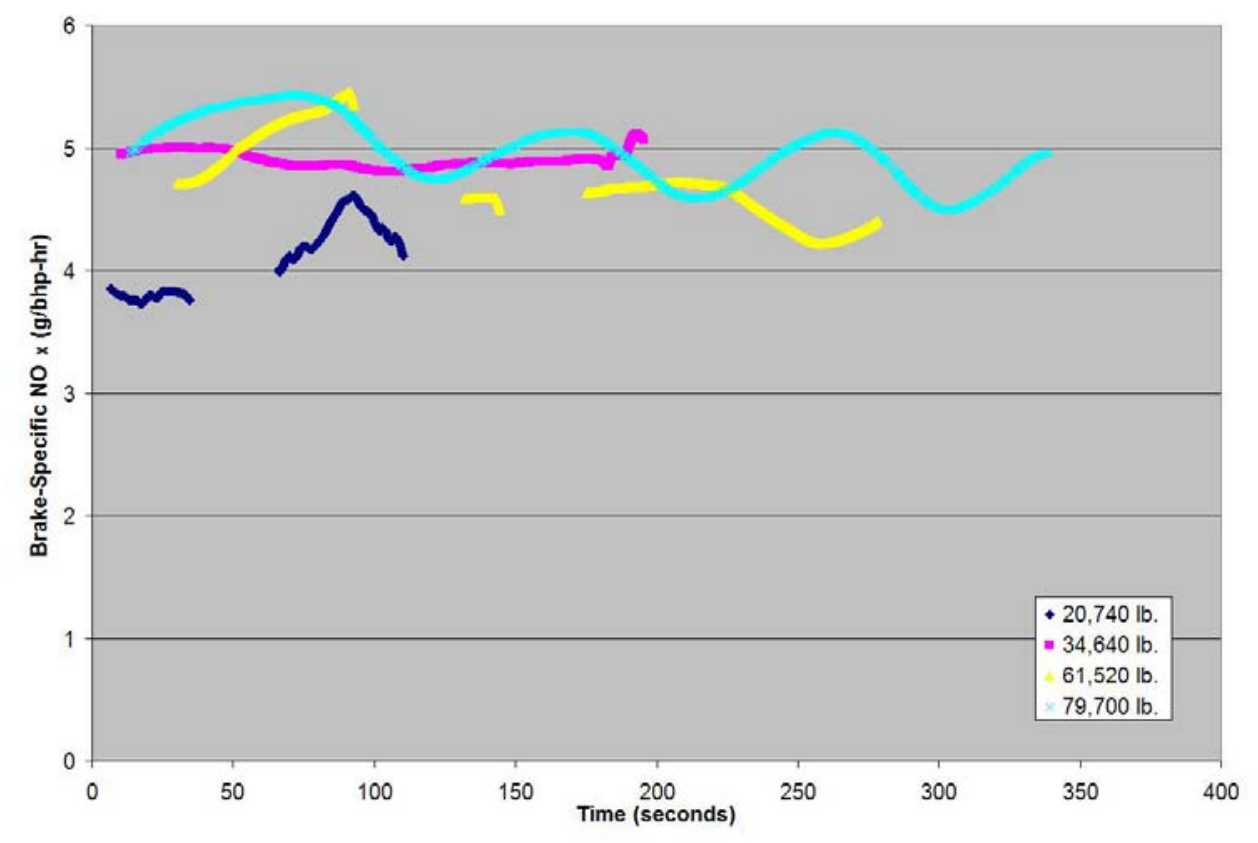

Figure 52 - Brake-Specific NTE NO ${ }_{x}$ for Cooper's Rock Section

\subsection{Vehicle Power versus Engine Power}

Within the recorded data, the percent load placed upon the engine can be used to determine the amount of power being produced by the engine at any point in time during the testing. However, this value does not consider any type of losses through the powertrain of the vehicle. Alternatively, one can consider the road load to determine the actual amount of power required to propel a vehicle in a given setting.

\subsubsection{Road Load Equation - Flat Road, Constant Speed}

The road load equation has a main term that considered the rolling resistance of the vehicle, weight of the vehicle, speed of the vehicle, and aerodynamic drag. These parameters were combined in Equation 4 to give the road load for the vehicle in horsepower.

$$
P_{r}(h p)=\frac{\left[C_{R} W_{v}(l b f)+0.0025 C_{D} A_{v}\left(f t^{2}\right) S_{v}(m i / h)^{2}\right] S_{v}(m i / h)}{375}
$$

\section{Equation 4}




\subsubsection{Road Load Equation - Acceleration Load}

Equation 4, however is only valid for a vehicle traveling on a flat road at a steady speed. For roads with elevation changes and accelerations, more terms were necessary to determine the amount of power needed by the vehicle. Equation 5 is the portion of the road load that can be attributed to the acceleration of the vehicle. In this equation, $m$ represents the mass of the vehicle in pounds-mass, $V$ is the velocity of the vehicle in feet per second, $d V / d t$ is the acceleration of the vehicle in feet per second squared, and 550 is a conversion factor to obtain an answer in horsepower.

$$
P_{\text {acceleration }}=\frac{m * V * \frac{d V}{d t}}{550}
$$

\section{Equation 5}

In order to determine the acceleration accurately, a central difference method can be used as described in the thesis of Nathan Moynahan [29]. The four-point method shown in Equation 6 can take the instantaneous velocity data and obtain the numerical derivative to determine the acceleration. The velocities came from two data points in each direction around the point of interest, and $h$ is the step size of 0.2 seconds between data points.

$$
\begin{gathered}
a=\frac{-V_{i+2}+8 V_{i+1}-8 V_{i-1}+V_{i-2}}{12 h} \\
\text { Equation } 6
\end{gathered}
$$

\subsubsection{Road Load Equation - Road Grade Consideration}

In addition, the angle of inclination of the road was important to determining the road load on the vehicle. Equation 7 is the component of the road load attained because of the angle of inclination of the road. The angle theta $(\theta)$ represents the angle at which the roadway is elevated. The method for deriving this angle can be found in the following section.

$$
P_{\text {road grade }}=m * \sin \theta * V
$$

Equation 7 


\subsubsection{Road Inclination Angle Derivation}

In his thesis, Nathan Moynahan [29] detailed a procedure by which the angle of inclination can be determined using ambient pressure data along with the vehicle's distance traveled to determine the angle of inclination of the road being traversed. The first step in this process was to determine the altitude of the vehicle. There were data from the GPS system for this value, but the data was somewhat scrambled by the military as a precautionary measure for missile defense purposes. As a result, some test routes that began at the same location had varying values for the altitude given by the GPS. Instead, the ambient pressure can be used since the relationship between changes in ambient pressure and altitude has been well documented. Equation 8 illustrates the relationship in the change in pressure to the change in altitude over the test route.

$$
h_{i}=h_{i-1}-960 * \Delta p
$$

\section{Equation 8}

A triangular relation can be used between the difference in height and difference in horizontal distance traveled. After determining the two known sides of the triangle, the Pythagorean Theorem can be utilized to determine the length of the third side of the triangle. This formula is shown in Equation 9.

$$
\Delta d_{h}=\sqrt{\Delta d-\Delta h}
$$

\section{Equation 9}

Once the values are established, trigonometry can be used to find the desired angle using Equation 10. Some instantaneous values resulted in completely unrealistic values for the inclination angle, so the data was smoothed. For the data in this thesis, a ten-second moving average was used to eliminate any anomalies that may occur as a result of the instantaneous data.

$$
\theta=\tan ^{-1}\left(\frac{\Delta h}{\Delta d_{h}}\right)
$$

\section{Equation 10}




\subsubsection{Road Load Power}

Once all the components of the road load had been calculated, the numbers were added together to arrive at the road load power. This number should be somewhat comparable to the power broadcast by the ECU. However, Figure 53 shows that these numbers, while similar in magnitude, do not align at the instantaneous points throughout the vehicle test. These results were similar for each of the routes tested, and Figure 53 illustrates the trend. This may be due to resolution issues in the engine power value being recorded by the data acquisition system. Also, the discontinuous nature of the altitude data and the acceleration data may cause some of the anomalies in the calculated road load power. The data shown was taken from a Bruceton run, and only the data from the Cooper's Rock hill climb section is shown.

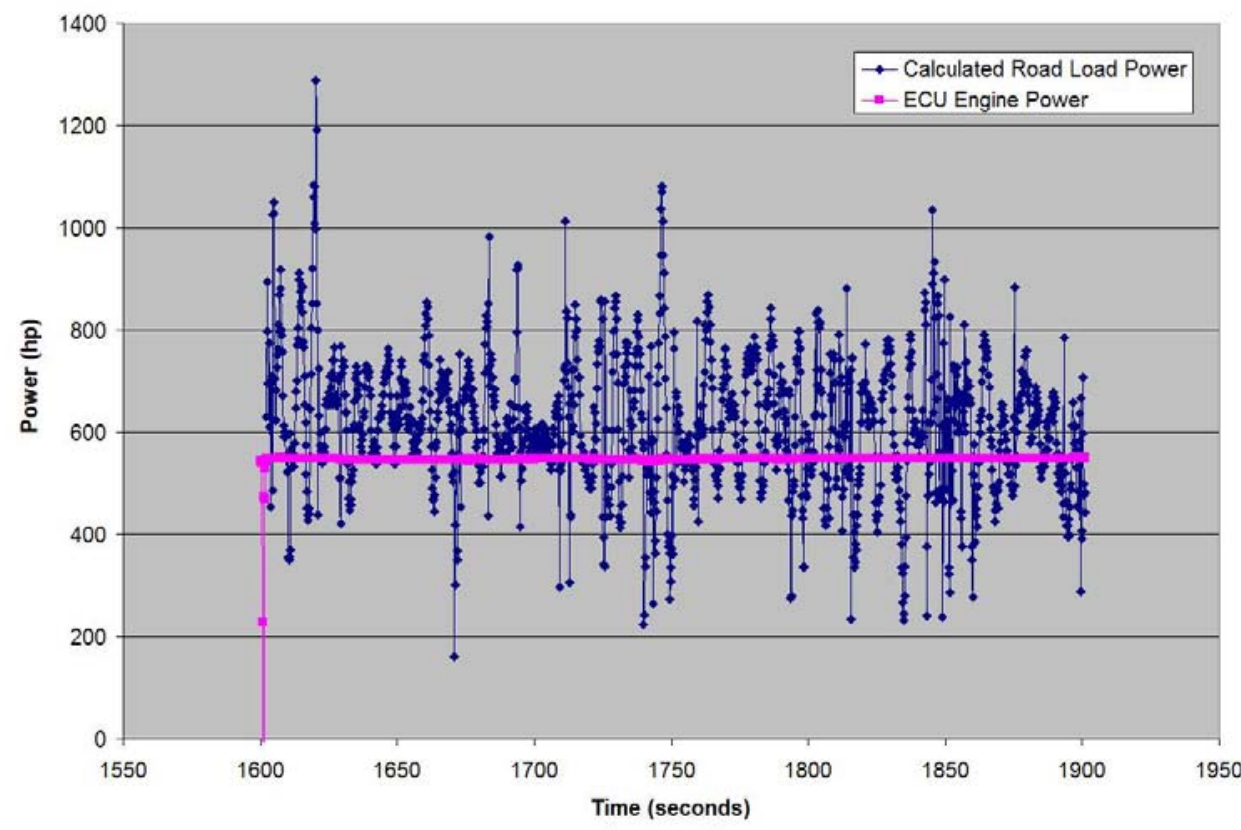

Figure 53 - Calculated Road Load Power and Engine Output Comparison 


\section{Conclusions and Recommendations}

Overall, this work has examined an over-the-road tractor with an 80,000 GVWR and its behavior while being driven in varying terrain and varying stages of vehicle loading. The vehicle was shown to spend more time in the NTE zone as the vehicle weight increased. Also, the vehicle spent a great deal more time in the NTE zone when the terrain became more mountainous and included more hill climbs.

As the vehicle weight increased, the distance-specific $\mathrm{NO}_{\mathrm{X}}$ emissions confirmed the findings of Gajendran and Clark [21]. This resulted in an increase of approximately $\mathrm{X} / 2 \%$ for an $\mathrm{X} \%$ increase in test weight.

An inverse relation can be concluded for fuel economy. A test weight increase of $15,000 \mathrm{lb}$. equated to a 0.5 miles per gallon decrease in fuel economy. The effects of the terrain, however, produced a uniform change in fuel economy when comparing tests conducted at similar vehicle weight. The Bruceton and Saltwell routes, which were considered mountainous, caused fuel economy to decrease by about $1.2 \mathrm{miles} /$ gallon for each test weight when compared with the flatter PA 43 route. These changes were most likely the result of the terrain on the vehicle's emissions.

Overall, the vehicle weight seemed to have a more profound effect on emissions and fuel economy than the terrain on which a vehicle was operated. For example, the fuel economy could decline by approximately 2 miles/gallon from 20,000 lb. to 80,000 lb., whereas the terrain only caused a decrease of around 1.2 miles/gallon.

Future emissions inventory calculations should include factors for a vehicle's typical weight profile as well as its usual driving areas. It is obvious from this work that vehicles operating in flat areas will utilize less fuel and produce fewer emissions than the same vehicle operating in a mountainous environment.

More work should be done to verify these results across multiple test vehicles. Although the vehicle tested had clear patterns of behavior, newer vehicles which utilize newer emissions control and reductions technologies may behave differently. Future studies should address these issues by testing a wide variety of vehicles.

One concern during testing had been that vehicles may be entering and exiting the NTE region simply as a result of a change in the gear in which the vehicle is driven. This 
could lead to a discontinuity in the testing of manual shift and automatic shift vehicles. As shown by this research, the bulk of entrances and exits to the NTE are simply the result of changes in engine behavior. However, around a quarter of the entrances to the NTE are due to a gear change, so these regions may be of interest in comparing vehicles tested with automatic transmissions and those with manual transmissions. In future studies, special attention should be given to the vehicle's transmission while examining NTE events.

Because this study has been among the first to explore the on-road relationship between vehicle weight, road grade, emissions, and fuel economy, recommendations include further validation of the findings of this thesis. Primarily, more routes should be tested to determine the effect of the terrain on fuel economy and emissions. In this study, the flat route was not as flat as roads that exist in the Great Plains region of the United States. The effects of testing the vehicle in such a scenario might yield interesting and more distinct results. For the most part, the routes in this study have been examined as complete testing cycles. However, smaller portions of the routes could be closely scrutinized to determine the specific effect of certain terrain features or engine behaviors on the emissions profile.

As for the fuel economy, there seemed to be an anomaly in the relationship when moving from "bobtail" operation to trailer-pulling operation. The change in fuel economy when adding weight to the tractor did not conform to the linear pattern created when adding weight to the trailer of the test vehicle. This specific area may need to be explored to determine the causation behind this initial decrease in fuel economy before entering into the linear relationship discovered in this research.

Also, further refinement is needed for the road grade angle determination. Instruments outside of the typical on-road emissions testing realm may be necessary to obtain usable data for use in road load studies. The instantaneous changes reported by the ECU and other engine systems will present difficulty in this area for future research. 


\section{References}

1. "Draft Technical Support Document: In-Use Testing for Heavy-Duty Diesel Engines and Vehicles,” EPA Document No. EPA420-D-04-003, June 2004.

2. Charmley, W. J., "The Federal Government's Role in Reducing Heavy Duty Diesel Emissions," SAE Technical Paper No. 2004-01-2708, Warrendale, PA, 2004.

3. U.S. Environmental Protection Agency. Consent Decrees. ONLINE. 1998. Environmental Protection Agency. Available: http://www.epa.gov/compliance/ resources/decrees /civil/caa/detroitcd.pdf [07 Jul. 2006].

4. Shade, B. C., "A Performance Evaluation of the MEMS-An On-Road Emissions Measurement System Study," M.S. Thesis, Department of Mechanical and Aerospace Engineering, West Virginia University, Morgantown, WV, 2000.

5. "Emisssions Standards: USA Heavy-duty Truck and Bus Engines," $<$ www.dieselnet.com>, Ecopoint Inc., Brampton, ON, 2005.

6. Englund, M. S., "Field Compatible $\mathrm{NO}_{\mathrm{X}}$ Emission Measurement Technique," SAE Technical Paper No. 820647, Warrendale, PA, 1982.

7. Chan, L., Carlson, D.H., and Johnson, J.H., "Evaulation and Application of a Portable Tailpipe Emissions Measurement Apparatus for Field Use," SAE Technical Paper No. 921647, Warrendale, PA, 1992.

8. Jetter, J., Maeshiro, S., Hatcho, S., and Klebba, R., "Development of an On-Board Analyzer for Use on Advanced Low Emission Vehicles," SAE Technical Paper No. 2000-01-1140, 2000.

9. Kihara, N., Tsukamoto, T., Matsumoto, K., Ishida, K., Kon, M., and Murase, T., "Real-time On-board Measurement of Mass Emission of $\mathrm{NO}_{\mathrm{X}}$, Fuel Consumption, Road Load, and Engine Output for Diesel Vehicles," SAE Technical Paper No. 2000-01-1141, Warrendale, PA, 2000.

10. Vojtisek-Lom, M. and Allsop, J. E., "Development of Heavy-Duty Diesel Portable, On-Board Mass Exhaust Emissions Monitoring System With $\mathrm{NO}_{\mathrm{X}}, \mathrm{CO}_{2}$, And Qualitative PM Capabilities," SAE Technical Paper No. 2001-01-3641, Warrendale, PA, 2001.

11. Vojtisek-Lom, M. and Allsop, J. E., "Real-world Emissions From 40 Heavy-Duty Diesel Trucks Recruited at Tulare, CA Rest Area," SAE Technical Paper No. 2002-01-2901, Warrendale, PA, 2002.

12. Gautam, M., Thompson, G. J., Carder, D. K., Clark, N. N., Shade, B. C., Riddle, W. C., and Lyons, D. W., "Measurement of In-Use, On-Board Emissions from Heavy-Duty Diesel Vehicles: Mobile Emissions Measurement System," SAE Technical Paper No. 2001-01-3643, Warrendale, PA, 2001. 
13. Nakamura, H., Kihara, N., Adachi, M., and Ishida, K., "Development of a Wetbased NDIR and Its Application to On-board Emission Measurement System," SAE Technical Paper No. 2002-01-0612, Warrendale, PA, 2002.

14. Thompson, G. J., Clark, N. N., Gautam, M., Carder, D. K., and Lyons, D. W., Inference of Torque and Power from Heavy-Duty Diesel Engines for On-Road Emissions Testing, SAE Paper 2002-01-0614, SAE World Congress, Detroit, Michigan, March 4-7, 2002.

15. Weaver, C. S. and Balam-Almanza, M. V. "Development of the 'RAVEM' RideAlong Vehicle Emissions Measurement System for Gaseous and Particulate Emissions," SAE Technical Paper No. 2001-01-3644, Warrendale, PA, 2001.

16. Hawirko, J. D. and Checkel, D. M., "Real-Time, On-Road Measurement of Driving Behavior, Engine Parameters and Exhaust Emissions," SAE Technical Paper No. 2002-01-1714, Warrendale, PA, 2002.

17. Hawirko, J. D. and Checkel, D. M., "Quantifying Vehicle Ambient Conditions using an On-Road, Real-Time Emissions System," SAE Technical Paper No. 2003-01-0301, Warrendale, PA, 2003.

18. Brown, E. J., King, F. G., Mitchell, W. A., Squier, W. C., Harris, D. B., and Kinsey, J. S., "On-Road Facility to Measure and Characterize Emissions from Heavy-Duty Diesel Vehicles," Journal of the Air \& Waste Management Association, Vol. 52, No. 4, 388-395, Pittsburgh, PA, 2002.

19. Cocker, D. R. III, Shah, S. D., Johnson, K., Norbeck, J. M., , E. J., King, "Development and Application of a Mobile Laboratory for Measuring Emissions from Diesel Engines," Environmental Science and Technology, Vol. 38, No. 7, 2182-2189, Washington, DC, 2004.

20. Durbin, Thomas D., and Norbeck, Joseph M., "Effect of Payload on Exhaust Emissions from Light Heavy-Duty Diesel and Gasoline Trucks," Environmental Science and Technology, Vol. 34, No. 22, 4708-4713, Washington, DC, 2000.

21. Gajendran, Prakash, and Clark, Nigel, "Effect of Truck Operating Weight on Heavy-Duty Diesel Emissions," Environmental Science and Technology, Vol. 37, No. 18, 4309-4317, Washington, DC, 2005.

22. Strimer, C. M., Carder, D. K., Gautam, M., Thompson, G.J., "Impact of Vehicle Weight on Truck Behavior and Emissions, Using On-board Measurement," SAE Technical Paper No. 2005-01-3788, Warrendale, PA, 2005.

23. "Standard Outline Dimensional Drawing for Annubar Primary Flow Element," Drawing No. C-3602, Dietrich Standard, Boulder, CO, 1999.

24. Bruceton Mills, WV [map]. 2006. Scale undetermined; generated by Corey Strimer; using "MapQuest.com, Inc". < http://www.mapquest.com/mapsdirections/>

(7 Jul. 2006). 
25. West Virginia [map]. 2006. Scale undetermined; generated by Corey Strimer; using "MapQuest.com, Inc". < http://www.mapquest.com/maps-directions/> (7 Jul. 2006).

26. Pennsylvania [map]. 2006. Scale undetermined; generated by Strimer; using "MapQuest.com, Inc". < http://www.mapquest.com/maps-directions/> (7 Jul. 2006).

27. Morgantown, $W V$ [map]. 2006. Scale undetermined; generated by Strimer; using "MapQuest.com, Inc". < http://www.mapquest.com/maps-directions/> (7 Jul. 2006).

28. Code of Federal Regulations, Title 40, Part 86, Subpart N - Emission Regulations for New Otto-Cycle and Diesel Heavy-Duty Engines; Gaseous and Particulate Exhaust Test Procedures, 1998.

29. Moynahan, N. A., "Development of a Vehicle Road Load Model for ECU Broadcast Power Verification in On-Road Emissions Testing," M.S. Thesis, Department of Mechanical and Aerospace Engineering, West Virginia University, Morgantown, WV, 2005. 